WSRC-TR-2001-00436

revision 0

Key Words: Salt Disposition

Plutonium,

Uranium,

Neptunium, HLW,

Alkaline,

Composition

\title{
Strontium and Actinide Removal Testing with Monosodium Titanate and Other Sorbents
}

M. J. Barnes

T. B. Edwards

D. T. Hobbs

K. M. Marshall

Publication Date: October 29, 2001 
This document was prepared in conjunction with work accomplished under Contract No. DE-AC09-96SR18500 with the U.S. Department of Energy.

\section{DISCLAIMER}

This report was prepared as an account of work sponsored by an agency of the United States Government. Neither the United States Government nor any agency thereof, nor any of their employees, makes any warranty, express or implied, or assumes any legal liability or responsibility for the accuracy, completeness, or usefulness of any information, apparatus, product or process disclosed, or represents that its use would not infringe privately owned rights. Reference herein to any specific commercial product, process or service by trade name, trademark, manufacturer, or otherwise does not necessarily constitute or imply its endorsement, recommendation, or favoring by the United States Government or any agency thereof. The views and opinions of authors expressed herein do not necessarily state or reflect those of the United States Government or any agency thereof.

This report has been reproduced directly from the best available copy.

Available for sale to the public, in paper, from: U.S. Department of Commerce, National Technical Information Service, 5285 Port Royal Road, Springfield, VA 22161

phone: (800) 553-6847

fax: (703) 605-6900

email: orders@ntis.fedworld.gov

online ordering: http://www.ntis.gov/support/index.html

Available electronically at http://www.doe.gov/bridge

Available for a processing fee to U.S. Department of Energy and its contractors, in paper, from: U.S. Department of Energy, Office of Scientific and Technical Information, P.O. Box 62, Oak Ridge, TN 37831-0062

phone: (865)576-8401

fax: $(\mathbf{8 6 5}) 576-5728$

email: reportseadonis.osti.gov 

Approvals

S. D. Fink, TFA System Lead and Liquid Waste Processing Manager Date

R. E. Edwards, Manager, HLW Processing Engineering Date

J. T. Carter, Director, Salt Disposition Engineering Date 


\subsection{Summary}

SRTC researchers examined the affects of solution phase composition, the oxidation state of plutonium and neptunium and different production batches on the performance of monosodium titanate (MST) to remove strontium and actinides from alkaline salt solutions. Testing also evaluated the performance of alternate sorbents including sodium nonatitanate (ST), crystalline silicotitanate and pharamacosiderite materials. Results indicated the following.

- The solution composition does affect the performance of MST to remove strontium and the actinides.

- In general, the decontamination factor (DF) increased with increasing sodium nitrate concentration.

- Evidence suggests that the relationship between MST performance and solute concentration does not fit a linear model.

- Preliminary evidence suggests that $\mathrm{Pu}(\mathrm{VI})$ is stable in alkaline solutions for several weeks and exhibits a higher solubility than $\mathrm{Pu}(\mathrm{IV})$.

- Test results suggest that the rates of Pu(IV) and Pu(VI) removal are similar.

- Test results yielded inconclusive evidence for the stability of $\mathrm{Np}(\mathrm{IV})$ in an alkaline salt solution.

- Test results indicated no significant changes in neptunium removal upon contact of solutions prepared with $\mathrm{Np}(\mathrm{V})$ or $\mathrm{Np}(\mathrm{IV})$.

- Measurable differences in strontium removal, but not in actinide removal, occurred with different MST production batches.

- Measurable changes in the performance of MST Lot \#33180 occurred during the course of testing which we attribute to errors associated with delivering the same quantity of MST, sampling and analytical measurements.

- Samples of ST and pharmacosiderites exhibited strontium and actinide removal performance as good or better than that observed for MST.

Based on these finding we recommend the following.

- Conduct additional tests to more completely understand and model the performance of MST as a function of solution composition.

- Conduct additional tests to determine the stability of $\mathrm{Pu}(\mathrm{VI}), \mathrm{Pu}(\mathrm{V}), \mathrm{Np}(\mathrm{IV})$ and $\mathrm{Np}$ (VI) oxidation states in alkaline salt solutions.

- Increase database on MST batch variability by sampling and measuring strontium and actinide removal for archived MST presently stored at SRS.

- Continue evaluation of sorbent materials as alternates to MST including examinations of performance over a range of solution compositions.

\subsection{Introduction}

The baseline process for the removal of ${ }^{90} \mathrm{Sr}$ and alpha-emitting radionuclides from highlevel liquid waste solution at the Savannah River Site uses an inorganic material, monosodium titanate (MST). ${ }^{1}$ Previous testing indicated that plutonium removal kinetics and neptunium capacity of the MST material impacts the size of equipment and waste blending plans for the proposed Salt Processing Project facility. Consequently, the 
Salt Processing Project requested that SRTC conduct tests evaluating the effects of solution composition, plutonium and neptunium oxidation states and MST synthesis batch variability on removal performance as well as evaluate alternate sorbent materials and removal methods. ${ }^{2}$ Additional testing features characterization of the interaction between the sorbate and the MST using fine structure X-ray absorption fine structure spectroscopy (XAFS) techniques. This information will provide a more complete understanding of the removal mechanism of the MST for each sorbate. Separate reports will summarize the findings of the measurements to date.

Previous testing with simulants used a single solution composition. ${ }^{3,4,5}$ Changes in solution composition could affect the nature of the sorbate species present in solution and thus the rate and extent of removal with MST. For example, increasing hydroxide concentration may change the predominant sorbate species to a more highly hydroxide substituted complex (e.g., $\mathrm{Sr}^{2+}$ vs. $\mathrm{Sr}(\mathrm{OH})^{+}$and $\mathrm{UO}_{2}\left(\mathrm{NO}_{3}\right)_{4}{ }^{2-}$ vs. $\mathrm{UO}_{2}(\mathrm{OH})_{4}{ }^{2-}$ or $\left.\mathrm{UO}_{2}(\mathrm{OH})_{5}{ }^{3-}\right)$. The more highly hydroxide substituted complex may sorb differently than the uncomplexed or nitrate substituted complex. Thus, we conducted a series of tests with simulants having a range of solution compositions to determine if solution composition significantly influences sorbate removal with MST.

Literature data indicate plutonium and neptunium exhibit multiple oxidation states in alkaline aqueous solutions. ${ }^{6,7,8}$ No previous studies exist that definitively identify plutonium and neptunium oxidation states in the range of solution compositions that will exist during supernatant processing. Multiple oxidation states and species in solution could affect the extent and rate of removal with the MST. For example, Phase IV test results exhibited a change in the plutonium removal rate after about 10 hours. ${ }^{9,10}$ Thus, tests used solutions containing different plutonium and neptunium oxidation states to determine if the oxidation state of the plutonium and neptunium significantly influences sorption.

Previous testing for the Salt Processing Project featured a single batch of MST (Optima Lot \#33180) originally produced for use in the In-Tank Precipitation (ITP) process. During qualification of vendors for the production of MST, testing indicated considerable variance among various samples in strontium removal performance. The large variance prevented successful correlation of the strontium removal performance with a physical property (e.g., particle size distribution or surface area) and, therefore, qualification of each MST batch included the determination of the strontium decontamination factor. ${ }^{11}$ Actinide removal variability was not tested during this time, but we expect it to vary to some degree as observed with strontium.

Initial evaluation of alternate materials featured sodium titanate materials available from commercial vendors. ${ }^{4}$ In general, strontium removal with the alternate materials was similar to that with MST. Actinide removal proved poorer with the alternate materials compared to the MST. We attributed the poorer actinide removal to the large particle size of these alternate materials. SRTC contracted with Professor Abraham Clearfield of Texas A\&M University during FY2001 to prepare a range of new titanate-based sorbent materials for evaluation. Professor Clearfield has over 40 years of experience in the 
synthesis and characterization of inorganic sorbents and ion-exchange materials. This report includes strontium and actinide removal characteristics of several samples prepared at TAMU and submitted to SRTC for evaluation. In addition to the TAMU samples, we also evaluated one new sample from a commercial vendor.

\section{$\underline{\text { 3.0 Experimental }}$}

\subsection{Preparation of Salt Solutions}

Personnel prepared all solutions using reagent grade chemicals and deionized distilled water. Except as noted personnel treated the alkaline salt solutions with MST to remove tramp strontium. After filtering the salt solution to remove MST solids, personnel added the targeted amount of ${ }^{85} \mathrm{Sr}$ radiotracer(NEN Cat. \#NEZ082, Lot \#00M51M7) and the actinides. Actinide sources included uranyl nitrate hexahydrate (Mallinckrodt Lot \# 8640KDAL) and nitric acid solutions of plutonium(IV) $(19.328 \mathrm{~g} / \mathrm{L})$ and neptunium(V) $(67.1 \mathrm{~g} / \mathrm{L})$ supplied by the Actinide Technology Section of SRTC. After addition of the ${ }^{85} \mathrm{Sr}$ and actinides, we allowed the solutions to mix for one week at ambient room temperature. After one week, we filtered the solutions through 0.45-micron pore size nylon membrane filters to remove any residual solids. Table 3.1 lists the initial sorbate and radiotracer concentrations.

Table 3.1. Measured Initial and Predicted Sorbate Concentrations for Salt Solutions

\begin{tabular}{|c|c|c|c|c|c|c|}
\hline Trial No. & $\begin{array}{c}\text { Meas. [Sr] } \\
\qquad(\mu \mathrm{g} / \mathrm{L})\end{array}$ & $\begin{array}{c}\text { Meas. }[\mathbf{P u}] \\
(\mu \mathrm{g} / \mathrm{L})\end{array}$ & $\begin{array}{c}\text { Pred. [Pu] } \\
(\mu \mathrm{g} / \mathrm{L})\end{array}$ & $\begin{array}{c}\text { Meas. [U] } \\
(\mu \mathrm{g} / \mathrm{L})\end{array}$ & $\begin{array}{c}\text { Pred. [U] } \\
(\mu \mathrm{g} / \mathrm{L})\end{array}$ & $\begin{array}{c}\text { Meas. [Np] } \\
\qquad(\mu \mathrm{g} / \mathrm{L})\end{array}$ \\
\hline 1 & 621 & 231 & 404 & 7050 & 12,300 & 241 \\
\hline 2 & 656 & 102 & 404 & 8080 & 7420 & 244 \\
\hline 3 & 302 & 42.8 & 83.8 & 5960 & 10600 & 242 \\
\hline 4 & 541 & 140 & 151 & 7120 & 8360 & 249 \\
\hline 5 & 537 & 121 & 76.8 & 4490 & 1550 & 249 \\
\hline 6 & 828 & 119 & 404 & 5490 & 22100 & 190 \\
\hline 7 & 617 & 208 & 226 & 6620 & 8480 & 218 \\
\hline 8 & 649 & 203 & 226 & 6980 & 8400 & 220 \\
\hline 9 & 742 & 242 & 217 & 10400 & 8440 & 307 \\
\hline 10 & 628 & 203 & 226 & 6950 & 8480 & 225 \\
\hline 11 & 568 & 65.7 & 112 & 4320 & 3360 & 215 \\
\hline Std. Dev.* & 16.3 & 2.95 & & 200 & & 3.54 \\
\hline Targeted Conc. & 100 & 200 & & 10000 & & 400 \\
\hline
\end{tabular}


Plutonium and neptunium oxidation state testing required the preparation of simulant salt solution (see Table 3.2 for composition) containing single isotopes of $\mathrm{Pu}$ (IV), $\mathrm{Pu}$ (VI), $\mathrm{Np}$ (IV), or $\mathrm{Np}(\mathrm{V})$. Researchers used the nitric acid stock solutions of $\mathrm{Pu}$ (IV) and $\mathrm{Np}$ (V) described above. They oxidized $\mathrm{Pu}$ (IV) to $\mathrm{Pu}$ (VI) by treating $4.021 \mathrm{~mL}$ of 0.965 $\mathrm{mg} / \mathrm{mL}$ acidic $\mathrm{Pu}(\mathrm{IV})$ with a stoichiometric amount $\left(15.9 \mathrm{~mL}\right.$ ) of $0.001 \mathrm{M} \mathrm{KMNO}_{4}$ (in 1 $\mathrm{M} \mathrm{HNO}_{3}$ acid). ${ }^{14}$ The color of the solution provided an indicator of complete oxidation. The initial solution was colorless. Upon first addition of the purple-colored $\mathrm{KMNO}_{4}$, the $\mathrm{Pu}$ solution turned purple but soon thereafter turned colorless again. After addition of all required $\mathrm{KMnO}_{4}$, the solution remained colored indicating complete oxidation.

Personnel reduced $\mathrm{Np}(\mathrm{V})$ to $\mathrm{Np}(\mathrm{IV})$ by treating $1.448 \mathrm{~mL}$ of $2.68 \mathrm{mg} / \mathrm{mL}$ acidic $\mathrm{Np}(\mathrm{V})$ with a stoichiometric quantity $(1.28 \mathrm{~mL})$ of $0.0128 \mathrm{M} \mathrm{H}_{2} \mathrm{O}_{2}{ }^{15}$ Again, the color of the solutions provided an indicator of reduction. The starting $\mathrm{Np}(\mathrm{V})$ solution was pale yellow and turned colorless upon addition of the $\mathrm{H}_{2} \mathrm{O}_{2}$. The difficulty and requirements associated with handling the materials prevented spectroscopic or electrochemical analysis to verify their oxidation states.

Table 3.2. Salt Solution Composition Used in Adsorption Testing

\begin{tabular}{|c|c|}
\hline Component & Concentration (M) \\
\hline $\mathrm{NaNO}_{3}$ & 2.60 \\
\hline $\mathrm{NaOH}$ & 1.33 \\
\hline $\mathrm{Na}_{2} \mathrm{SO}_{4}$ & 0.521 \\
\hline $\mathrm{NaAl}(\mathrm{OH})_{4}$ & 0.429 \\
\hline $\mathrm{NaNO}_{2}$ & 0.134 \\
\hline $\mathrm{Na}_{2} \mathrm{CO}_{3}$ & 0.0260 \\
\hline Total Na & 5.6 \\
\hline
\end{tabular}

We prepared a $2000 \mu \mathrm{g} / \mathrm{L} \mathrm{Pu}(\mathrm{VI})$-spiked, salt solution by adding the acidic $\mathrm{Pu}(\mathrm{VI})$ solution prepared above to a portion of the $5.6 \mathrm{M} \mathrm{Na}^{+}$simulated salt solution. We prepared similar solutions using the $\mathrm{Np}$ (IV) solution, as well as the starting $\mathrm{Pu}(\mathrm{IV})$ and $\mathrm{Np}(\mathrm{V})$ solutions. All four solutions contained $2000 \mu \mathrm{g} / \mathrm{L}$ of their respective isotope. After stirring the solutions overnight, we sampled each bottle and continued stirring. After 3 or 4 days of stirring, we filtered each solution and stored the filtered solutions in clean polyethylene (PE) bottles. Personnel sampled each bottle and analyzed for plutonium and neptunium content.

Table 3.3 presents the analytical data for each test solution. The data indicate that both plutonium solutions appeared unstable as evidenced by decreasing plutonium concentrations. Furthermore, the $\mathrm{Pu}(\mathrm{VI})$-spiked solution had a higher solubility under the preparation conditions compared to the $\mathrm{Pu}(\mathrm{IV})$-spiked solutions. Both $\mathrm{Np}$ solutions appeared stable with time with similar concentrations. 
Table 3.3. ICP-MS and PuTTA Analyses of the Starting Salt Solutions

\begin{tabular}{|c|c|c|c|c|}
\hline Time (h) & $\begin{array}{c}\text { Pu (IV) } \\
(\mu \mathbf{g} / \mathbf{L})^{\mathbf{a}}\end{array}$ & $\begin{array}{c}\text { Pu (VI) } \\
(\mu \mathbf{g} / \mathbf{L})^{\mathbf{a}}\end{array}$ & $\begin{array}{c}\text { Np (IV) } \\
(\mu \mathbf{g} / \mathbf{L})^{\mathbf{a}}\end{array}$ & $\begin{array}{c}\text { Np (V) } \\
(\mu \mathbf{g} / \mathbf{L})^{\mathbf{a}}\end{array}$ \\
\hline 25 & $\mathrm{NA}^{\mathrm{b}}$ & 1193 & 1150 & $\mathrm{NA}^{\mathrm{b}}$ \\
\hline 47 & 107 & $\mathrm{NA}^{\mathrm{b}}$ & $\mathrm{NA}^{\mathrm{b}}$ & 1375 \\
\hline 126 & $\mathrm{NA}^{\mathrm{b}}$ & 715 & 1160 & $\mathrm{NA}^{\mathrm{b}}$ \\
\hline 148 & 37.3 & $\mathrm{NA}^{\mathrm{b}}$ & $\mathrm{NA}^{\mathrm{b}}$ & 1260 \\
\hline
\end{tabular}

${ }^{\text {a}} \mathrm{Pu}$ values determined by PuTTA. Np values determined by ICP-MS.

${ }^{\mathrm{b}} \mathrm{NA}$ indicates no analysis performed.

Testing for MST batch affects and alternate sorbent materials salt solution comprised of the same solution composition provided in Table 3.2. We treated the salt solution with MST to remove tramp strontium and then spiked as previously described with ${ }^{85} \mathrm{Sr}$ radiotracer (NEN Cat. \#NEZ082, Lot \#00M51M7) and nitric acid solutions of uranyl nitrate hexahydrate (Mallinckrodt Lot \# 8640KDAL), plutonium(IV) (19.328 g/L) and neptunium(V) $(67.1 \mathrm{~g} / \mathrm{L})$ supplied by the Actinide Technology Section of SRTC. After filtering to remove undissolved solids, we stored the filtered solutions in clean PE bottles.

\subsection{Adsorption Tests}

Researchers added between 115 and $200 \mathrm{~mL}$ of the appropriate salt solution into labeled PE bottles and then randomly placed the bottles in a Lab Line shaking waterbath (ColeParmer Catalog \#E-01290-20) set to maintain a temperature of $25^{\circ} \mathrm{C}$. Personnel kept the level of the water at or above the liquid level in the sample bottles. Temperature measurements occurred via a thermistor thermometer (Omega ${ }^{\circledR}$ Model \# 5831) with probes (Omega ${ }^{\circledR}$ Model \#OL-703). After incubating for one day, testing began with an initial sampling of each bottle, and the addition of the appropriate quantity of MST to provide a MST concentration of $0.4 \mathrm{~g} / \mathrm{L}$. For sorbents other than MST, researchers placed a weighed quantity of the sorbent, which provided the same quantity of titanium equivalent to $0.4 \mathrm{~g} / \mathrm{L}$ MST. Sampling of each bottle occurred in random order at the desired sampling interval after the addition of MST.

The sampling method consisted of removing the test bottle from the waterbath, briskly shaking for about 30 seconds to provide a homogeneous suspension, and pulling approximately 5-6 mL of the suspension into a disposable plastic syringe. The researcher then inserted a $0.45 \mu \mathrm{m}$ disk filter (nylon membrane) onto the syringe, collected about 5 $\mathrm{mL}$ of filtrate into a clean PE sample bottle and pipetted $4 \mathrm{~mL}$ of the resulting filtrate into a glass vial containing $4 \mathrm{~mL}$ of $5 \mathrm{M}$ nitric acid. A white precipitate formed immediately upon mixing of the sample and the nitric acid. Personnel then capped the glass sample vial, gently agitated it and then allowed it to stand at ambient laboratory temperature until all solids dissolved. Personnel recapped the test bottle and returned it to the waterbath. The total time outside of the waterbath for sampling did not exceed three minutes.

The Analytical Development Section of SRTC performed all radiostrontium and actinide analyses. ${ }^{16}$ The ${ }^{85} \mathrm{Sr}$ activity measurement occurred by gamma pulse height 
spectroscopy. ${ }^{17}$ Personnel determined concentrations of ${ }^{237} \mathrm{~Np},{ }^{238} \mathrm{U},{ }^{239} \mathrm{Pu}$ and ${ }^{240} \mathrm{Pu}$ by Inductively Coupled Plasma Mass Spectroscopy (ICP-MS) analysis. ${ }^{18}$ The $^{239 / 240} \mathrm{Pu}$ and

${ }^{238} \mathrm{Pu}$ activity determination relied on alpha spectroscopy after chemically separating the plutonium from neptunium. ${ }^{19}$

\subsection{Results and Discussion}

4.1 Affects of Solution Composition

Solution composition testing featured a statistically designed test matrix consisting of 11 experimental trials, as listed in Table 4.1.1. ${ }^{20}$ The purpose of the first six trials examined whether a linear relationship exists between MST adsorption ability and the concentrations of $\mathrm{NaNO}_{3}$, free $\mathrm{NaOH}, \mathrm{NaNO}_{2}, \mathrm{NaAl}(\mathrm{OH})_{4}, \mathrm{Na}_{2} \mathrm{CO}_{3}$, and $\mathrm{Na}_{2} \mathrm{SO}_{4}$. We selected the range of molar concentrations for each salt to fall within expected value and so that the change in concentrations would likely produce a measurable affect, but these values do not represent a bounding range of concentrations that may occur during facility operations. Table 4.1.2 provides a list of the lower and upper range of molar concentrations tested.

Table 4.1.1. Statistically Designed Trials

\begin{tabular}{|c|c|c|c|c|c|c|c|}
\hline Trial & Description & \multicolumn{7}{|c|}{ Component Concentration (M) } \\
\hline & & $\mathrm{NaNO}_{3}$ & Free $\mathrm{NaOH}$ & $\mathrm{NaNO}_{2}$ & $\mathrm{NaAl}(\mathrm{OH})_{4}$ & $\mathrm{Na}_{2} \mathrm{CO}_{3}$ & $\mathrm{Na}_{2} \mathrm{SO}_{4}$ \\
\hline 1 & Statistical Trial & 1.000 & 3.000 & 0.500 & 0.100 & 0.020 & 0.490 \\
\hline 2 & Statistical Trial & 1.000 & 3.000 & 0.100 & 0.100 & 0.200 & 0.443 \\
\hline 3 & Statistical Trial & 3.000 & 1.070 & 0.100 & 0.100 & 0.020 & 0.600 \\
\hline 4 & Statistical Trial & 3.000 & 1.630 & 0.500 & 0.100 & 0.200 & 0.100 \\
\hline 5 & Statistical Trial & 1.730 & 1.000 & 0.500 & 0.500 & 0.200 & 0.600 \\
\hline 6 & Statistical Trial & 2.170 & 3.000 & 0.100 & 0.500 & 0.020 & 0.100 \\
\hline 7 & Centroid & 1.959 & 2.122 & 0.292 & 0.299 & 0.106 & 0.379 \\
\hline 8 & Centroid & 1.959 & 2.122 & 0.292 & 0.299 & 0.106 & 0.379 \\
\hline $9^{\ddagger}$ & Centroid with secondary & 1.907 & 2.066 & 0.284 & 0.291 & 0.104 & 0.369 \\
\hline 10 & Salts & & & & & & 0.106 \\
\hline 11 & Centroid with no MST & 1.959 & 2.122 & 0.292 & 0.299 & 0.379 \\
\hline
\end{tabular}

‡Trial 9 also spiked with salts listed in Table 4.1.3.

Additional input to the development of these trials included two constraints. First, we required that the ionic strength would remain constant for each trial solution at $6.13 \mathrm{M}$ (i.e., ionic strength for $5.6 \mathrm{M} \mathrm{Na}^{+}$simulated waste solution of composition provided in Table 3.2). The second constraint required that the concentration of $\mathrm{NaNO}_{3}$ in the salt solutions equaled at least three times that of the $\mathrm{NaAl}(\mathrm{OH})_{4}$ concentration. The solution preparation generates $\mathrm{NaAl}(\mathrm{OH})_{4}$ from the reaction of $\mathrm{Al}\left(\mathrm{NO}_{3}\right)_{3}$ and four equivalents of $\mathrm{NaOH}$ releasing three equivalents of nitrate per equivalent of aluminum and thus necessitating this constraint. 
Table 4.1.2. Range of Molar Concentrations for Salts of Interest

\begin{tabular}{|c|c|c|c|c|}
\hline Lower Limit & & Salt & & Upper Limit \\
\hline 1.0 & $\leq$ & $\mathrm{NaNO}_{3}$ & $\leq$ & 3.0 \\
\hline 1.0 & $\leq$ & Free $\mathrm{NaOH}$ & $\leq$ & 3.0 \\
\hline 0.1 & $\leq$ & $\mathrm{NaNO}_{2}$ & $\leq$ & 0.5 \\
\hline 0.1 & $\leq$ & $\mathrm{NaAl}(\mathrm{OH})_{4}$ & $\leq$ & 0.5 \\
\hline 0.020 & $\leq$ & $\mathrm{Na}_{2} \mathrm{CO}_{3}$ & $\leq$ & 0.2 \\
\hline 0.1 & $\leq$ & $\mathrm{Na}_{2} \mathrm{SO}_{4}$ & $\leq$ & 0.6 \\
\hline
\end{tabular}

The relative ionic strengths of the six primary salt solution components subject to the ranges provided in Table 4.1.2 and the two constraints of the previous paragraph define the region of interest for this mixture study. Cornell provides a detail discussion of the statistical methods for the design and analysis of such mixture experiments. ${ }^{21} \mathrm{We}$ used these methods to determine a minimal (only 6 trials) experimental design ${ }^{20}$ that supported the evaluation of a six-term linear model relating each decontamination factor (DF) response of interest to the six primary salt solution components. These six trials were optimally selected from the set of extreme vertices bounding the region defined by the ranges of Table 4.1.2 and the two associated constraints.

Trials 7-10 in the statistical matrix specified a centroid concentration determined by averaging the extreme compositional vertices of the defined area for the six salt components. The constraints as previously defined also applied to this composition. Trials 7 and 8 used the centroid as is, while Trial 10 utilized the centroid as a control by omitting the addition of MST. Trial 9 used the centroid spiked with trace amounts of secondary salts as listed in Table 4.1.3 to determine the gross effect on MST performance of having these secondary salts present.

Table 4.1.3. Secondary Salts Added to Trial Nine

\begin{tabular}{|c|c|}
\hline Component & Concentration (M) \\
\hline $\mathrm{Na}_{2} \mathrm{C}_{2} \mathrm{O}_{4}$ & 0.0080 \\
\hline $\mathrm{Na}_{3} \mathrm{PO}_{4}$ & 0.0100 \\
\hline $\mathrm{NaF}$ & 0.0320 \\
\hline $\mathrm{NaCl}$ & 0.0250 \\
\hline $\mathrm{Na}_{2} \mathrm{SiO}_{3}$ & 0.0040 \\
\hline $\mathrm{Na}_{2} \mathrm{MoO}_{4}$ & 0.0002 \\
\hline $\mathrm{KNO}_{3}$ & 0.0150 \\
\hline $\mathrm{CsNO}_{3}$ & 0.00014 \\
\hline
\end{tabular}

The last trial of the experimental series, Trial 11, specified the use of salt solution previously used in strontium and actinide removal testing (referred to as Phase V salt 
solution). ${ }^{3}$ This trial provides a quantitative measure of the reproducibility of this data set with that in previous testing.

Researchers intended to use a constant set of initial sorbate concentrations across the 11 trials. The actual concentrations differed significantly from the targets and across the different solution compositions. Table 3.1 provides the initial concentrations for each sorbate. The strontium values exceeded the targeted because personnel did not remove tramp strontium from the reagent chemicals prior to solution preparation. A second contributing factor to the variations may have been that the solutions sat unmixed after spiking with the radionuclides for 9 days prior to being placed on stir plates and mixed due to an expected laboratory outage.

A third probable cause of the variations in sorbate levels involves the effect of solution composition on the solubility of each sorbate. Prior to design of the experiment, SRTC researchers expected different sorbate concentrations for the trials due to wide range of solution compositions and previous studies that showed significant changes in uranium and plutonium solubilities as a function of the solution composition. ${ }^{12,13,22}$ Table 3.1 presents the measured and predicted concentrations for uranium and plutonium in each of the test solutions. The predicted concentration assumes that there is sufficient uranium present to achieve the predicted solubility. Researchers targeted uranium and plutonium concentrations at $10,000 \mu \mathrm{g} / \mathrm{L}$ and $200 \mu \mathrm{g} / \mathrm{L}$, respectively. Thus, for those solutions that have predicted concentrations equal to or greater than the target concentrations, the measured concentrations will not achieve the predicted concentrations.

Solutions for Trials \#3, 4, 5 and 11 all have predicted solubilities below $200 \mu \mathrm{g} / \mathrm{L}$. Measured plutonium concentrations followed the predicted concentration for all of the solutions with the exception of solution in Trial \#5. For Trial \#5, the measured concentration was below the target, but higher than the predicted concentration. At the 95\% confidence limit, the measured concentration is within the higher prediction value $(169 \mu \mathrm{g} / \mathrm{L})$. Only the Trial \#9 solution had a measured concentration that exceeded the target concentration.

Uranium concentrations for all of the solutions measured at or below the target concentration of $10,000 \mu \mathrm{g} / \mathrm{L}$. Replicate measurements of the solutions for Trials \#7, \#8 and \#10 exhibited a single standard deviation of $\pm 200 \mu \mathrm{g} / \mathrm{L}$. This result indicates a small error for the determination of the uranium concentrations. Three solutions, Trials \#2, \#5 and \#9 exhibited uranium concentrations above the predicted concentration. The uranium concentrations for Trial \#2 and Trial \#9 solutions are within the range of values predicted at the $95 \%$ confidence interval. The uranium concentration for the Trial \#5 solution is about a factor of 3 higher than the predicted value and well outside the $95 \%$ confidence interval.

Trial 6 solution represented one of the extreme vertices of the salt compositional region investigated. A relatively hard-to-dissolve white precipitate formed in Trial 6 samples taken directly after addition of strontium and actinides. Although most of the trial samples exhibited the precipitates upon addition of 5M nitric acid, the Trial 6 sample 
required a second addition of the $5.0 \mathrm{M}$ nitric acid to completely dissolve the solids. The additional acid was needed to neutralize all of the alkalinity in the Trial 6 composition, which had the highest combination of $\mathrm{NaAl}(\mathrm{OH})_{4}(0.5 \mathrm{M})$ and free $\mathrm{NaOH}(3.0 \mathrm{M})$.

The investigation included one test bottle, Trial 10, containing no MST to serve as a control. Trial 10 solution represented the centroid or center of the compositional region tested in Trials $1-6$. This trial served as a means to correct for removal of sorbates by sorption onto the bottle walls, the filter or by precipitation. The results indicated no significant removal of sorbates in the control sample (See Table 4.1.4) within the duration of the experiments. For this reason, the results for tests with MST did not require correction for sorption by mechanisms other than that with MST.

\section{Table 4.1.4. Control Sample Results}

\begin{tabular}{|c|c|c|c|c|}
\hline Sample Time & \multicolumn{4}{|c|}{ Sorbate Concentration $(\mu \mathrm{g} / \mathbf{L})$} \\
\hline & Total Sr & Total Pu & Total U & Np-237 \\
\hline Time 0 & 628 & 203 & 6952 & 225 \\
\hline Time 24 hours & 578 & 200 & 8208 & 286 \\
\hline Time 168 hours & 541 & 205 & 6893 & 239 \\
\hline Average & 582 & 203 & 7351 & 250 \\
\hline Std. Dev. & 43.9 & 2.55 & 742 & 31.9 \\
\hline \% RSD & $7.5 \%$ & $1.3 \%$ & $10.1 \%$ & $12.7 \%$ \\
\hline
\end{tabular}

Trials 7 and 8 of the experimental series served as duplicates of the centroid composition. Initial sorbate concentrations in each were in close agreement (See Table 3.1.1). Table 4.1.5 presents the DFs calculated from the 24-hour and 168-hour sample results. All values showed good agreement except for the 24-hour strontium result. The difference in the strontium sample analyses results at 24 hours may reflect error associated with the handling of the sample prior to or during analysis. Reanalysis of the 24-hour samples using the residues from the gamma and alpha counting aliquots confirmed the relatively high strontium concentration in Trial 8, which results in a low strontium DF value. Since good agreement resulted for the 7-day strontium values and all of the actinide values in both trials, we conclude that the 24-h result for Trial \#8 cannot be discarded. Consequently, statistical analysis includes the 24-hour result for Trial \#8.

Trial 11 of the experimental series used the same salt solution composition previously used in strontium and actinide removal testing for the program. ${ }^{3,45}$ Table 4.1.6 contains a summary of the data from Trial 11 and values previously reported. We averaged the four individual results and compared the average to the values obtained in Trial 11. The measured DFs in Trial 11 agreed well with the averages determined in the previous tests as evident by the small percent difference values calculated for each sorbate at 24-hours and 7-days. Poorer agreement occurred for the uranium 7-day and neptunium 24-hour values. However, even in these cases, the Trial 11 values fall within the range spanned by the average and (plus or minus) two standard deviations. 
Table 4.1.5. Duplicate Sample Results

\begin{tabular}{|c|c|c|c|c|c|c|c|c|}
\hline & \multicolumn{7}{|c|}{ Decontamination Factor } \\
\hline & Sr & Sr & $\mathbf{P u}$ & $\mathbf{P u}$ & $\mathbf{U}$ & $\mathbf{U}$ & $\mathbf{~ N p}$ & $\mathbf{N p}$ \\
\hline & $\mathbf{2 4} \mathbf{h}$ & $\mathbf{7 d}$ & $\mathbf{2 4} \mathbf{h}$ & $\mathbf{7 d}$ & $\mathbf{2 4} \mathbf{h}$ & $\mathbf{7 d}$ & $\mathbf{2 4} \mathbf{h}$ & $\mathbf{7 d}$ \\
\hline Trial 7: EV Centroid & 100 & 126 & 5.70 & 13.8 & 1.15 & 1.66 & 1.24 & 2.17 \\
\hline Trial 8: EV Centroid & 18.8 & 141 & 4.64 & 13.9 & 1.15 & 1.74 & 1.41 & 2.64 \\
\hline & & & & & & & & \\
\hline Average & 59.6 & 133 & 5.17 & 13.9 & 1.15 & 1.70 & 1.33 & 2.41 \\
\hline Std Dev & 57.7 & 11.0 & 0.75 & 0.09 & 0.01 & 0.06 & 0.12 & 0.34 \\
\hline RSD & $96.7 \%$ & $8.2 \%$ & $14.6 \%$ & $0.7 \%$ & $0.4 \%$ & $3.3 \%$ & $8.9 \%$ & $14.1 \%$ \\
\hline
\end{tabular}

Table 4.1.6. Comparison of Trial 11 and Previous Test Results

\begin{tabular}{|c|c|c|c|c|c|c|c|c|}
\hline \multirow[b]{2}{*}{ Trial } & \multicolumn{6}{|c|}{ Decontamination Factor } & \multirow[b]{2}{*}{$\begin{array}{c}\text { Np } \\
24 \text { h }\end{array}$} & \multirow[b]{2}{*}{$\begin{array}{r}\text { Np } \\
\text { 7d }\end{array}$} \\
\hline & $\begin{array}{c}\mathrm{Sr} \\
24 \mathrm{~h} \\
\end{array}$ & $\begin{array}{l}\mathrm{Sr} \\
7 \mathrm{~d} \\
\end{array}$ & $\begin{array}{c}\text { Pu } \\
24 \text { h } \\
\end{array}$ & $\begin{array}{c}\text { Pu } \\
7 d \\
\end{array}$ & $\begin{array}{c}\text { U } \\
24 \text { h } \\
\end{array}$ & $\begin{array}{c}\mathrm{U} \\
7 \mathrm{~d} \\
\end{array}$ & & \\
\hline Trial 11 & $1.37 \mathrm{E}+02$ & $1.81 \mathrm{E}+02$ & $1.24 \mathrm{E}+01$ & $3.76 \mathrm{E}+01$ & $1.42 \mathrm{E}+00$ & $2.27 \mathrm{E}+00$ & $2.25 \mathrm{E}+00$ & $8.27 \mathrm{E}+00$ \\
\hline Test \#1 reference 3 & $1.38 \mathrm{E}+02$ & $1.43 \mathrm{E}+02$ & $1.23 \mathrm{E}+01$ & $3.68 \mathrm{E}+01$ & $9.50 \mathrm{E}-01$ & $1.47 \mathrm{E}+00$ & $2.91 \mathrm{E}+00$ & $8.17 \mathrm{E}+00$ \\
\hline Test \#2 reference 3 & $1.21 \mathrm{E}+02$ & $1.38 \mathrm{E}+02$ & $1.36 \mathrm{E}+01$ & $3.65 \mathrm{E}+01$ & $1.63 \mathrm{E}+00$ & $1.52 \mathrm{E}+00$ & $5.13 \mathrm{E}+00$ & $6.80 \mathrm{E}+00$ \\
\hline Test \#3 reference 5 & $1.50 \mathrm{E}+02$ & $3.05 \mathrm{E}+02$ & $1.13 \mathrm{E}+01$ & $3.23 \mathrm{E}+01$ & $1.14 \mathrm{E}+00$ & $1.36 \mathrm{E}+00$ & $3.47 \mathrm{E}+00$ & $8.08 \mathrm{E}+00$ \\
\hline Test \#4 reference 5 & $1.58 \mathrm{E}+02$ & $1.90 \mathrm{E}+02$ & $1.03 \mathrm{E}+01$ & $2.96 \mathrm{E}+01$ & $2.08 \mathrm{E}+00$ & $1.36 \mathrm{E}+00$ & $5.56 \mathrm{E}+00$ & $1.34 \mathrm{E}+01$ \\
\hline Average Tests \#1-4 & $1.42 \mathrm{E}+02$ & $1.94 \mathrm{E}+02$ & $1.19 \mathrm{E}+01$ & $3.38 \mathrm{E}+01$ & $1.45 \mathrm{E}+00$ & $1.43 \mathrm{E}+00$ & $4.27 \mathrm{E}+00$ & $9.11 \mathrm{E}+00$ \\
\hline Standard Deviation Tests \#1-4 & $1.61 \mathrm{E}+01$ & $7.76 \mathrm{E}+01$ & $1.41 \mathrm{E}+00$ & $3.47 \mathrm{E}+00$ & $5.08 \mathrm{E}-01$ & $8.06 \mathrm{E}-02$ & $1.28 \mathrm{E}+00$ & $2.93 \mathrm{E}+00$ \\
\hline Relative Std Dev Tests \#1-4 & $11.4 \%$ & $40.0 \%$ & $11.9 \%$ & $10.3 \%$ & $35.1 \%$ & $5.6 \%$ & $29.9 \%$ & $32.1 \%$ \\
\hline$\%$ Difference & $-3.19 \%$ & $-6.57 \%$ & $4.75 \%$ & $11.22 \%$ & $-2.37 \%$ & $59.32 \%$ & $-47.17 \%$ & $-9.24 \%$ \\
\hline
\end{tabular}

This agreement in DF values confirms the assumption that the initial sorbate concentration does not significantly affect the measured DF. As seen in Table 4.1.7, the initial sorbate concentrations differ among the three test sets from about a factor of 2 for neptunium to as high as about a factor of 6 for strontium. The differences in DFs between Trial 11 and the two previous data sets prove much smaller. The greatest difference (uranium - 7days) equaled $59.3 \%$ which is consistent with the initial lower uranium concentration in Trial 11 compared to the previous test sets.

Table 4.1.7. Initial Sorbate Concentrations

\begin{tabular}{|c|c|c|c|}
\hline \multirow[b]{2}{*}{ Sorbate } & \multicolumn{3}{|c|}{ Concentration $(\mu \mathrm{g} / \mathrm{L})$} \\
\hline & Trial 11 & $\underline{\text { Set } \# 1^{a}}$ & $\underline{\text { Set } \# 2^{b}}$ \\
\hline $\mathrm{Sr}$ & 568 & 86.7 & 92.4 \\
\hline $\mathrm{Pu}$ & 65.7 & 190 & 222 \\
\hline $\mathrm{U}$ & 4316 & 9040 & 11500 \\
\hline $\mathrm{Np}$ & 215 & $\begin{array}{l}416 \\
\text { reference } \\
\text { reference }\end{array}$ & 489 \\
\hline
\end{tabular}


Table 4.1.8 provides the measured decontamination factors for each trial in the statistical design. Exhibits 3 through 10 in the Appendix provide Box Plots of the DFs for each species of interest. These plots group the extreme vertices (Trials 1 through 6) and the duplicate centroids. The plots display the other trials individually. The DF for Trail 10, the control, ranged from 0.79 to 1.16 , versus an anticipated value of 1.0 .

Table 4.1.8. Decontamination Factors for Solution Composition Trials

\begin{tabular}{|c|c|c|c|c|c|c|c|c|}
\hline Trial & $\begin{array}{c}\mathrm{Sr} \\
24 \mathrm{~h}\end{array}$ & $\begin{array}{l}\mathrm{Sr} \\
7 \mathrm{~d}\end{array}$ & $\begin{array}{c}\text { Pu } \\
24 h\end{array}$ & $\begin{array}{l}\text { Pu } \\
7 d\end{array}$ & $\begin{array}{c}\mathrm{U} \\
24 \mathrm{~h}\end{array}$ & $\begin{array}{c}\mathbf{U} \\
7 \mathrm{~d}\end{array}$ & $\begin{array}{c}\text { Np } \\
24 h\end{array}$ & $\begin{array}{l}\text { Np } \\
\text { 7d }\end{array}$ \\
\hline Trial 1 & 123 & 155 & 4.13 & 9.10 & 1.36 & 1.62 & 1.53 & 2.02 \\
\hline Trial 2 & 10.8 & 112 & 3.40 & 8.42 & 1.27 & 1.58 & 1.59 & 2.72 \\
\hline Trial 3 & 78.5 & 246 & 16.5 & 43.3 & 1.56 & 2.30 & 2.50 & 9.82 \\
\hline Trial 4 & 174 & 190 & 7.91 & 20.9 & 1.43 & 2.08 & 1.90 & 3.55 \\
\hline Trial 5 & 102 & 140 & 10.6 & 24.2 & 1.48 & 2.35 & 2.21 & 4.28 \\
\hline Trial 6 & 50.5 & 137 & 4.14 & 8.06 & 1.26 & 1.74 & 1.94 & 3.56 \\
\hline Trial 7: EV Centroid & 100 & 126 & 5.70 & 13.8 & 1.15 & 1.66 & 1.24 & 2.17 \\
\hline Trial 8: EV Centroid & 18.8 & 141 & 4.64 & 13.9 & 1.15 & 1.74 & 1.41 & 2.64 \\
\hline Trial 9: EV Centroid w/ Trace Salts & 90.7 & 127 & 3.85 & 9.31 & 1.16 & 1.56 & 1.00 & 1.43 \\
\hline Trial 10: EV Centroid, No MST, Control & 1.09 & 1.16 & 1.01 & 0.99 & 0.85 & 1.01 & 0.79 & 0.94 \\
\hline Trial 11: Phase V Solution & 137 & 181 & 12.4 & 37.6 & 1.42 & 2.27 & 2.25 & 8.27 \\
\hline
\end{tabular}

Exhibit 11 provides correlations among the DFs for these 11 trials as well as the corresponding scatter plots. Strong linear correlations exist for the following pairs of these data: Pu DF-24h and Pu DF-7d (0.9853), and U DF-24h and U DF-7d (0.9127), Np DF-7d and Pu DF-24h (0.9326), Np DF-7d and Pu DF-7d (0.9466), Np DF-24h and U DF-24h (0.9142), and Np DF-24h and U DF-7d (0.9156).

Exhibit 12 provides a series of plots of the DFs versus the normalized ionic strength $\left(\mathrm{N}_{\mathrm{is}}\right)$ fractions of the six primary salt solution components. The plots offer an opportunity to investigate trends and other patterns in the DF values relative to each of the six primary salt solution components in turn.

Exhibits 13 through 20 of the Appendix provide a formal statistical analysis using the JMP statistical analysis software for each set of DFs. ${ }^{23}$ Each of these exhibits contains the JMP output from fitting a linear (mixture) model (in normalized ionic strength fractions) relating the six primary salt solution components to a set of DF values. We only used Trials 1 through 8 to conduct these analyses. However, the corresponding "Actual by Predicted" plots presented as part of the exhibits provide results for Trials 9 and 11. These exhibits also include estimated effects, plots of "Residual by Predicted," and tests for "lack of fit" for the linear models. A value, for Prob $>|\mathbf{t}|$ (for an estimated linear effect) or Prob>F (for a "lack of fit" test) less than 0.05, indicates a statistically significant effect or lack of fit, respectively, at a 5\% significance level. The following sections discuss the results from each model fit. 


\section{Sr 24-hour DFs}

The results presented in Exhibit 13 indicate no significant linear effects for these data. In addition, there is no indication of a lack of fit for the model. However, these conclusions are tempered by the poor repeatability demonstrated for Trials 7 and 8 discussed earlier.

\section{Sr 7-day DFs}

The results of Exhibit 14 indicate a significant linear effect for $\mathrm{NaNO}_{3}$ at the $5 \%$ significance level. There is no indication of a lack of fit for the model at the $5 \%$ level. However, the residual plot indicates that the centroids of the factor space (Trials 7 and 8) are (relatively) poorly predicted by the linear model suggesting that a more complex model might be worth investigating.

\section{Pu 24-hour DFs}

The results in Exhibit 15 indicate a significant linear effect for $\mathrm{NaNO}_{3}$ at the $5 \%$ significance level. There is no indication of a lack of fit for the model at the $5 \%$ level. However, the residual plot indicates that the centroids of the factor space (Trials 7 and 8) are (relatively) poorly predicted by the linear model suggesting that a more complex model might be worth investigating.

\section{Pu 7-day DFs}

The results presented in Exhibit 16 indicate significant linear effects for $\mathrm{NaNO}_{3}$ and $\mathrm{Na}_{2} \mathrm{SO}_{4}$ at the $5 \%$ significance level. There is no indication of a lack of fit for the model at the $5 \%$ level. However, at a $10 \%$ significance level an indication of a lack of fit does occur, and the residual plot indicates that the centroids of the factor space (Trials 7 and 8) are (relatively) poorly predicted by the linear model suggesting that a more complex model might be worth investigating.

\section{U 24-hour DFs}

The results in Exhibit 17 indicate no significant linear effects at the 5\% significance level. At a $10 \%$ level of significance, only the effect for $\mathrm{NaNO}_{3}$ would be considered statistically significant for these data. In addition, there is no indication of a lack of fit for the model at the 5\% level. However, at a $10 \%$ significance level there would be an indication of a lack of fit, and the residual plot indicates that the centroids of the factor space (Trials 7 and 8) are (relatively) poorly predicted by the linear model suggesting that a more complex model might be worth investigating.

\section{$\underline{\text { U 7-day DFs }}$}

The results in Exhibit 18 indicate a significant linear effect for $\mathrm{NaNO}_{3}$ at the $5 \%$ significance level and an indication of a lack of fit for the model at the 5\% level. The residual plot indicates that the centroids of the factor space (Trials 7 and 9) are poorly predicted by the linear model suggesting that a more complex model might be worth investigating. 


\section{Np 24-hour DFs}

The results in Exhibit 19 indicate no significant linear effects at the 5\% significance level. In addition, there is no indication of a lack of fit for the model at the $5 \%$ level. However, at a $10 \%$ significance level there would be an indication of a lack of fit, and the residual plot indicates that the centroids of the factor space (Trials 7 and 8) are (relatively) poorly predicted by the linear model suggesting that a more complex model might be worth investigating.

\section{Np 7-day DFs}

The results in Exhibit 20 indicate no significant linear effects at the 5\% significance level. In addition, there is no indication of a lack of fit for the model at the 5\% level. However, at a $10 \%$ significance level, the effect for $\mathrm{NaNO}_{3}$ is significant and there would be an indication of a lack of fit. The residual plot indicates that the centroids of the factor space (Trials 7 and 8 ) are (relatively) poorly predicted by the linear model suggesting that a more complex model might be worth investigating.

\section{Modeling}

Exhibits 21 through 28 provide plots of the actual DFs versus predictions from the fitted models. For each fitted model, the plots show actual DFs as individual points, and depicts the model predictions (Pred Formula ...) as a straight, dark line. The exhibits also provide a 95\% confidence interval (Lower 95\% Mean ... and Upper 95\% Mean ...) for the expected fitted line as the pair of lines closest to the straight, dark line, and a 95\% prediction interval (Lower 95\% Indiv ... and Upper 95\% Indiv ...) for an individual DF value shown as the other pair of lines.

Equations $1-8$ provide the predictive equations for calculating the sorbate DF derived from the statistical analysis with solution component expressed in units of mole per liter (M).

$$
\begin{aligned}
& \mathrm{DF}^{\mathrm{Sr}}{ }_{24 \mathrm{~h}}=25.4 *\left[\mathrm{NO}_{3}{ }^{-}\right]+0.513 *\left[\mathrm{OH}^{-}\right]+238 *\left[\mathrm{NO}_{2}{ }^{-}\right]-56.4 *\left[\mathrm{Al}(\mathrm{OH})_{4}{ }_{4}\right]-106 *\left[\mathrm{CO}_{3}{ }^{2-}\right]-39.8 *\left[\mathrm{SO}_{4}{ }^{2-}\right] \\
& \mathrm{DF}^{\mathrm{Sr}}{ }_{7 \mathrm{~d}}=53.7 *\left[\mathrm{NO}_{3}{ }^{-}\right]+13.3 *\left[\mathrm{OH}^{-}\right]+42.3 *\left[\mathrm{NO}_{2}{ }^{-}\right]-54.0^{*}\left[\mathrm{Al}(\mathrm{OH})_{4}{ }^{-}\right]-135 *\left[\mathrm{CO}_{3}{ }^{2-}\right]+89.5 *\left[\mathrm{SO}_{4}{ }^{2-}\right] \\
& \mathrm{DF}^{\mathrm{Pu}}{ }_{24 \mathrm{~h}}=3.50^{*}\left[\mathrm{NO}_{3}{ }^{-}\right]-1.63 *\left[\mathrm{OH}^{-}\right]-1.55^{*}\left[\mathrm{NO}_{2}^{-}\right]-0.457 *\left[\mathrm{Al}(\mathrm{OH})_{4}^{-{ }^{-}}\right]-3.39 *\left[\mathrm{CO}_{3}{ }^{2-}\right]+11.9^{*}\left[\mathrm{SO}_{4}{ }^{2-}\right] \\
& \mathrm{DF}^{\mathrm{Pu}}{ }_{7 \mathrm{~d}}=9.76 *\left[\mathrm{NO}_{3}^{-}\right]-4.29 *\left[\mathrm{OH}^{-}\right]-5.85^{-} *\left[\mathrm{NO}_{2}{ }^{-}\right]-7.28 *\left[\mathrm{Al}(\mathrm{OH})_{4}{ }^{-}\right]-6.47 *\left[\mathrm{CO}_{3}{ }^{2-}\right]+30.5^{*}\left[\mathrm{SO}_{4}{ }^{2-}\right] \\
& \mathrm{DF}_{24 \mathrm{~h}}^{\mathrm{U}}=0.272 *\left[\mathrm{NO}_{3}^{-}\right]+0.169 *\left[\mathrm{OH}^{-}\right]+0.330^{*}\left[\mathrm{NO}_{2}^{-}\right]+0.149 *\left[\mathrm{Al}(\mathrm{OH})_{4}^{-}\right]+0.544 *\left[\mathrm{CO}_{3}{ }^{2-}\right]+0.817 *\left[\mathrm{SO}_{4}{ }^{2-}\right] \\
& \mathrm{DF}_{7 \mathrm{~d}}^{\mathrm{U}}=0.446^{*}\left[\mathrm{NO}_{3}{ }^{-}\right]+0.100 *\left[\mathrm{OH}^{-}\right]+0.420^{*}\left[\mathrm{NO}_{2}^{-}\right]+0.732^{-} *\left[\mathrm{Al}(\mathrm{OH})_{4}^{-}\right]+1.14 *\left[\mathrm{CO}_{3}{ }^{2-}\right]+1.19 *\left[\mathrm{SO}_{4}{ }^{2-}\right] \\
& \mathrm{DF}^{\mathrm{Np}}{ }_{24 \mathrm{~h}}=0.484 *\left[\mathrm{NO}_{3}{ }^{-}\right]+0.128 *\left[\mathrm{OH}^{-}\right]-0.0629 *\left[\mathrm{NO}_{2}{ }^{-}\right]+0.737 *\left[\mathrm{Al}(\mathrm{OH})_{4}^{-}\right]+0.280 *\left[\mathrm{CO}_{3}{ }^{2-}\right]+1.40 *\left[\mathrm{SO}_{4}{ }^{2-}\right] \\
& \mathrm{DF}^{\mathrm{Np}}{ }_{7 \mathrm{~d}}=2.28 *\left[\mathrm{NO}_{3}^{-}\right]-0.444 *\left[\mathrm{OH}^{-}\right]-4.73 *\left[\mathrm{NO}_{2}^{-}\right]-0.885 *\left[\mathrm{Al}(\mathrm{OH})_{4}^{-}\right]-4.68 *\left[\mathrm{CO}_{3}{ }^{2-}\right]+7.14^{-}\left[\mathrm{SO}_{4}{ }^{2-}\right]
\end{aligned}
$$

Looking at equations $1-8$, the predicted DF increases with increased nitrate concentration for all sorbates. In general, the hydroxide concentration decreases, or has limited affect (i.e., small factor coefficient) on, the predicted DF. This trend for the two main solution components may indicate the role of complexation on strontium and 
actinide removal. At high hydroxide concentration, the predominant solution phase sorbate species may be a hydroxide complex such as $\mathrm{Sr}(\mathrm{OH})^{+}, \mathrm{Pu}(\mathrm{OH})_{6}{ }^{2-}, \mathrm{NpO}_{2}(\mathrm{OH})_{4}{ }^{3-}$, $\mathrm{UO}_{2}(\mathrm{OH})_{4}{ }^{2-}$ or $\mathrm{UO}_{2}(\mathrm{OH})_{5}{ }^{3-}$. With decreasing hydroxide and increasing nitrate concentrations, the predominant sorbate species may shift to a mixed nitrate/hydroxide complex or the corresponding nitrate complex. Nitrate typically forms weaker complexes than hydroxide and thus the strontium and actinide species in high nitrate media may exhibit increased tendency to sorb onto the MST due to more favorable reaction thermodynamics.

Alternatively, solution components could be interacting directly with the MST surface (e.g., binding the hydroxide, nitrate or other component to the MST), which alters the interaction between the sorbate and the MST. Nitrate and hydroxide are the two predominant anions and, therefore, would be expected to produce the more pronounced, if any, affect on the MST surface. Interaction of oxyanions and titanate surfaces would be expected to be minor since the titanate framework is negatively charged. A literature search failed to identify any reports of strong surface interactions between inorganic oxyanions and titanates and titanium oxides. Bourikas, Hiemstra and Van Riemsdijk reported recently that interactions of anions are weaker than cations for titanium oxides. ${ }^{24}$ Thus, we conclude that direct interaction between oxyanions and the MST surface plays a minor role, if any, on the observed variances in sorbate DFs.

\subsection{Affects of Plutonium and Neptunium Oxidation States}

These tests examined whether the oxidation state of either $\mathrm{Pu}$ or Np significantly affected the extent and rate of their removal using MST as the removal agent. The tests targeted $\mathrm{Pu}(\mathrm{IV})$ and $\mathrm{Pu}(\mathrm{VI})$ for comparison and, similarly, $\mathrm{Np}$ (IV) and $\mathrm{Np}$ (V). These oxidation states represent the two most probable (i.e., stable) oxidation states for each element in alkaline radioactive waste. We tested each species in triplicate. The Appendix contains concentration vs. time data from the twelve individual tests. Data discussed below represents the average of each set of three tests. We compare the data with $\mathrm{Pu}(\mathrm{IV})$ and $\mathrm{Np}(\mathrm{V})$ data from previous tests performed under similar conditions $\left(5.6 \mathrm{M} \mathrm{Na}^{+}\right.$and 0.4 $\mathrm{g} / \mathrm{L}$ MST). ${ }^{3,4,5}$ However, the previous testing used multiple sorbate solutions while the current tests used single sorbate solutions.

\subsubsection{Plutonium Removal}

Figure 4.2.1.1 compares the average plutonium concentration as a function of time for the two plutonium oxidation state tests along with previous data. Initial observation shows the starting soluble plutonium concentration in the $\mathrm{Pu}(\mathrm{VI})$ tests at $712 \mu \mathrm{g} / \mathrm{L}$. Correspondingly, the starting plutonium concentration in the $\mathrm{Pu}(\mathrm{IV})$ tests measured 37 $\mu \mathrm{g} / \mathrm{L}$, nearly twenty times less than that of $\mathrm{Pu}(\mathrm{VI})$. In the previous testing, ${ }^{3}$ the initial soluble Pu concentration measured $190 \mu \mathrm{g} / \mathrm{L}$. The equilibrium soluble plutonium concentration for the $\mathrm{Pu}(\mathrm{IV}), \mathrm{Pu}(\mathrm{VI})$ and the previous $\mathrm{Pu}(\mathrm{IV})$ tests measured 2.68, 25.27, and $5.19 \mu \mathrm{g} / \mathrm{L}$, respectively.

No data exists to establish stability and lifetime of $\mathrm{Pu}(\mathrm{VI})$ in alkaline waste solutions. A potential exists that $\mathrm{Pu}(\mathrm{VI})$ reduces to $\mathrm{Pu}(\mathrm{IV})$ over time due to radiolytic or chemical reactions (e.g., reduction with nitrite). However, the persistent high concentration of 
plutonium in the experiments that added $\mathrm{Pu}(\mathrm{VI})$ suggest that reduction did not likely complete during the duration of the experiment (i.e., 2 weeks). Furthermore, recent data from the Extended X-ray Absorption Fine Spectroscopy (EXAFS) analysis of MST loaded with plutonium indicates that $\mathrm{Pu}(\mathrm{VI})$ persisted on the solids with about $20 \%$ of the plutonium present as $\mathrm{Pu}(\mathrm{VI})$ based on the observation of plutonyl axial oxygen atoms. ${ }^{25}$

Table 4.2.1.1 contains decontamination factors (DFs) and equilibrium distribution constants $\left(\mathrm{K}_{\mathrm{d}}\right)$, and removal rate constants from the average plutonium concentration data. The listed DFs and $\mathrm{K}_{\mathrm{d}} \mathrm{s}$ derive from samples collected after about 1 day (29.7 hours in these tests and 24.1 hours in the earlier testing ${ }^{3}$ ) and 7 days of contact. DF and $\mathrm{K}_{\mathrm{d}}$ data for the three data sets $(\mathrm{Pu}(\mathrm{IV}), \mathrm{Pu}(\mathrm{VI})$ and previous $\mathrm{Pu}(\mathrm{IV}))$ are within a factor of approximately two of each other. Inspection of Figure 4.2.1.1 indicates similar changes in the solution plutonium concentration with time for each test suggesting similar removal kinetics for both $\mathrm{Pu}(\mathrm{IV})$ and $\mathrm{Pu}(\mathrm{VI})$.

Removal rates for sorption or ion-exchange of sorbates and porous sorbents depend on three consecutive mass transport steps; (1) bulk transport of the sorbate in the solution phase, (2) transport of the sorbate through a hydrodynamic boundary layer or film and (3) transport of the sorbate within the pore volume of the sorbent to the active sorption or ion exchange site. ${ }^{26}$ The latter step also includes the steps involved in sorption or exchange at the sorbent site (e.g., dehydration, exchange, etc.). Generally, the latter two steps are the major factors controlling rates of removal. Since these steps act in series, the slower of the two steps will be rate limiting. In the system under investigation, the removal kinetics are further complicated by the fact that at least four different sorbates $\mathrm{Sr}, \mathrm{Pu}, \mathrm{Np}$ and $U$ ) interacting with the MST. Each could have a different rate limiting step or influence the transport of other sorbates during any of the above steps.

During the early stages of contact between the MST and alkaline solutions containing the sorbates removal kinetics may exhibit a first or second order dependence on the sorbate concentration. Inspection of graphs plotting the plutonium concentration versus time indicate that overall, the removal kinetics do not fit first or second order expressions in plutonium concentration. However, between 1 and 4 hours, plutonium removal fits first order kinetics with respect to the concentration of plutonium (see Figure 4.2.1.2).

We calculated removal rate constants from the linear fit of the average concentrations for the time interval of 1 to 4 hours using equation 1 . The rate constants are reported in Table 4.2.1.1. Reaction rate constants are known to vary with oxidation state ${ }^{27}$ and, thus, determination of the rate constants for the $\mathrm{Pu}(\mathrm{IV})$ and $\mathrm{Pu}(\mathrm{VI})$ spiked solutions may provide additional information concerning the stability and reactivity of $\mathrm{Pu}(\mathrm{IV})$ and $\mathrm{Pu}(\mathrm{VI})$ in alkaline solutions. The average rate constants for the tests using the $\mathrm{Pu}(\mathrm{IV})$ spiked solutions ranged from 1.29 to 1.42 times greater than that for the solution spiked with $\mathrm{Pu}(\mathrm{VI})$. This suggests a slight increase in the removal rate for $\mathrm{Pu}(\mathrm{IV})$ compared to $\mathrm{Pu}(\mathrm{VI})$. However, given the experimental variance in rate constants calculated for each individual test, the ranges in rate constants defined by $\pm 2 \sigma$ overlap all three test cases. Thus, with this limited data set, we cannot conclusively establish that $\mathrm{Pu}(\mathrm{IV})$ removal is faster than $\mathrm{Pu}(\mathrm{VI})$ between 1 and 4 hours of contact with MST. 
Figure 4.2.1.1. Plutonium Concentration as a Function of Elapsed Time

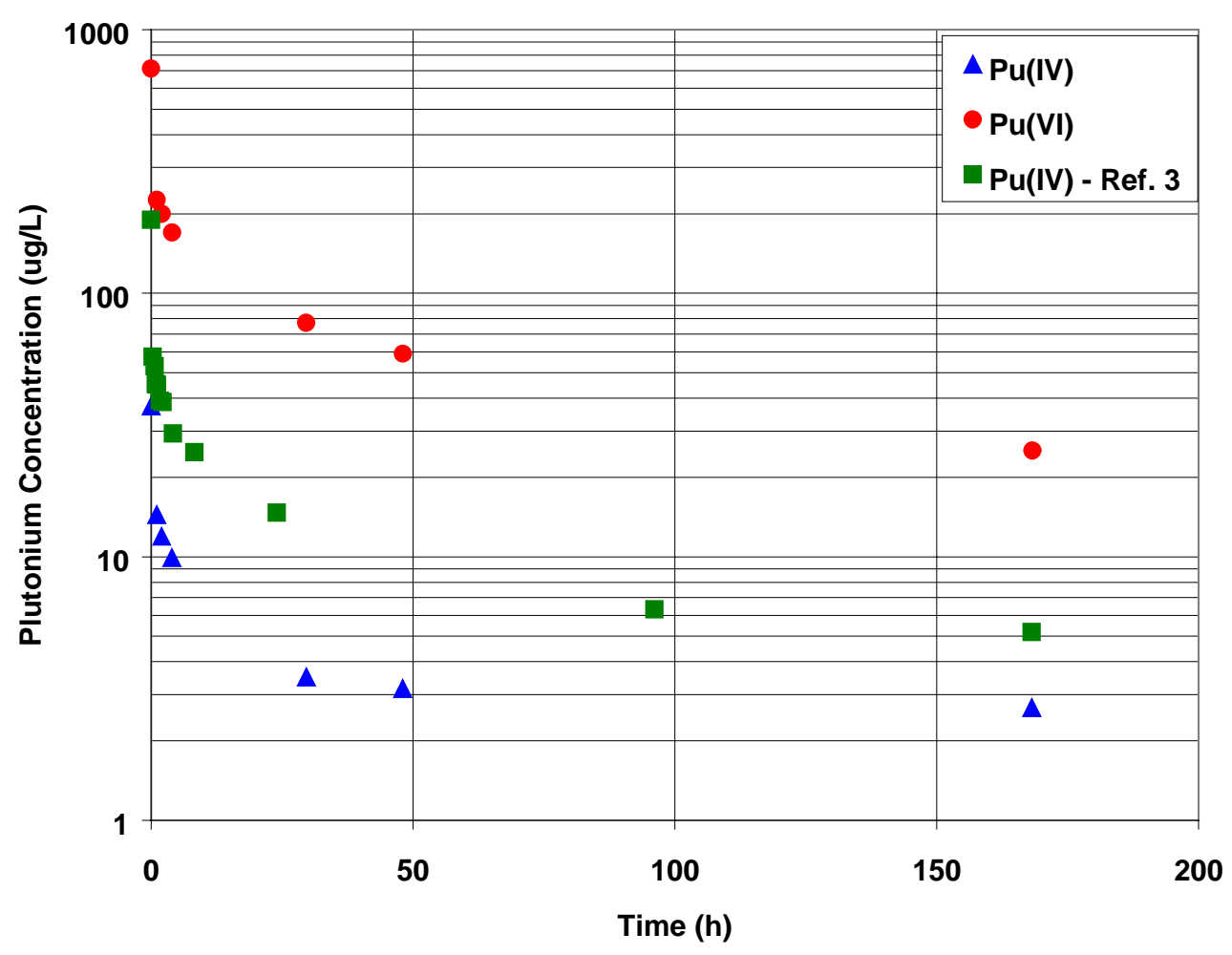

Table 4.2.1.1. Plutonium Decontamination Factors, Equilibrium Distribution Constants, and Sorption Rates

\begin{tabular}{|c|c|c|c|c|c|}
\hline \multirow[b]{2}{*}{ Species } & \multicolumn{2}{|c|}{$\underline{\text { DF }}$} & \multicolumn{2}{|c|}{$\underline{K}_{d} \times 10^{-4}(\mathrm{~mL} / \mathrm{g})$} & \multirow{2}{*}{\begin{tabular}{|c|} 
Rate Constant* \\
$\left(\mathbf{h}^{-1}\right)$
\end{tabular}} \\
\hline & 1 Day & 7 Day & 1 Day & 7 Day & \\
\hline $\mathrm{Pu}(\mathrm{IV})$ & 14.8 & 18.5 & 3.46 & 4.36 & 0.0227 \\
\hline $\mathrm{Pu}(\mathrm{VI})$ & 9.2 & 28.2 & 2.05 & 6.77 & 0.0176 \\
\hline $\mathrm{Pu}(\mathrm{IV})-$ Ref. 3 & 12.9 & 36.6 & 2.99 & 8.92 & 0.0250 \\
\hline
\end{tabular}

* Determined by linear fit of concentration data between approximately 1 and 4 hours of contact with the MST (see Figure 4.2.1.2.)

Figure 4.1.1.2. Plutonium Removal as a Function of Time Between 1 and 4 Hours of Contact with MST 


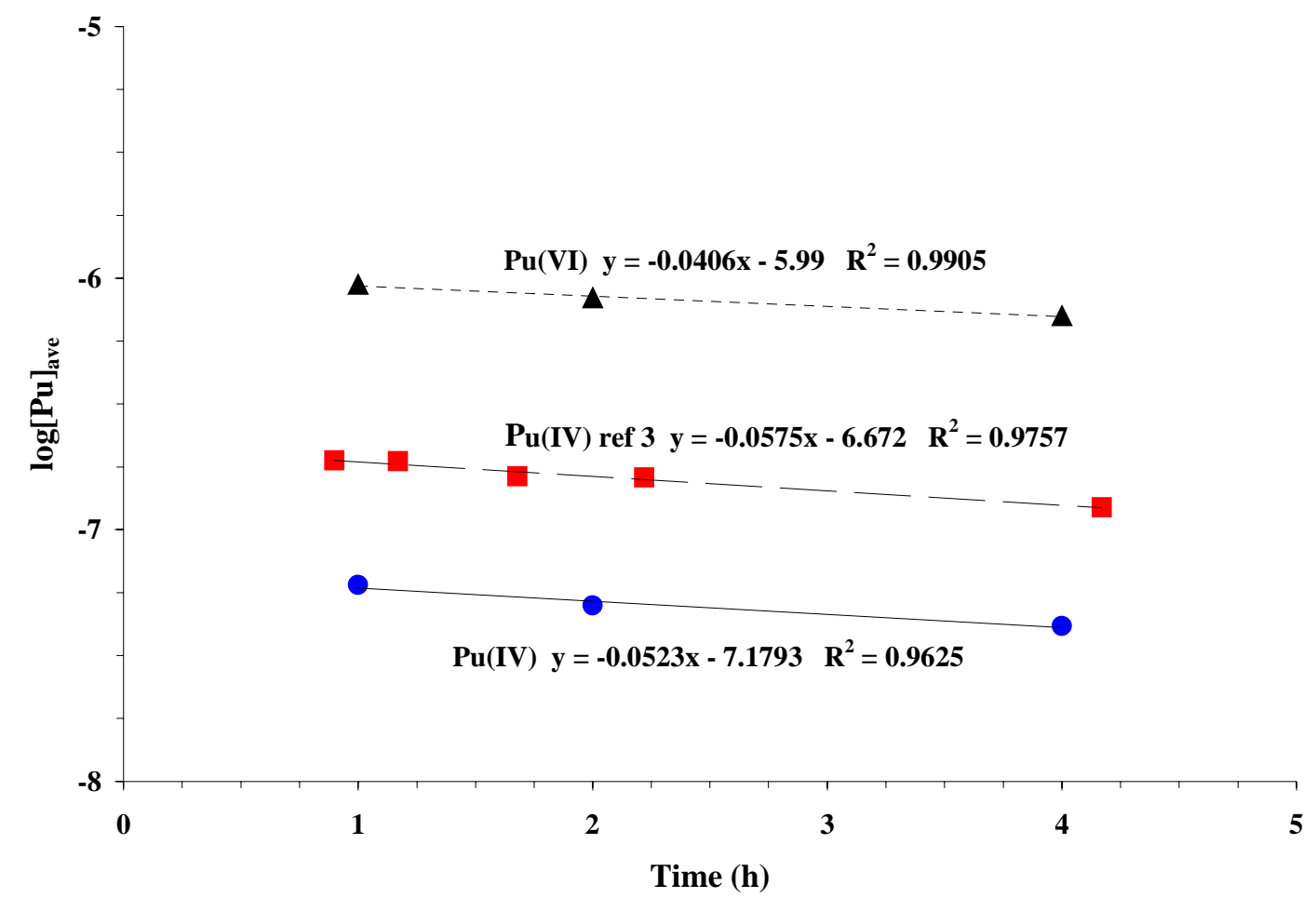

\subsubsection{Neptunium Removal}

Figure 4.2.2 compares the average neptunium concentration as a function of time for the two neptunium oxidation state tests along with previous testing data. ${ }^{3}$ The starting soluble neptunium concentrations in the $\mathrm{Np}(\mathrm{IV})$ and $\mathrm{Np}(\mathrm{V})$ tests were nearly the same $(1159 \mu \mathrm{g} / \mathrm{L}$ and $1259 \mu \mathrm{g} / \mathrm{L}$, respectively). The soluble neptunium concentration in the earlier testing ${ }^{3}$ measured $415 \mu \mathrm{g} / \mathrm{L}$. The lower value in the earlier testing does not represent the solubility limit but rather a lower target concentration. The equilibrium soluble neptunium concentrations measured 40.6, 122, and $55.8 \mu \mathrm{g} / \mathrm{L}$ for $\mathrm{Np}(\mathrm{IV}), \mathrm{Np}(\mathrm{V})$ and the earlier $\mathrm{Np}(\mathrm{V})$ testing, respectively. Only the test with the $\mathrm{Np}(\mathrm{IV})$ spiked solution met the Z-Area limit for neptunium activity $(53 \mu \mathrm{g} / \mathrm{L} \mathrm{Np})$. The lack of difference in concentration data provides no evidence to support or refute the presumption that the testing featured two different neptunium oxidation states. Unlike that observed for the plutonium experiments, EXAFS analysis identified only one oxidation state of neptunium on the MST solids. ${ }^{28}$ Note that the EXAFS analysis could not conclude which oxidation state existed.

Table 4.2.2.1 contains decontamination factors (DFs), equilibrium distribution constants $\left(\mathrm{K}_{\mathrm{d}} \mathrm{S}\right)$ and the removal rate constants calculated from the average neptunium concentration data. We calculated the neptunium removal rate constants based upon the average concentration changes between 4 and 48 hours on contact with the MST. The 1day $\mathrm{DF}$ and $\mathrm{K}_{\mathrm{d}}$ values for all 3 data sets show good agreement. One would expect this finding if all the solutions contained neptunium with the same oxidation state. The 7-day $\mathrm{Np}(\mathrm{IV}) \mathrm{DF}$ and $\mathrm{K}_{\mathrm{d}}$ values proved significantly larger than those of the other two. The 
higher $\mathrm{Np}$ (IV) values may reflect precipitation of the $\mathrm{Np}$ (IV) from solution in addition to sorption onto the MST. The chemical literature reports a lower solubility of $\mathrm{Np}(\mathrm{IV})$ compared to $\mathrm{Np}(\mathrm{V})$.

Figure 4.2.3.2 provides a plot of the log of the neptunium concentration versus time for the contact interval from 4 to 48 hours. During this interval, the graphs indicate a fairly linear relationship suggesting first order dependence on neptunium concentration during this time period. As discussed previously for plutonium, we determined the first order rate constants based on the average concentrations (see Table 4.2.2.1). The rate constants for the $\mathrm{Np}(\mathrm{V})$ and $\mathrm{Np}(\mathrm{IV})$ spiked solutions prepared in this test set proved very similar. The rate constant obtained from previous testing proved about 50\% higher. However, given the experimental variance in rate constants calculated for each individual test, the ranges in rate constants defined by $\pm 2 \sigma$ overlap all three test cases. Thus the reaction kinetics do not provide information confirming the presence of $\mathrm{Np}(\mathrm{IV})$ and whether the removal rate of $\mathrm{Np}(\mathrm{IV})$ is different from that of $\mathrm{Np}(\mathrm{V})$.

\section{Figure 4.2.3.1. Neptunium Concentration as a Function of Elapsed Time}

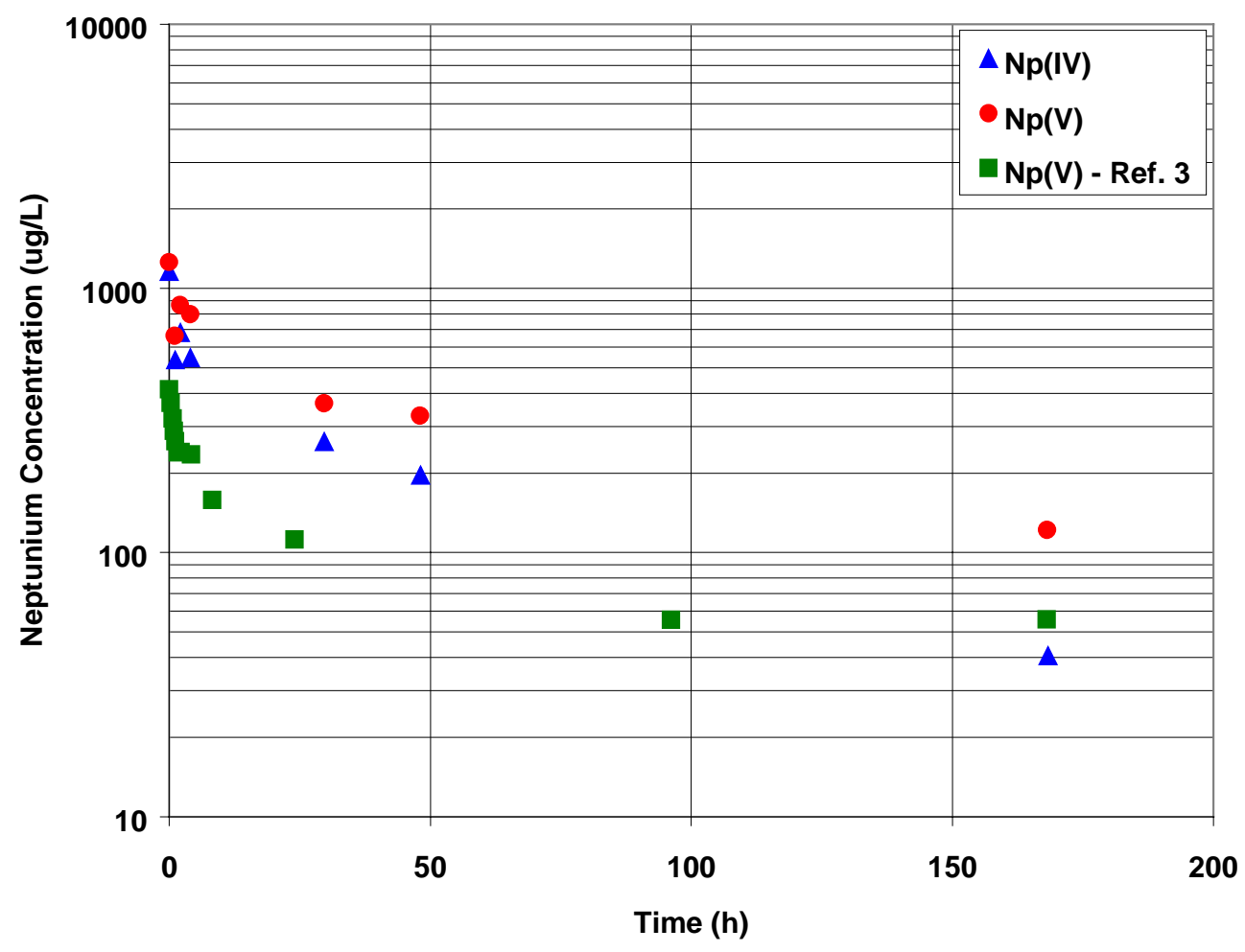

Table 4.2.2.1. Neptunium Decontamination Factors, Equilibrium Distribution Constants and Removal Rate Constants 


\begin{tabular}{|c|c|c|c|c|c|}
\hline \multirow[b]{2}{*}{ Species } & \multicolumn{2}{|c|}{ DF } & \multicolumn{2}{|c|}{$\underline{K}_{\underline{d}} \times 10^{-3}(\mathrm{~mL} / \mathrm{g})$} & \multirow{2}{*}{\begin{tabular}{|c|} 
Rate Constant* \\
$\left(\mathbf{h}^{-1}\right)$
\end{tabular}} \\
\hline & 1 Day & 7 Day & 1 Day & 7 Day & \\
\hline $\mathrm{Np}(\mathrm{IV})$ & 4.43 & 29.8 & 8.56 & 71.9 & 0.00391 \\
\hline $\mathrm{Np}(\mathrm{V})$ & 3.45 & 12.4 & 6.07 & 28.2 & 0.00456 \\
\hline$N p(V)-$ Ref. 3 & 3.7 & 7.4 & 6.78 & 16.1 & 0.00621 \\
\hline
\end{tabular}

* Determined by linear fit of concentration data between approximately 4 and 48 hours of contact with the MST (see Figure 4.2.3.2.)

Figure 4.2.3.2. Neptunium Removal as a Function of Time Between 4 and 48 Hours of Contact with MST

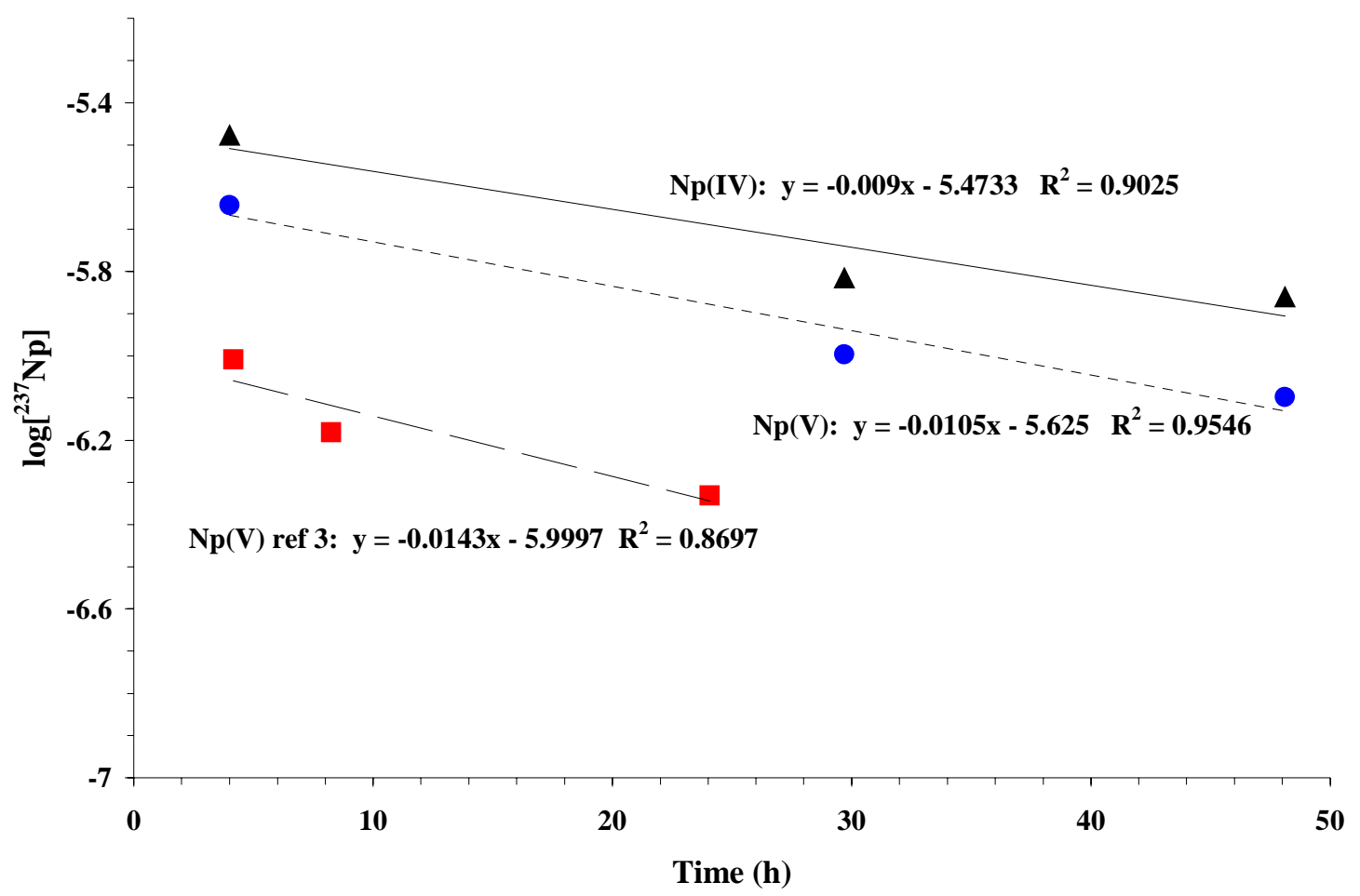




\subsubsection{Plutonium and Neptunium Oxidation State Testing Conclusions}

Single component oxidation state tests yielded the following observations and conclusions.

- Preliminary evidence suggests that $\mathrm{Pu}(\mathrm{VI})$ remains stable in alkaline solutions for periods as long as 2 weeks and exhibits a higher solubility than $\mathrm{Pu}(\mathrm{IV})$.

- Test results suggest that the rates of $\mathrm{Pu}(\mathrm{IV})$ and $\mathrm{Pu}(\mathrm{VI})$ removal are similar.

- Test results yielded inconclusive evidence for the stability of $\mathrm{Np}(\mathrm{IV})$ in an alkaline salt solution.

- Test results indicated no significant changes in neptunium removal upon contact of solutions prepared with $\mathrm{Np}(\mathrm{V})$ or $\mathrm{Np}(\mathrm{IV})$.

\subsection{Evaluation of Different MST Samples}

Testing featured three different sampleses of MST (see Table 4.3.1) prepared by Optima Chemical Company. All three samples were prepared several years ago for use in the InTank Precipitation process. Samples identified as \#33180 and \#33407 represent archived process samples produced by Optima Chemical Company and sent to SRTC during vendor qualification testing. The MST \#TNX sample was obtained from a drum of MST slurry stored at SRS which had been produced by Optima Chemical Company for use in pilot-scale testing at SRTC. The much lower titanium content in the \#33180 sample occurred upon the deliberate addition of water to the sample after delivery and storage at SRTC for several years. The original titanium concentration of the \#33180 sample was very similar to those for the other two samples.

\section{Table 4.3.1 Identification and Weight Percent Titanium Content of MST Samples}

\begin{tabular}{|c|c|}
\hline Sample ID & wt $\% \mathrm{~T}$ \\
\hline 33180 & 9.25 \\
\hline 33407 & 23.4 \\
\hline TNX & 21.1 \\
\hline
\end{tabular}

Evaluation of the MST samples used the $5.6 \mathrm{M} \mathrm{Na}^{+}$salt solution previously used in testing of MST performance. Each test had a MST concentration of $0.4 \mathrm{~g} / \mathrm{L}$. Figures 4.3.1 through 4.3.4 provide graphs of each sorbate concentration ( $\mathrm{Sr}, \mathrm{Pu}, \mathrm{U}$ and $\mathrm{Np}$, respectively) versus time for each MST sample. Each figure also includes the results for sample \#33180 for each set of tests conducted during FY2000 and FY2001 (labeled as Sets \# 1, 2 and 3).

MST samples \#33407 and \#TNX exhibited a lower capacity for strontium compared to \#33180. At each sampling period, the $\mathrm{DF}$ and $\mathrm{K}_{\mathrm{d}}$ values for both of these samples averaged about an order of magnitude lower than that of \#33180 (see Table 4.3.2). Note however, that the rate of removal appeared similar for all three materials as evidence by similar slopes in the graphs. We attribute the different strontium removal performance of the three MST samples to an unidentified characteristic (e.g., degree of crystallinity, population of active sites) of the samples that does not affect removal kinetics. Removal 
kinetics may be limited by transport of the sorbate to the reaction site, whereas removal capacity reflects the total number of site available to a particular sorbate.

The average strontium DF for samples \#33407 determined after 24 hours of contact falls below the values required for the bounding $(\mathrm{DF}=5.1)$ waste case. ${ }^{1}$ For sample \#TNX, the 24-hour DF measured 11.4, which is more than twice the value needed for the bounding case. Thus, the sample identified as \#TNX would provide satisfactory performance for all planned waste processing operations. In contrast, sample \#33407 may not provide satisfactory performance for all planned waste processing operations.

\section{Figure 4.3.1 Strontium Concentration versus Time for Different MST Samples}

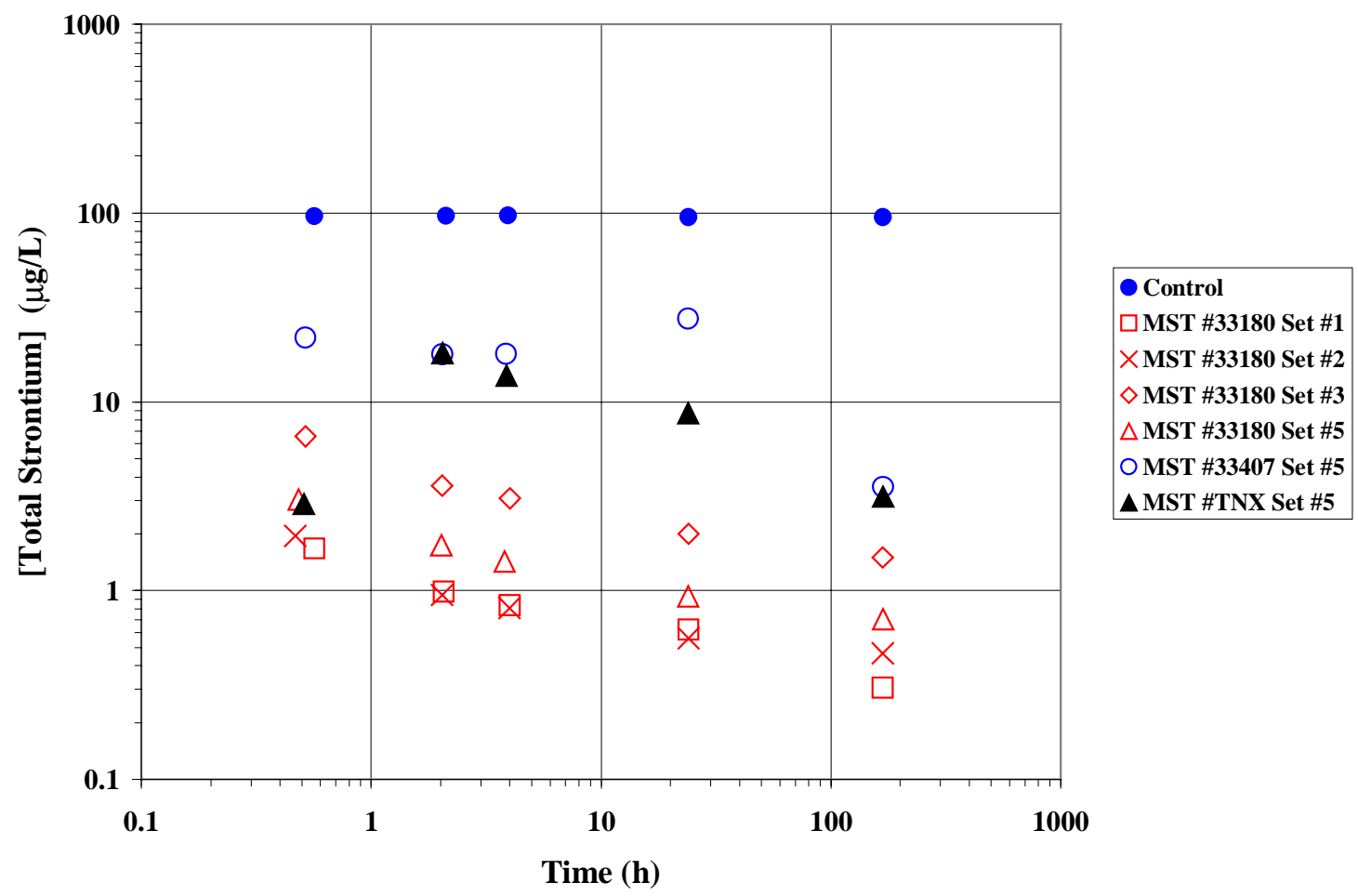

Note that a measurable difference exists in the performance of the same MST sample (\#33180) over the multiple test sets conducted during FY00 and FY01. Table 4.3.2 presents the strontium DF and $\mathrm{K}_{\mathrm{d}}$ values for all MST samples. With the exception of Set \#2 $(64.5 \mu \mathrm{g} / \mathrm{L})$, the initial total strontium concentration for each data set averaged $93.9 \pm 5.67 \mu \mathrm{g} / \mathrm{L}$ (including that reported in the Phase $\mathrm{V}$ testing but not shown in Figure 4.3.1). The low DF measured for the sample in set \#2 may in part result from the lower initial strontium concentration. Note however, based on the results investigating the affects of solution composition (section 4.1), we concluded that the initial sorbate concentration does not significantly affect strontium removal. As shown in Table 4.3.2, the variance between test sets decreases if we omit the results for Set \#2. We attribute the majority of the variance to errors associated with weighing out and delivering the same 
quantity of MST to each test and analytical measurement errors. Analytical measurement errors include those resulting from sampling, preparation of samples for measurement and actual radiochemical measurements.

\section{Table 4.3.2 Strontium Decontamination Factors and Distribution Constants for MST Samples

\begin{tabular}{|c|c|c|c|c|c|}
\hline \multirow[b]{2}{*}{ MST ID } & \multirow[b]{2}{*}{ Data Set } & \multicolumn{2}{|c|}{ DF } & \multicolumn{2}{|c|}{$K_{d}(m L / g)$} \\
\hline & & 24 hour & 7 day & 24 hour & 7 day \\
\hline 33180 & Phase $V^{\mathrm{a}}$ & 130 & 140 & $3.23 \mathrm{E}+05$ & $3 . \overline{48 \mathrm{E}+05}$ \\
\hline 33180 & 1 & 151 & 305 & $3.75 \mathrm{E}+05$ & $7.61 \mathrm{E}+05$ \\
\hline 33180 & 2 & 32.3 & 43.1 & $7.83 \mathrm{E}+04$ & $1.05 \mathrm{E}+05$ \\
\hline 33180 & 3 & 158 & 190 & $3.92 \mathrm{E}+05$ & $4.72 \mathrm{E}+05$ \\
\hline 33180 & 5 & 107 & 141 & $2.65 \mathrm{E}+05$ & $3.51 \mathrm{E}+05$ \\
\hline & Average & 115 & 164 & $2.86 \mathrm{E}+05$ & 4.07E+05 \\
\hline & Standard Deviation & 50.6 & 95.2 & $1.26 \mathrm{E}+05$ & $2.38 \mathrm{E}+05$ \\
\hline & $\begin{array}{l}\text { elative Standard Deviation } \\
\qquad\left([\mathrm{Pu}]_{\mathrm{o}} \sim 200 \mu \mathrm{g} / \mathrm{L}\right)\end{array}$ & $43.8 \%$ & $58.1 \%$ & $44.1 \%$ & $58.5 \%$ \\
\hline & Average w/o Set 2 & 136 & 194 & $3.388 \mathrm{E}+05$ & $4.84 \mathrm{E}+05$ \\
\hline & Standard Deviation & 22.9 & 77.5 & $5.72 \mathrm{E}+04$ & $1.94 \mathrm{E}+05$ \\
\hline & $\begin{array}{l}\text { elative Standard Deviation } \\
\qquad\left([\mathrm{Pu}]_{\mathrm{o}} \sim 100 \mu \mathrm{g} / \mathrm{L}\right)\end{array}$ & $16.8 \%$ & $40.0 \%$ & $16.9 \%$ & $40.3 \%$ \\
\hline 33407 & 5 & 3.62 & 28.1 & $6.57 \mathrm{E}+03$ & $6.80 \mathrm{E}+04$ \\
\hline TNX & 5 & 11.4 & 31.7 & $2.59 \mathrm{E}+04$ & $7.63 \mathrm{E}+04$ \\
\hline
\end{tabular}

Figure 4.3.2 and Table 4.3.3 present a summary of the plutonium removal performance for the three MST samples. All three samples exhibited similar plutonium removal kinetics. Plutonium removal performance for sample \#33180 measured about a factor of two higher than the other two samples (\#33407 and \#TNX). Over all data sets, the average plutonium DF and $\mathrm{K}_{\mathrm{d}}$ for sample \#33180 exhibited a relative standard deviation of approximately $33 \%$. As expected, the relative standard deviation proved smaller (i.e., ca. 9\% - see Table 4.3.3) for the tests conducted with a higher initial plutonium concentration (ca. $200 \mu \mathrm{g} / \mathrm{L}$ ). For the tests conducted with solutions containing approximately $100 \mu \mathrm{g} / \mathrm{L}$ plutonium, the relative standard deviation proved slightly greater (ca. 35\%) than that for all of the data sets combined.

The average plutonium DFs for samples \#33407 and \#TNX determined after 24 hours of contact fell below the values required for the average $(\mathrm{DF}=12)$ and bounding $(\mathrm{DF}=49)$ waste cases. Thus, these materials may not satisfactorily remove plutonium in all planned operations. Comparison of the average DFs for plutonium in tests with MST sample \#33180 indicated that the average DF decreased with a decrease in the initial plutonium concentration, as expected. Note however, that the DFs for the two data sets are not statistically different at the $95 \%$ confidence interval $( \pm 2 \sigma)$ 
Figure 4.3.2 Plutonium Concentration versus Time for Different MST Samples

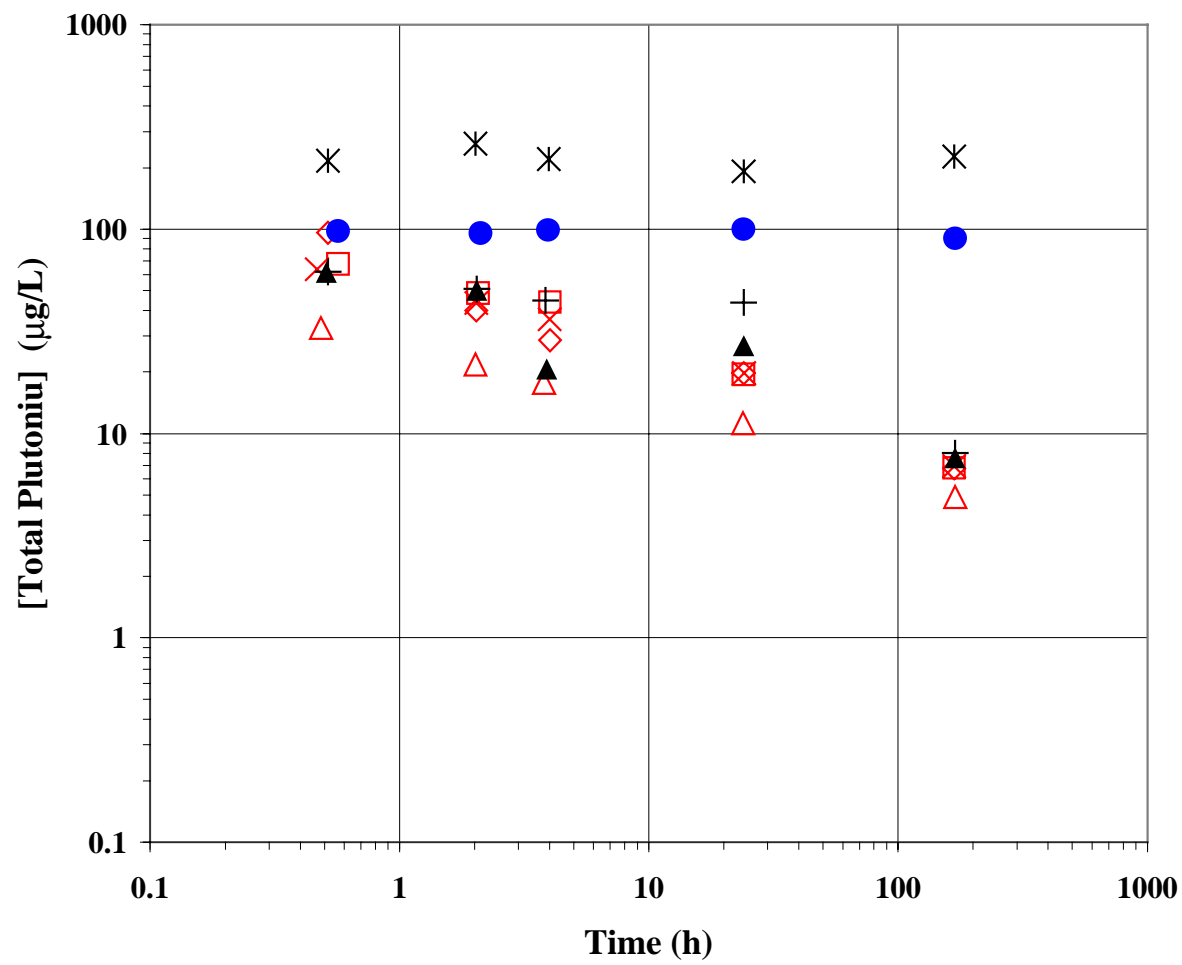

Table 4.3.3 Plutonium Decontamination Factors and Distribution Constants for MST Samples

\begin{tabular}{|c|c|c|c|c|c|}
\hline \multirow[b]{2}{*}{ MST ID } & \multirow[b]{2}{*}{ Data Set } & \multicolumn{2}{|c|}{ DF } & \multicolumn{2}{|c|}{$K_{d}(\mathbf{m L} / g)$} \\
\hline & & 24 hour & 7 day & 24 hour & 7 day \\
\hline 33180 & Phase $\mathrm{V}^{\mathrm{a}}$ & 12.9 & $\overline{36.6}$ & $\overline{2.98 \mathrm{E}+04}$ & $8 . \overline{90 \mathrm{E}+04}$ \\
\hline 33180 & 1 & 11.3 & 32.3 & $2.58 \mathrm{E}+04$ & $7.85 \mathrm{E}+04$ \\
\hline 33180 & 2 & 4.93 & 14.4 & $9.85 \mathrm{E}+03$ & $3.36 \mathrm{E}+04$ \\
\hline 33180 & 3 & 10.3 & 29.6 & $2.33 \mathrm{E}+04$ & $7.14 \mathrm{E}+04$ \\
\hline 33180 & 5 & 9.21 & 21.1 & $2.06 \mathrm{E}+04$ & $5.04 \mathrm{E}+04$ \\
\hline & Average & 9.73 & 26.8 & $2.19 \mathrm{E}+04$ & $6.46 \mathrm{E}+04$ \\
\hline & Standard Deviation & 3.01 & 8.94 & $7.52 \mathrm{E}+03$ & $2.23 \mathrm{E}+04$ \\
\hline & elative Standard Deviation & $30.9 \%$ & $33.4 \%$ & $34.4 \%$ & $34.6 \%$ \\
\hline & Average Phase V \& Set 1 & 12.1 & 34.5 & $2.78 \mathrm{E}+04$ & $8.37 \mathrm{E}+04$ \\
\hline & Standard Deviation & 1.12 & 3.02 & $2.76 \mathrm{E}+03$ & $7.43 \mathrm{E}+03$ \\
\hline & elative Standard Deviation & $9.3 \%$ & $8.8 \%$ & $9.9 \%$ & $8.9 \%$ \\
\hline & Average Sets $2,4 \& 5$ & 8.15 & 21.7 & $1.79 \mathrm{E}+04$ & $5.18 \mathrm{E}+04$ \\
\hline & Standard Deviation & 2.85 & 7.95 & $7.11 \mathrm{E}+03$ & $1.89 \mathrm{E}+04$ \\
\hline & elative Standard Deviation & $34.9 \%$ & $35.0 \%$ & $39.7 \%$ & $36.6 \%$ \\
\hline 33407 & 5 & 2.36 & 12.9 & $3.41 \mathrm{E}+03$ & $2.98 \mathrm{E}+04$ \\
\hline TNX & 5 & 3.87 & 13.7 & $7.14 \mathrm{E}+03$ & $3.16 \mathrm{E}+04$ \\
\hline
\end{tabular}


Figure 4.3.3 and Table 4.3.4 present a summary of the uranium removal performance for the three MST samples. All three samples exhibited similar uranium removal kinetics and capacity. On average the addition of $0.4 \mathrm{~g} / \mathrm{L} \mathrm{MST} \mathrm{removed} \mathrm{about} 30 \%$ of the uranium in solution. Although the fraction of uranium removed proved low, uranium represents the greatest sorbate removed on a mass basis. The high mass removal reflects the much higher uranium concentration (ca. 11,000 $\mu \mathrm{g} / \mathrm{L}$ ) compared to the other sorbates $(100-500 \mu \mathrm{g} / \mathrm{L})$. Statistically, there appeared to be no significant difference in the quantity of uranium removed after 24 hours compared to that after 7 days.

\section{Figure 4.3.3 Uranium Concentration versus Time for Different MST Samples}

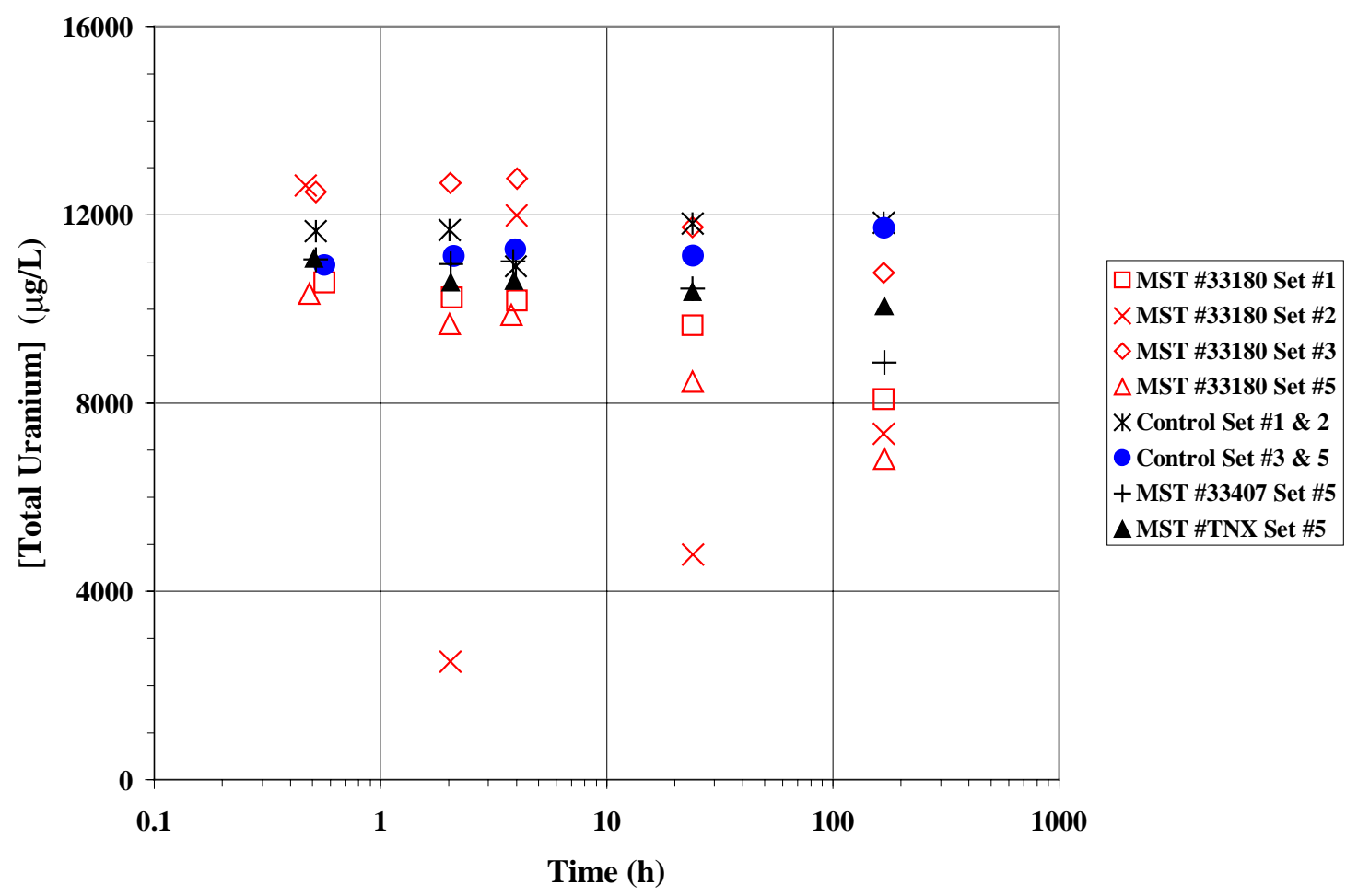

Table 4.3.4 Uranium Decontamination Factors for MST Samples

\begin{tabular}{|c|c|c|c|c|c|}
\hline \multirow[b]{2}{*}{ MST ID } & \multirow[b]{2}{*}{ Data Set } & \multicolumn{2}{|c|}{ DF } & \multicolumn{2}{|c|}{$\mathbf{K}_{\mathbf{d}}$} \\
\hline & & 24 hour & 7 day & 24 hour & 7 day \\
\hline 33180 & Phase $V^{a}$ & 1.20 & $\overline{1.50}$ & 500 & 1250 \\
\hline 33180 & 1 & 1.14 & 1.36 & 358 & 906 \\
\hline 33180 & 2 & 1.12 & 1.22 & 308 & 562 \\
\hline 33180 & 3 & 2.08 & 1.36 & 2710 & 888 \\
\hline 33180 & 5 & 1.4 & 1.74 & 1010 & 1860 \\
\hline & Average & 1.39 & 1.44 & 975 & 1090 \\
\hline & Standard Deviation & 0.40 & 0.20 & 1010 & 492 \\
\hline & Relative Standard Deviation & $29.0 \%$ & $13.7 \%$ & $103 \%$ & $45.0 \%$ \\
\hline 33407 & 5 & 1.14 & 1.31 & 347 & 852 \\
\hline TNX & 5 & 1.15 & 1.18 & 364 & 451 \\
\hline
\end{tabular}


Figure 4.3.4 and Table 4.3.5 present a summary of the neptunium removal performance for the three MST samples. All three samples exhibited similar neptunium removal kinetics. Over the five test sets, MST sample \#33180 exhibited an average neptunium removal of $70 \%$ after 24 hours and $87 \%$ after 7 days. The relative standard deviation for neptunium removal proved rather large $(44-52 \%)$. The average DF for the other two MST samples (\#33407 and \#TNX) remained lower than that measured for \#33180. This trend agrees with the results for other sorbates (e.g., strontium and plutonium). These results suggest that these two samples exhibit an inherently lower affinity for strontium and the actinides than does sample \#33180. Based on the DFs measured after 24 hours of contact, only the MST sample \#33180 exhibited neptunium removal that would meet the requirements at the bounding case $(\mathrm{DF}=2){ }^{1}$

\section{Figure 4.3.4 Neptunium Concentration versus Time for Different MST Samples}

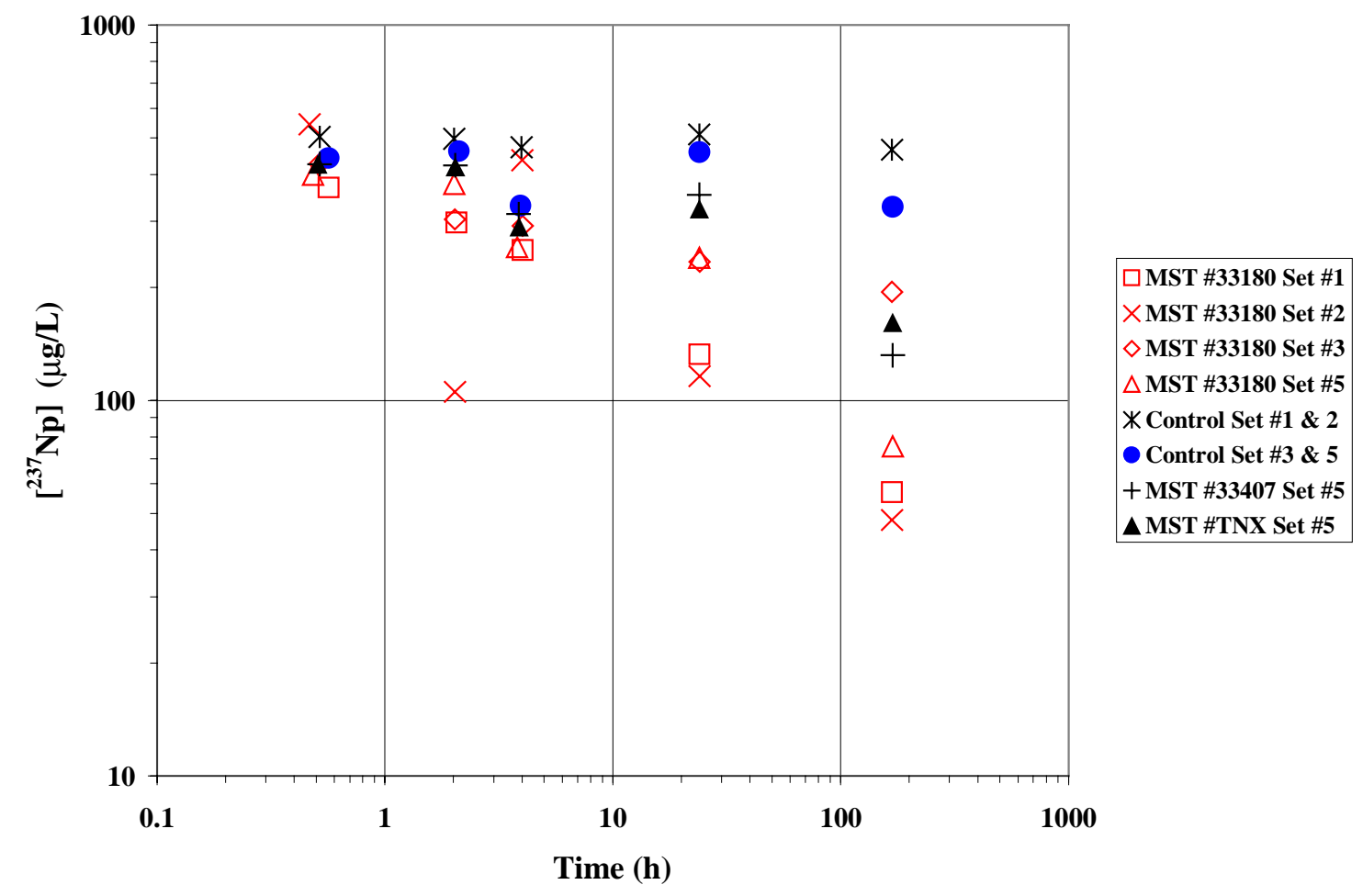




\begin{tabular}{|c|c|c|c|c|c|}
\hline \multirow{2}{*}{ MST ID } & \multirow[b]{2}{*}{ Data Set } & \multicolumn{2}{|c|}{ DF } & \multicolumn{2}{|c|}{$\mathbf{K}_{\mathbf{d}}$} \\
\hline & & 24 hour & 7 day & 24 hour & 7 day \\
\hline 33180 & Phase $V^{a}$ & 3.70 & 7.44 & 6750 & 16100 \\
\hline 33180 & 1 & 3.47 & 8.08 & 6180 & 17700 \\
\hline 33180 & 2 & 1.98 & 2.47 & 2450 & 3690 \\
\hline 33180 & 3 & 5.56 & 13.4 & 11400 & 31100 \\
\hline \multirow[t]{4}{*}{33180} & 5 & 2.02 & 6.42 & 2560 & 13600 \\
\hline & Average & 3.35 & 7.57 & 5870 & 16400 \\
\hline & Standard Deviation & 1.47 & 3.93 & 3670 & 9830 \\
\hline & Relative Standard Deviation & $44.0 \%$ & $52.0 \%$ & $62.6 \%$ & $59.8 \%$ \\
\hline 33407 & 5 & 1.37 & 3.68 & 938 & 6710 \\
\hline TNX & 5 & 1.50 & 3.02 & 1250 & 5010 \\
\hline
\end{tabular}

\subsection{Evaluation of Alternate Sorbent Materials}

Previously, SRTC evaluated samples of sodium nonatitanate (ST), crystalline silicotitanate (CST) and SrTreat ${ }^{\circledR}$ for the removal of strontium and actinides from alkaline salt solution. ${ }^{29,30}$ Testing results indicated that some of these samples exhibited removal capacities and kinetics for strontium and actinides as good as or better than MST. Consequently, we recommended further testing of these materials.

Additional testing completed during FY01 featured one SrTreat ${ }^{\circledR}$ sample, one sample of CST and 2 pharmacosiderites samples. Table 4.4.1 provides a listing of all tested materials to date with the most recently tested materials highlighted in boldface. Since all samples are titanium based, we selected the quantity of sorbent to add in each test to provide the same quantity of titanium added by the addition of $0.4 \mathrm{~g} / \mathrm{L} \mathrm{MST}$. Note, however, that the calculated distribution constants, $\mathrm{K}_{\mathrm{d}}$, are based on the total sorbent weight and not on a titanium basis alone. 
Table 4.4.1 Alternate Sorbent Materials

\begin{tabular}{cc} 
Sorbent ID & Source \\
\hline ST-0073A & Honeywell \\
ST-0073B & Honeywell \\
ST-01520 & Honeywell \\
ST-RC-4-23B & TAMU \\
ST-RC-4-64B & TAMU \\
ST-39287-5A & Honeywell \\
ST-39287 - 5B $^{\text {Honeywell }}$ & Honey \\
SrTreat $^{\circledR}$ \#48 & Fortum \\
SrTreat $^{\circledR}$ \#49 & Fortum \\
SrTreat $^{\circledR}$ \#8 & Fortum \\
& \\
CST IE-910 & UOP \\
CST IE-911 & UOP \\
DM1-11-1 & TAMU \\
EAB-II-23 & TAMU \\
DM-1-25 & TAMU
\end{tabular}
Description
ST - pilot scale production
ST - pilot scale production
ST - pilot scale production
ST - moderate crystallinity
ST - poor crystallinity
ST - lab scale production
ST - lab scale production
ST - commercial batch
ST - commercial batch

ST - commercial batch with smaller particle size distribution CST powder Lot \#899371998000001

CST engineered form Lot \#899902081000009

CST prepared for maximum $\mathrm{Sr}^{2+}$ uptake pharmacosiderite in $\mathrm{K}^{+}$form pharmacosiderite in $\mathrm{Na}^{+}$form

Tables 4.4.2 and 4.4.3 provide the DF and $\mathrm{K}_{\mathrm{d}}$ values, respectively, after 24 hours and 7 days of contact for each of the alternate sorbents listed in Table 4.4.1 except for the first three ST samples. As reported previously, the first three samples exhibited lower strontium and actinide removal characteristics than that for MST..$^{29,30}$ 
Table 4.4.2 Decontamination Factors for Alternate Sorbent Materials

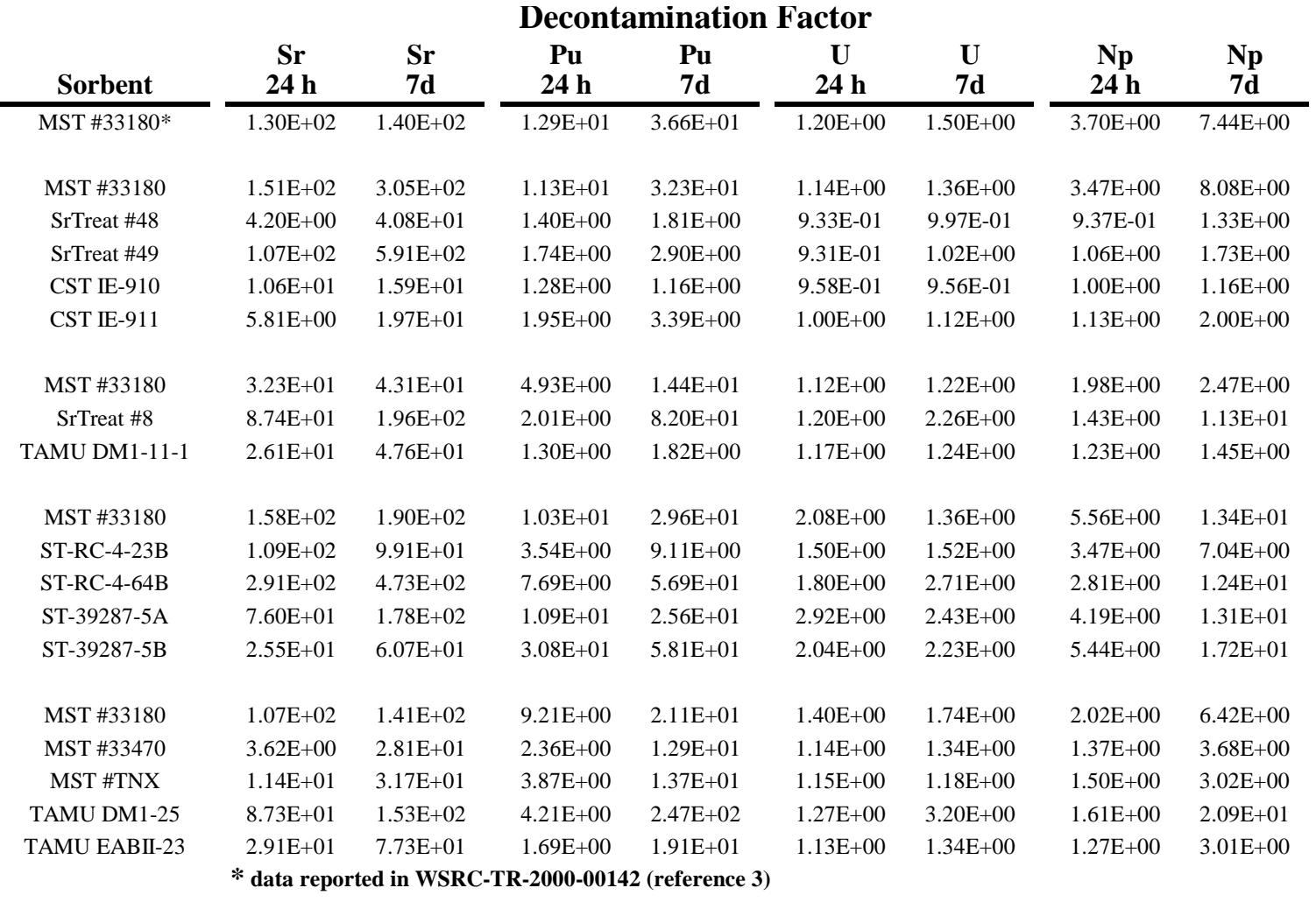


Table 4.4.3 Distribution Constants $\left(K_{d}\right)$ for Alternate Sorbent Materials

\begin{tabular}{|c|c|c|c|c|c|c|c|c|}
\hline & & & tribu & 1 Cons & $\mathbf{t}(\mathrm{mL} /$ & & & \\
\hline Sorbent & $\begin{array}{c}\mathrm{Sr} \\
24 \mathrm{~h}\end{array}$ & $\begin{array}{l}\mathrm{Sr} \\
7 \mathrm{~d}\end{array}$ & $\begin{array}{c}\text { Pu } \\
24 \mathrm{~h}\end{array}$ & $\begin{array}{l}\text { Pu } \\
\text { 7d }\end{array}$ & $\begin{array}{c}\mathrm{U} \\
24 \mathrm{~h}\end{array}$ & $\begin{array}{c}\mathbf{U} \\
\mathbf{7 d}\end{array}$ & $\begin{array}{c}\text { Np } \\
24 \mathrm{~h}\end{array}$ & $\begin{array}{l}\text { Np } \\
7 d\end{array}$ \\
\hline MST \#33180* & $3.23 \mathrm{E}+05$ & $3.48 \mathrm{E}+05$ & $2.98 \mathrm{E}+04$ & $8.90 \mathrm{E}+04$ & $5.00 \mathrm{E}+02$ & $1.25 \mathrm{E}+03$ & $6.75 \mathrm{E}+03$ & $1.61 \mathrm{E}+04$ \\
\hline MST \#33180 & $3.75 \mathrm{E}+05$ & $7.61 \mathrm{E}+05$ & $2.58 \mathrm{E}+04$ & $7.85 \mathrm{E}+04$ & $3.48 \mathrm{E}+02$ & $9.06 \mathrm{E}+02$ & $6.18 \mathrm{E}+03$ & $1.77 \mathrm{E}+04$ \\
\hline SrTreat \#48 & $6.97 \mathrm{E}+03$ & $8.67 \mathrm{E}+04$ & $8.80 \mathrm{E}+02$ & $1.77 \mathrm{E}+03$ & & & & $7.19 \mathrm{E}+02$ \\
\hline SrTreat \#49 & $2.22 \mathrm{E}+05$ & $1.23 \mathrm{E}+06$ & $1.54 \mathrm{E}+03$ & $3.97 \mathrm{E}+03$ & & $4.52 \mathrm{E}+01$ & $1.34 \mathrm{E}+02$ & $1.52 \mathrm{E}+03$ \\
\hline CST IE-910 & $8.82 \mathrm{E}+03$ & $1.37 \mathrm{E}+04$ & $2.57 \mathrm{E}+02$ & $1.46 \mathrm{E}+02$ & & & $4.46 \mathrm{E}+00$ & $1.45 \mathrm{E}+02$ \\
\hline CST IE-911 & $4.34 \mathrm{E}+03$ & $1.68 \mathrm{E}+04$ & $8.60 \mathrm{E}+02$ & $2.15 \mathrm{E}+03$ & & $1.08 \mathrm{E}+02$ & $1.15 \mathrm{E}+02$ & $9.00 \mathrm{E}+02$ \\
\hline MST \#33180 & $7.83 \mathrm{E}+04$ & $1.05 \mathrm{E}+05$ & $9.85 \mathrm{E}+03$ & $3.36 \mathrm{E}+04$ & $3.08 \mathrm{E}+02$ & $5.62 \mathrm{E}+02$ & $2.45 \mathrm{E}+03$ & $3.69 \mathrm{E}+03$ \\
\hline SrTreat \#8 & $3.52 \mathrm{E}+05$ & $7.95 \mathrm{E}+05$ & $4.10 \mathrm{E}+03$ & $3.30 \mathrm{E}+05$ & $8.05 \mathrm{E}+02$ & $5.14 \mathrm{E}+03$ & $1.76 \mathrm{E}+03$ & $4.20 \mathrm{E}+04$ \\
\hline TAMU DM1-11-1 & $5.42 \mathrm{E}+04$ & $1.01 \mathrm{E}+05$ & $6.47 \mathrm{E}+02$ & $1.76 \mathrm{E}+03$ & $3.73 \mathrm{E}+02$ & $5.11 \mathrm{E}+02$ & $4.97 \mathrm{E}+02$ & $9.82 \mathrm{E}+02$ \\
\hline MST \#33180 & $3.92 \mathrm{E}+05$ & $4.72 \mathrm{E}+05$ & $2.33 \mathrm{E}+04$ & $7.14 \mathrm{E}+04$ & $2.71 \mathrm{E}+03$ & $8.88 \mathrm{E}+02$ & $1.14 \mathrm{E}+04$ & $3.11 \mathrm{E}+04$ \\
\hline ST-RC-4-23B & $2.23 \mathrm{E}+05$ & $2.03 \mathrm{E}+05$ & $5.25 \mathrm{E}+03$ & $1.68 \mathrm{E}+04$ & $1.03 \mathrm{E}+03$ & $1.08 \mathrm{E}+03$ & $5.11 \mathrm{E}+03$ & $1.25 \mathrm{E}+04$ \\
\hline ST-RC-4-64B & $5.53 \mathrm{E}+05$ & $9.01 \mathrm{E}+05$ & $1.28 \mathrm{E}+04$ & $1.07 \mathrm{E}+05$ & $1.53 \mathrm{E}+03$ & $3.27 \mathrm{E}+03$ & $3.46 \mathrm{E}+03$ & $2.18 \mathrm{E}+04$ \\
\hline ST-39287-5A & $9.56 \mathrm{E}+04$ & $2.26 \mathrm{E}+05$ & $1.26 \mathrm{E}+04$ & $3.13 \mathrm{E}+04$ & $2.45 \mathrm{E}+03$ & $1.83 \mathrm{E}+03$ & $4.06 \mathrm{E}+03$ & $1.55 \mathrm{E}+04$ \\
\hline ST-39287-5B & $4.70 \mathrm{E}+04$ & $1.15 \mathrm{E}+05$ & $5.72 \mathrm{E}+04$ & $1.10 \mathrm{E}+05$ & $1.99 \mathrm{E}+03$ & $2.36 \mathrm{E}+03$ & $8.52 \mathrm{E}+03$ & $3.12 \mathrm{E}+04$ \\
\hline MST \#33180 & $2.65 \mathrm{E}+05$ & $3.51 \mathrm{E}+05$ & $2.06 \mathrm{E}+04$ & $5.04 \mathrm{E}+04$ & $1.01 \mathrm{E}+03$ & $1.86 \mathrm{E}+03$ & $2.56 \mathrm{E}+03$ & $1.36 \mathrm{E}+04$ \\
\hline MST \#33407 & $6.57 \mathrm{E}+03$ & $6.80 \mathrm{E}+04$ & $3.41 \mathrm{E}+03$ & $2.98 \mathrm{E}+04$ & $3.47 \mathrm{E}+02$ & $8.52 \mathrm{E}+02$ & $9.38 \mathrm{E}+02$ & $6.71 \mathrm{E}+03$ \\
\hline MST \#TNX & $2.59 \mathrm{E}+04$ & $7.63 \mathrm{E}+04$ & $7.14 \mathrm{E}+03$ & $3.16 \mathrm{E}+04$ & $3.64 \mathrm{E}+02$ & $4.51 \mathrm{E}+02$ & $1.25 \mathrm{E}+03$ & $5.01 \mathrm{E}+03$ \\
\hline TAMU DM1-25 & $9.13 \mathrm{E}+04$ & $1.60 \mathrm{E}+05$ & $3.40 \mathrm{E}+03$ & $1.60 \mathrm{E}+05$ & $2.88 \mathrm{E}+02$ & $2.33 \mathrm{E}+03$ & $6.45 \mathrm{E}+02$ & $2.11 \mathrm{E}+04$ \\
\hline TAMU EABII-23 & $3.37 \mathrm{E}+04$ & $9.14 \mathrm{E}+04$ & $8.22 \mathrm{E}+02$ & $2.16 \mathrm{E}+04$ & $1.56 \mathrm{E}+02$ & $4.13 \mathrm{E}+02$ & $3.21 \mathrm{E}+02$ & $2.41 \mathrm{E}+03$ \\
\hline & * data repo & d in WSRC & -2000-001 & (reference & & & & \\
\hline & lonlo indi & & & & & & & \\
\hline
\end{tabular}

\subsubsection{Strontium Removal}

Figure 4.4.1 presents a plot of the strontium concentration versus time for selected alternate sorbent materials. Samples that exhibited removal characteristics clearly better than any of the MST samples included the TAMU ST sample (ST-RC-4-64B) and the SrTreat ${ }^{\circledR}$ Lot \#8 sample. The two pharmacosiderite samples, the other ST sample and the modified CST sample exhibited removal characteristics within the range spanned by the three different MST samples.

Comparing the two TAMU ST samples, ST-RC-4-23B and ST-RC-4-64B, we find that strontium removal kinetics and capacity proved better for the sample having less crystallinity (ST-RC-4-64B). For the two pharmacosiderites, the results indicate greater strontium removal for the sodium form (DM-1-25) compared to that for the potassium form (EAB-II-23). The modified CST sample (DM1-11-1) exhibited increased removal kinetics and capacity compared to the previously tested commercially available CST powder and engineered form. 
Figure 4.4.1 Strontium Removal with MST, ST, CST and Pharmacosiderite Materials

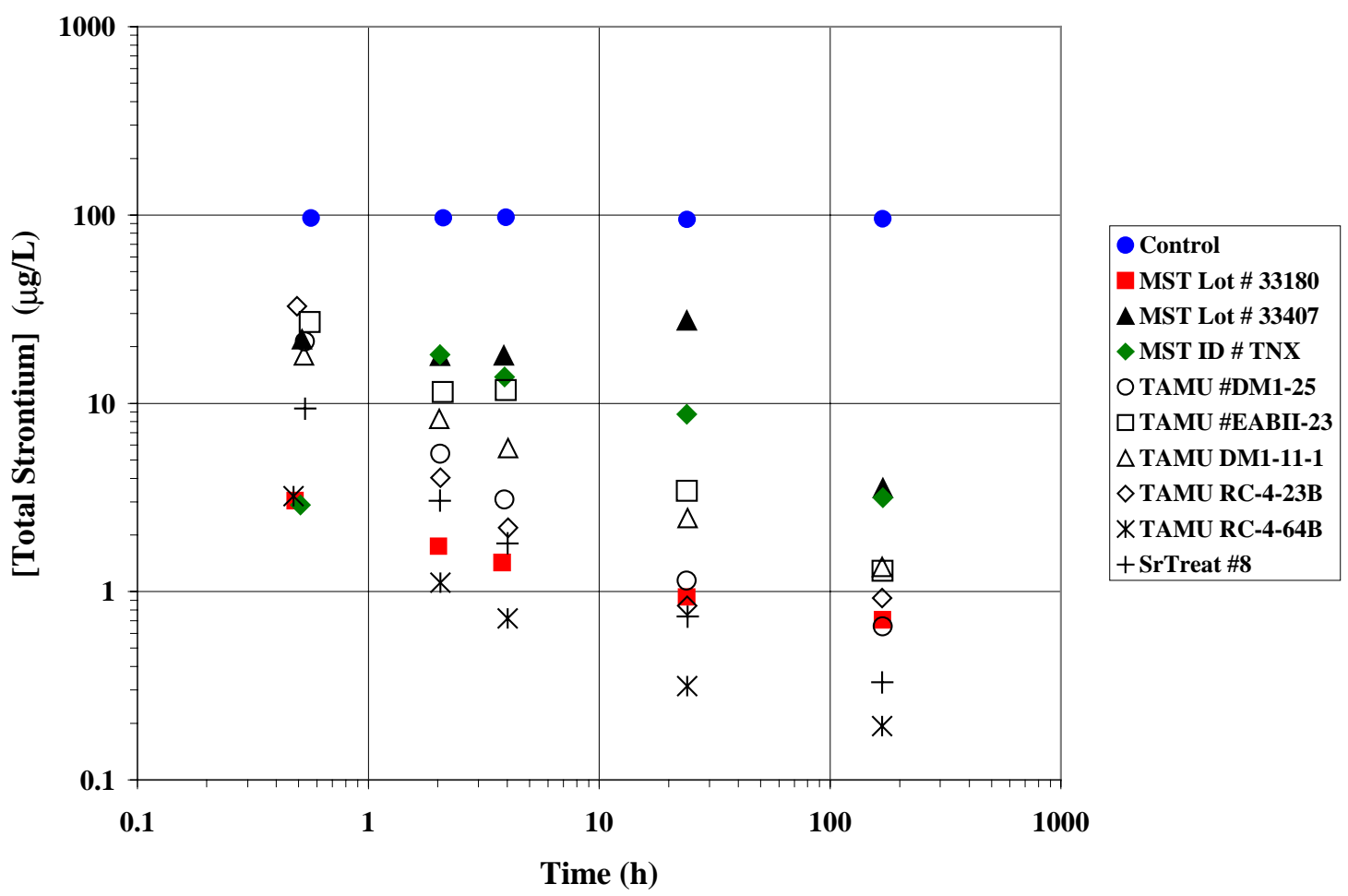

\subsubsection{Plutonium Removal}

Figure 4.4.2 presents a plot of the plutonium concentration versus time for selected alternate sorbent materials. The pharmacosiderite sample in the $\mathrm{K}^{+}$form exhibited removal kineticsbetter than the MST samples. The $\mathrm{Na}^{+}$form of the pharmacosiderite sample, one of the ST samples (ST-RC-4-64B) and the SrTreat ${ }^{\circledR}$ Lot \#8 sample exhibited removal capacities within the range spanned by the three different MST samples. Note however, that the plutonium $K_{d}$ value after 24 hours of contact (see Table 4.4.2)did not approach that of the best MST sample (\#33180) for any of the alternate sorbent samples. The pharmacosderite samples have a relatively low titanium content and when the weight of sorbent is factored into the determination of the $K_{d}$ value, the 24-hour $K_{d}$ value falls well below that of the MST \#33180 sample.

Comparing the two TAMU ST samples, ST-RC-4-23B and ST-RC-4-64B, we find that the less crystalline sample exhibited greater plutonium capacity and faster kinetics. For the two pharmacosiderites, the results indicate a faster removal rate for the potassium form than the sodium form. This finding is opposite to that observed with strontium removal kinetics (see section 4.4.1). Based on the 7-day results, the sodium form (DM125) appears to have a higher equilibrium capacity for plutonium than that of the potassium form (EAB-II-23). Unlike that observed for strontium, the modified CST sample (DM1-11-1) exhibited little affinity for plutonium. The low affinity of the CST 
sample for plutonium is very similar to that previously observed with CST IE-910 powder.

The SrTreat ${ }^{\circledR}$ Lot \#8 sample exhibited a much higher equilibrium capacity for plutonium compared to the previously tested samples (see Tables 4.4.1 and 4.4.2). Note however, that the plutonium removal kinetics proved considerably slower than that for the best of the MST samples. The measured DF for plutonium after 24 hours of contact fell well below the values needed to achieve the necessary DFs for the average and bounding waste cases.

Figure 4.4.2 Plutonium Removal with MST, ST, CST and Pharmacosiderite Materials

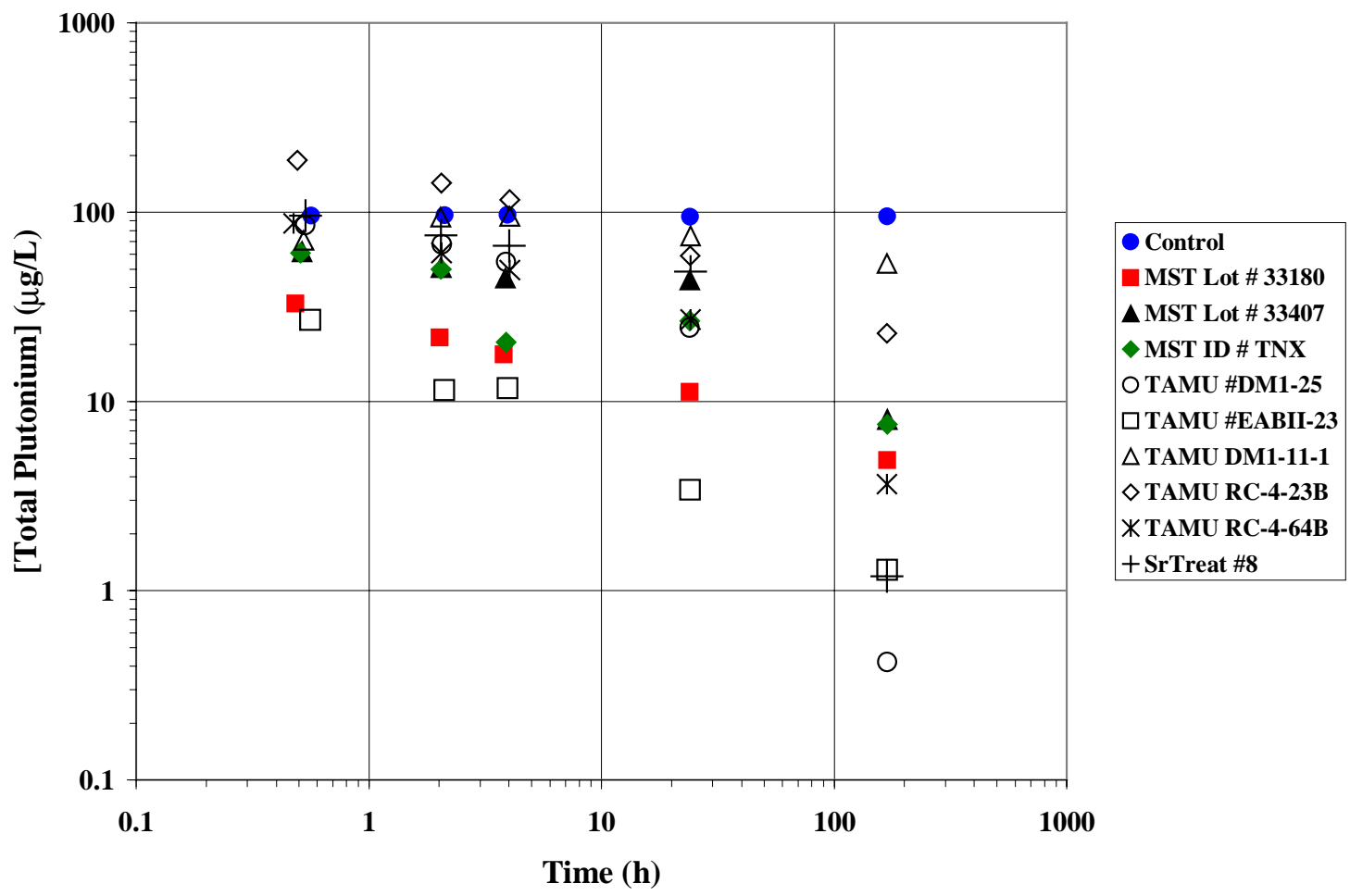

\subsubsection{Uranium Removal}

Figure 4.4.3 presents a plot of the uranium concentration versus time for selected alternate sorbent materials. None of the samples exhibited removal characteristics clearly better than the MST samples during the first 24 hours of contact. After 168 hours of contact, the modified CST, the less crystalline ST and the SrTreat ${ }^{\circledR}$ samples removed more uranium than any of the MST samples (see Figure 4.4.3). The uranium removal characteristics for these three materials result in higher $\mathrm{K}_{\mathrm{d}}$ values after 7-days of contact than those measured for the MST samples (see Table 4.4.2).. 
Figure 4.4.3 Uranium Removal with MST, ST, CST and Pharmacosiderite Materials

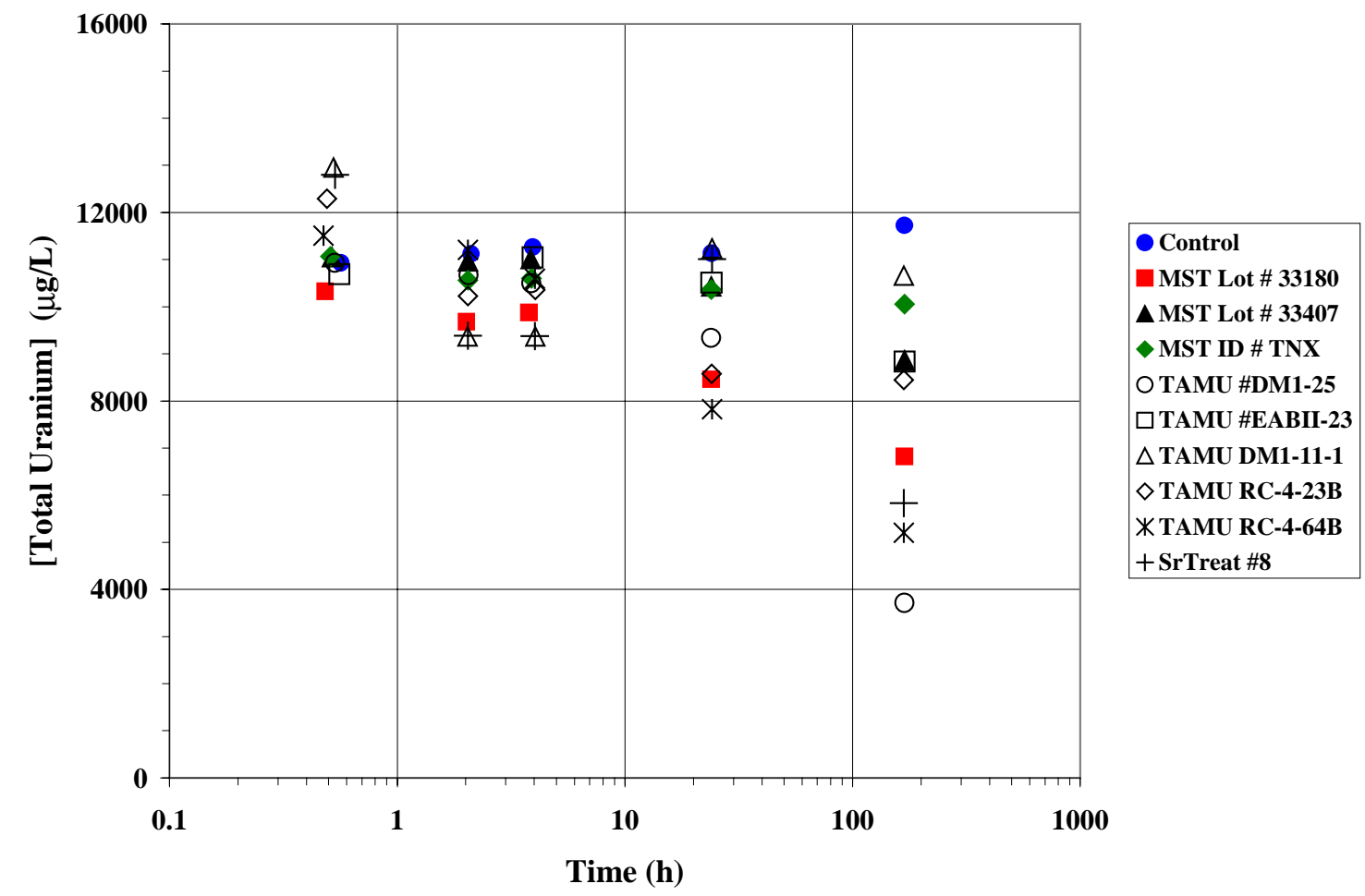

\subsubsection{Neptunium Removal}

Figure 4.4.4 presents a plot of the ${ }^{237} \mathrm{~Np}$ concentration versus time for selected alternate sorbent materials. None of the samples exhibited neptunium removal characteristics clearly better than any of the MST samples. However, SrTreat ${ }^{\circledR}$ Lot \#8 sample, and the two TAMU ST samples (ST-RC-4-23B and ST-RC-4-64B) exhibited comparable removal characteristics to the best of the MST samples. The pharmacosiderite sample in the $\mathrm{Na}^{+}$form exhibited a higher capacity than the pharmacosiderite sample in the $\mathrm{K}^{+}$ form. The CST sample (DM1-11-1) exhibited very low affinity for removing neptunium from the alkaline salt solution. 
Figure 4.4.4 Neptunium Removal with MST, ST, CST and Pharmacosiderite Materials

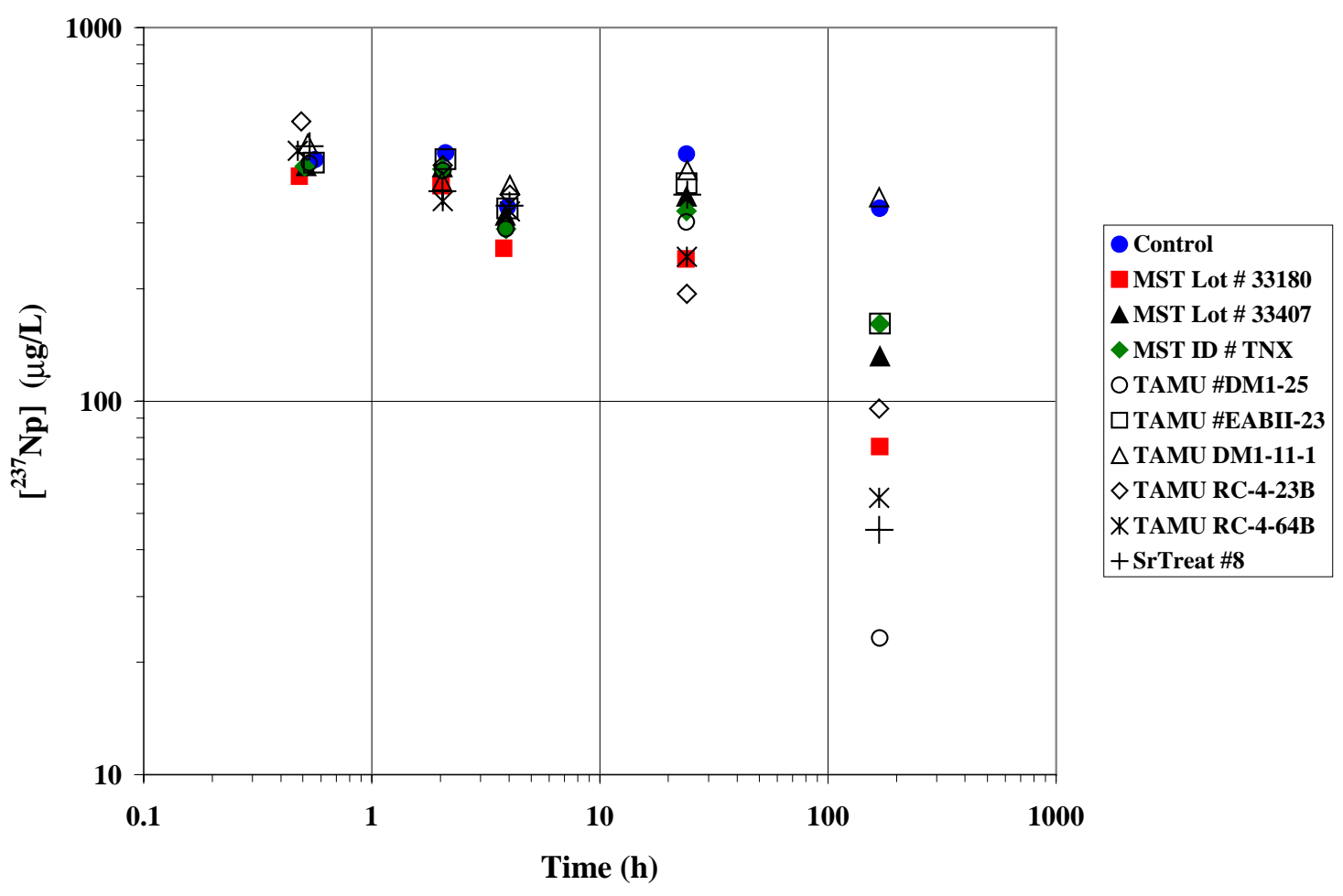

\subsubsection{Alternate Sorbent Conclusions}

Results of the screening tests indicate that sodium nonatitanate and pharmacosiderite materials exhibit as good or better performance than MST samples. Sodium nonatitanate samples exhibiting good performance included the TAMU sample \#ST-RC-4-64B and the Fortum SrTreat ${ }^{\circledR} \# 8$ samples. Both of the pharmacosiderite samples exhibited good strontium and actinide separation performance. With the exception of plutonium, the sodium form (DM-1-25) of the pharmacosiderite exhibited better performance characteristics than the potassium form (EAB-II-23).

\subsection{Quality Assurance}

This work used the following task plan.

D. T. Hobbs, T. B. Peters, M. J. Barnes, M. C. Duff and K. M. Marshall, "Task Technical and Quality Assurance Plan for FY01 Strontium and Actinide Removal Testing," WSRCRP-2001-00188, Rev. 1, July 31, 2001.

This document provides deliverables for the affects of solution composition and plutonium and neptunium oxidation states and the performance of alternate sorbent materials requested in the authorizing task request, 
Savannah River Site Salt Processing Project Research and Development Program Plan, PNNL-13253, Rev. 1, November 2000.

Notebooks WSRC-NB-2000-00120 (D. T. Hobbs), WSRC-NB-2001-00011 (D. T. Hobbs), WSRC-NB-2001-00168 (M. J. Barnes) and WSRC-NB-2001-00124 (K. M. Marshall) contain the experimental data obtained from this work.

\subsection{References}

1 R. A. Dimena, H. H. Elder, J. R. Fowler, R. C. Fowler, M. V. Gregory, T. Hang, R. A. Jacobs, P. K. Paul, J. A. Pike, P. L. Rutland, F. G. Smith III, S. G. Subosits, G. A. Taylor and S. G. Campbell, "Bases, Assumptions, and Results of the Flowsheet Calculations for the Short List Salt Disposition Alternatives," WSRC-RP-99-00006, Rev. 2, April, 4, 2001.

2 Savannah River Site Salt Processing Project Research and Development Program Plan, PNNL-13253, Rev. 1, November 2000.

${ }^{3}$ D. T. Hobbs, M. S. Blume, H. L. Thacker, "Phase V Testing of Monosodium Titanate Adsorption Kinetics,” WSRC-TR-2000-00142, May 24, 2000.

${ }^{4}$ D. T. Hobbs, M. S. Blume, H. L. Thacker, "Screening Evaluation of Sodium Nonatitanate for Strontium and Actinide Removal from Alkaline Salt Solution, WSRC-TR-2000-00361, October 2, 2000.

${ }^{5}$ D. T. Hobbs, M. S. Blume, H. L. Thacker, "Screening Evaluation of Alternate Sorbents and Methods for Strontium and Actinide Removal from Alkaline Salt Solution, WSRC-TR-2001-00072, February, 2001.

6 David T. Hobbs and David G. Karraker, "Recent Results on the Solubility of Uranium and Plutonium in Savannah River Site Waste Supernate,” Nuclear Technology, 1996 (114), 318 - 324.

7 C. H. Delegard, "Solubility of $\mathrm{PuO}_{2} \mathrm{xH}_{2} \mathrm{O}$ in Alkaline Hanford High-Level Waste Solution," Radiochem. Acta, 41 (1987), 11.

8 Comprehensive Inorganic Chemistry, J. C. Bailar, ed., Pergammon Press, New York, 1973, Vol. 5, p. 465-635.

9 D. T. Hobbs and R. L. Pulmano, "Phase IV Simulant Testing Monosodium Titanate Adsorption Kinetics," WSRC-TR-99-00219, Rev. 0, June 29, 1999.

${ }^{10}$ D. T. Hobbs and R. L. Pulmano, "Phase IV Testing of Monosodium Titanate Adsorption with Radioactive Waste,” WSRC-TR-99-00286, Rev. 0, September 3, 1999.

11 J. B. Harris, "Specification for Procurement of Monosodium Titanate," Specification No. Z-SPP-H00001 , Rev. 2, May 1992.

${ }^{12}$ D. T. Hobbs and T. B. Edwards, "Solubility of Uranium in Alkaline Salt Solutions (U)," WSRC-TR-93454, March 29, 1994.

${ }^{13}$ D. T. Hobbs and T. B. Edwards, "Solubility of Plutonium in Alkaline Salt Solutions (U)," WSRC-TR93-131, February 26, 1993.

${ }^{14}$ J. M. Cleveland, The Chemistry of Plutonium, Gordon \& Breach, 579, pp. 49-52 (1970), (Am. Nucl. Soc. Reprint 1979).

${ }^{15}$ A. G. Burney and R. M. Harbour, Radiochemistry of Neptunium, NAS-NS-3060, 150, p. 189, Technical Information Center, USAEC (1974). 
${ }^{16}$ Procedure Manual L16.1, Analytical Development Section, Analytical Operating Procedures (U).

${ }^{17}$ Procedure Manual L16.1, Analytical Development Section, Analytical Operating Procedures (U), ADS2420, Rev. 3.

${ }^{18}$ Procedure Manual L16.1, Analytical Development Section, Analytical Operating Procedures (U), ADS1455, Rev. 1.

${ }^{19}$ Procedure Manual L16.1, Analytical Development Section, Analytical Operating Procedures (U), ADS2453, Rev. 0.

${ }^{20}$ T. B. Edwards, “A Revised, Statistically Designed Test Matrix for Studying MST Performance (U)," SRT-SCS-2001-00019, May 1, 2001.

${ }^{21}$ J. A. Cornell, Experiments with Mixtures, Second Edition, John Wiley \& Sons, New York, 1990.

${ }^{22}$ D. T. Hobbs, T. B. Edwards, and S. D. Fleischman, "Solubility of Plutonium and Uranium in Alkaline Salt Solution (U)", WSRC-TR-93-056, February 12, 1993.

${ }^{23}$ SAS Institute, Inc., "JMP Statistics and Graphics Guide: Version 4 of JMP," SAS Institute, Inc., Cary, NC, 2000.

${ }^{24}$ K. Bourikas, T. Hiemstra and W. H. Van Riemsdijk, "Ion Pair Formation and Primary Charging Behavior of Titanium Oxide (Anatase and Rutile), Langmuir, 2001, 17(3), 749-756.

${ }^{25}$ M. C. Duff, D. B. Hunter, D. T. Hobbs, M. J. Barnes and S. D. Fink, "Characterization of Sorbed Uranium, Plutonium and Neptunium on Monosodium Titanate", WSRC-TR-2001-00467, Rev. 0, October 1, 200.

${ }^{26}$ F. L. Slejko, Adsorption Technology: A Step-by-Step Approach to Process Evaluation and Application, Tall Oaks Publishing, Inc., Voorhees, New Jersey, 1985, 18 - 22.

${ }^{27}$ F. A. Cotton and G. Wilkinson, Advanced Inorganic Chemistry A Comprehensive Text, Third Edition, Interscience Publishers, New York, 1972, $652-680$.

${ }^{28}$ M. C. Duff, D. B. Hunter, D. T. Hobbs, M. J. Barnes and S. D. Fink, "Characterization of Sorbed Uranium, Plutonium and Neptunium on Monosodium Titanate”, WSRC-TR-2001-00356, Rev. 0, September 19, 2001.

${ }^{29}$ D. T. Hobbs, M. S. Blume, H. L. Thacker, "Screening Evaluation of Sodium Nonatitanate for Strontium and Actinide Removal from Alkaline Salt Solution, WSRC-TR-2000-00361, October 2, 2000.

${ }^{30}$ D. T. Hobbs, M. S. Blume, H. L. Thacker, "Screening Evaluation of Alternate Sorbents and Methods for Strontium and Actinide Removal from Alkaline Salt Solution, WSRC-TR-2001-00072, February, 2001. 
Plutonium (IV) Concentration Data

\section{Appendix 1}

\begin{tabular}{|c|c|c|c|c|}
\hline & \multicolumn{4}{|c|}{ Pu(IV) Concentration $(\mu \mathrm{g} / \mathbf{L})$} \\
\hline Time & Test Pu(IV)-1 & Test Pu(IV)-2 & Test Pu(IV)-3 & Average \\
\hline 0 & \multicolumn{4}{|c|}{} \\
\hline 1.0 & 15.06 & 37.26 & 37.26 \\
\hline 2.0 & 11.60 & 14.42 & 13.91 & 14.46 \\
\hline 4.0 & 10.25 & 9.72 & 12.53 & 11.97 \\
\hline 29.6 & 1.33 & 4.85 & 9.85 & 9.94 \\
\hline 48.0 & 3.14 & 3.97 & 4.31 & 3.50 \\
\hline 168 & 1.48 & 1.65 & 2.40 & 3.17 \\
\hline
\end{tabular}

Plutonium (VI) Concentration Data

\begin{tabular}{|c|c|c|c|c|}
\hline & \multicolumn{4}{|c|}{ Pu(VI) Concentration $(\mu \mathrm{g} / \mathrm{L})$} \\
\hline Time & Test Pu(VI)-1 & Test Pu(VI)-2 & Test Pu(VI)-3 & Average \\
\hline 0 & \multicolumn{3}{|c|}{712.04} & 712.04 \\
\hline 1.1 & 239.90 & 197.79 & 239.90 & 225.86 \\
\hline 2.1 & 202.89 & 193.96 & 204.17 & 200.34 \\
\hline 4.0 & 172.27 & 164.61 & 172.27 & 169.72 \\
\hline 29.7 & 81.92 & 72.99 & 76.56 & 77.16 \\
\hline 48.0 & 61.51 & 55.13 & 60.23 & 58.95 \\
\hline 168 & 25.65 & 24.12 & 26.03 & 25.27 \\
\hline
\end{tabular}

Neptunium (IV) Concentration Data

\begin{tabular}{|c|c|c|c|c|}
\hline & \multicolumn{4}{|c|}{ Np(IV) Concentration $(\mu \mathrm{g} / \mathrm{L})$} \\
\hline Time & Test Np(IV)-1 & Test Np(IV)-2 & Test Np(IV)-3 & Average \\
\hline 0 & \multicolumn{3}{|c|}{1159.4} & 1159.42 \\
\hline 1.2 & 519.4 & 532.7 & 556.7 & 536.23 \\
\hline 2.1 & 643.7 & 691.7 & 702.6 & 679.31 \\
\hline 4.1 & 530.3 & 567.1 & 540.5 & 545.95 \\
\hline 29.7 & 242.0 & 259.2 & 287.6 & 262.95 \\
\hline 48.1 & 191.7 & 203.4 & 194.3 & 196.46 \\
\hline 168 & 35.1 & 53.3 & 33.4 & 40.63 \\
\hline
\end{tabular}

Neptunium (V) Concentration Data

\begin{tabular}{|c|c|c|c|c|}
\hline & \multicolumn{4}{|c|}{ Np(V) Concentration $(\mu \mathbf{g} / \mathbf{L})$} \\
\hline Time & Test Np(V)-1 & Test Np(V)-2 & Test Np(V)-3 & Average \\
\hline 0 & \multicolumn{3}{|c|}{} & 1259.00 \\
\hline 1.1 & 647.4 & 1259.0 & 662.20 \\
\hline 2.1 & 879.1 & 669.2 & 670.0 & 865.41 \\
\hline 4.0 & 769.8 & 848.6 & 868.6 & 797.95 \\
\hline 29.7 & 327.3 & 758.0 & 866.1 & 367.19 \\
\hline 48.1 & 295.1 & 388.3 & 386.0 & 330.11 \\
\hline 168 & 61.7 & 312.7 & 382.5 & 121.73 \\
\hline
\end{tabular}




\section{Appendix 2}

We designated the eleven (11) experiments Trials 1 through 11. The first 6 used conditions selected from the set of extreme vertices (EVs) that bound the mixture region of interest in this study. Trials 7 and 8 represent duplicates of the centroid of the mixture region. Trials 9 was this centroid spiked with trace amounts of the minor salts, Trial 10 contained no MST (a control), and Trial 11 duplicated a Phase V trial. The following plot shows the symbols, colors, and trial labels used in the following analyses.

Exhibit 1: Colors and Symbols Used to Represent the 11 Experimental Trials

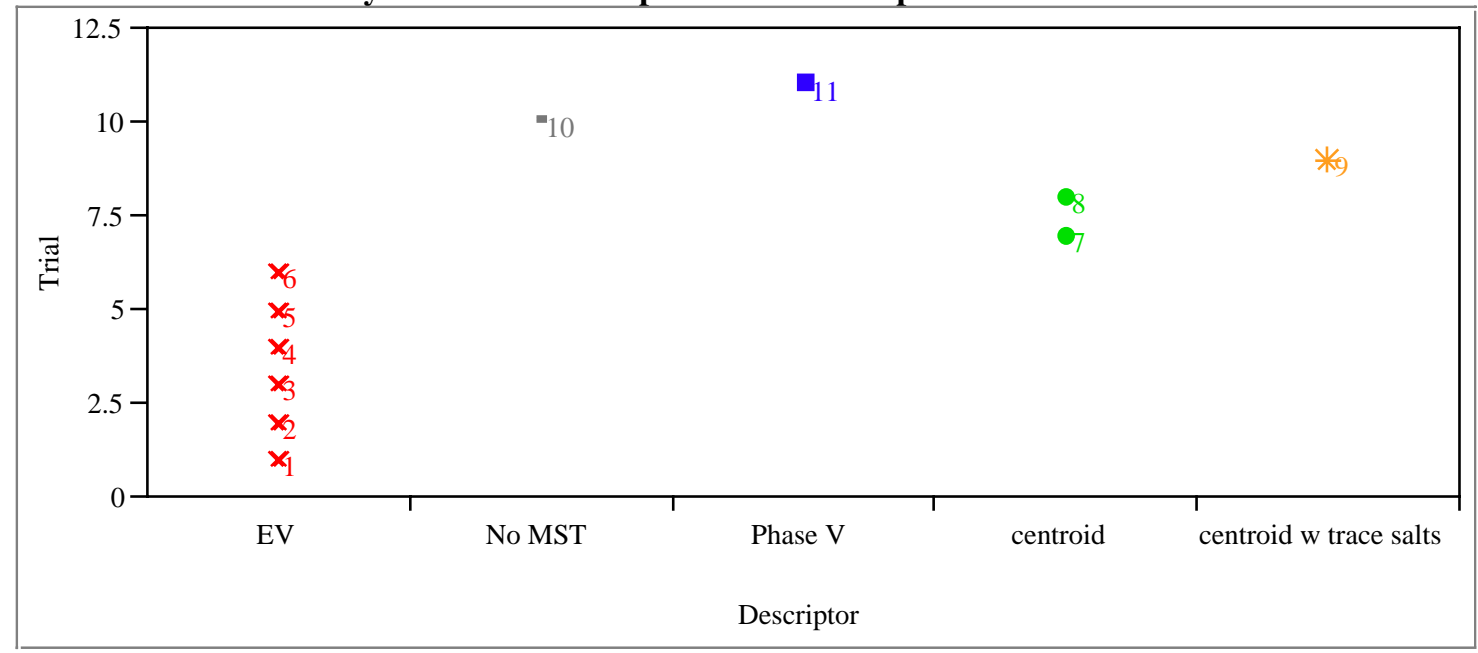


Exhibit 2: Correlations and Scatter Plot of Design Points in Normalized Ionic Strength Space

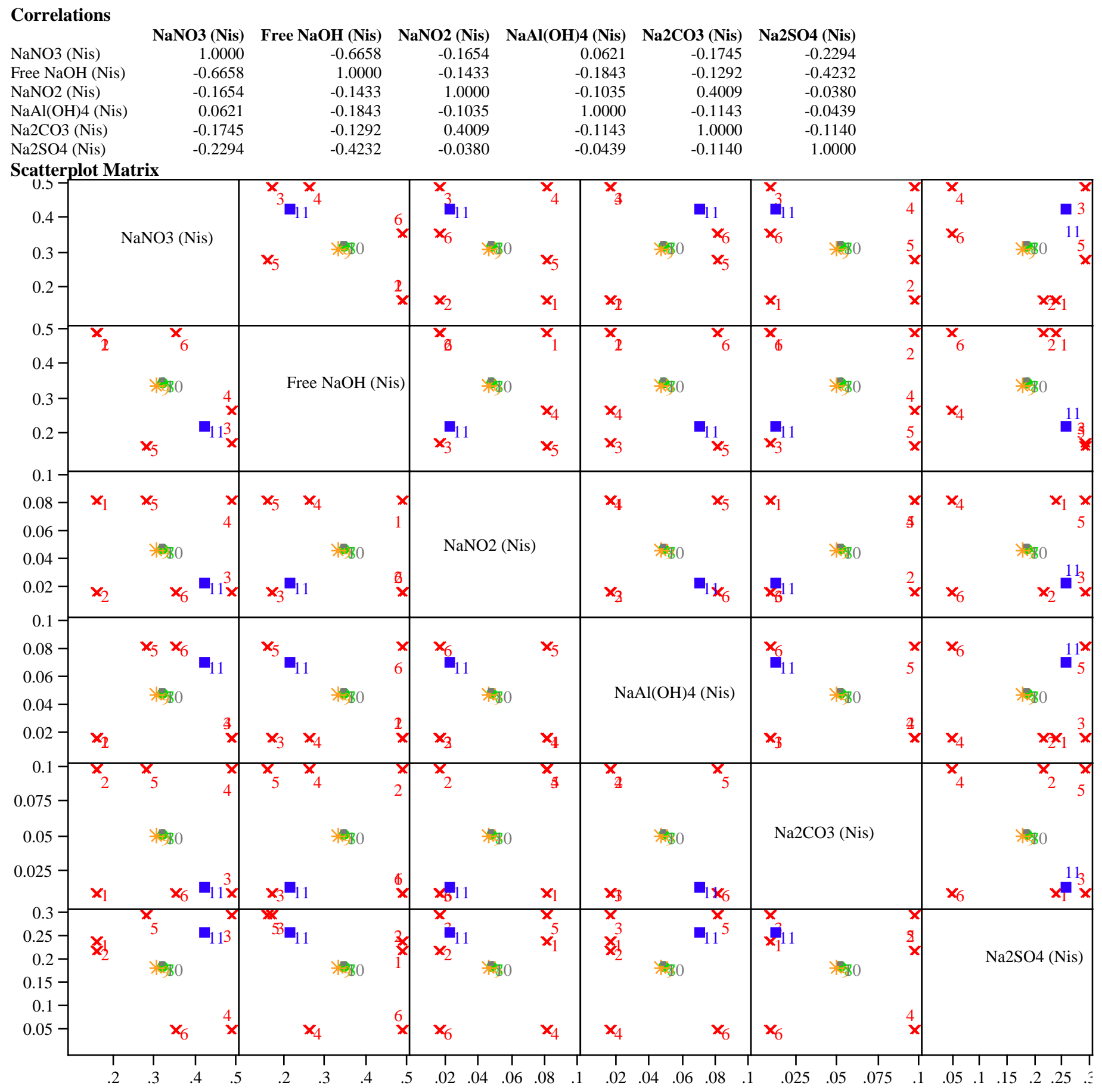


Exhibit 3: Sr DF-24h by Trial Descriptor

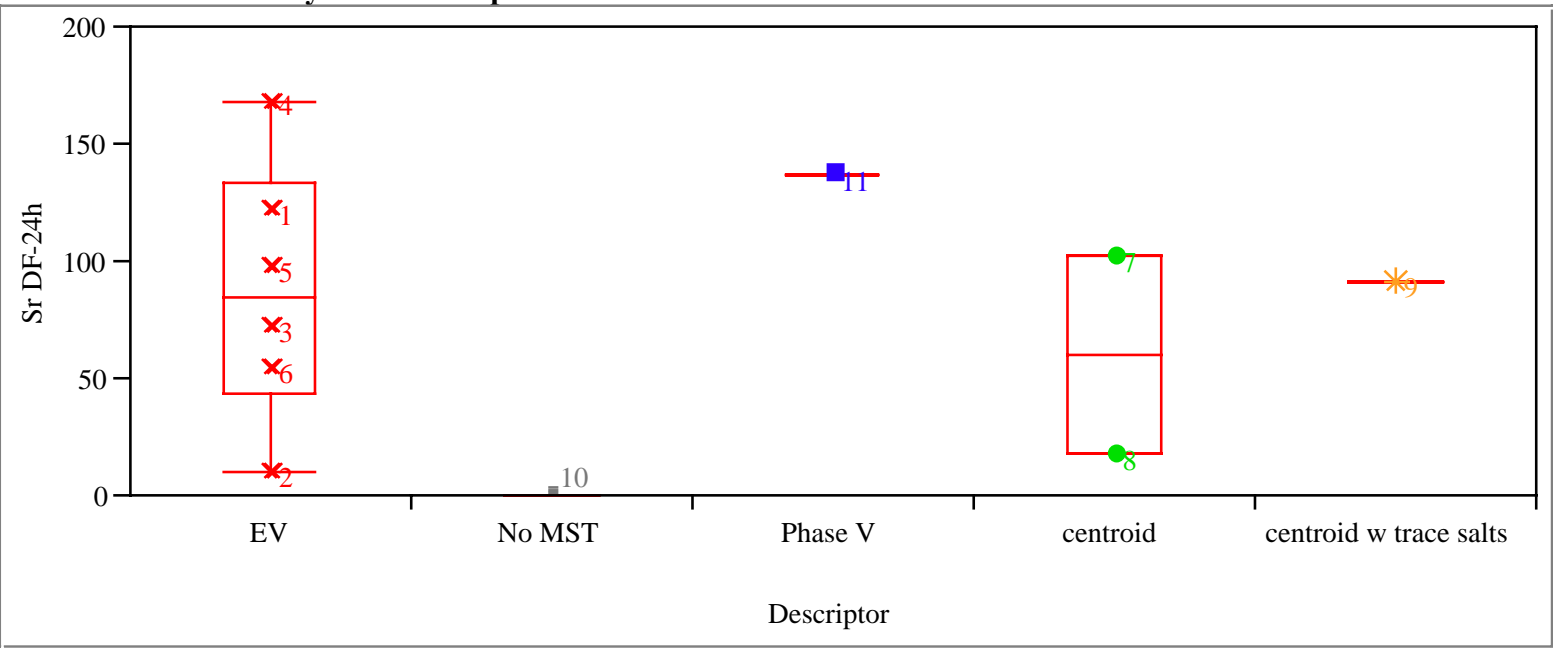

Exhibit 4: Sr DF-7d by Trial Descriptor

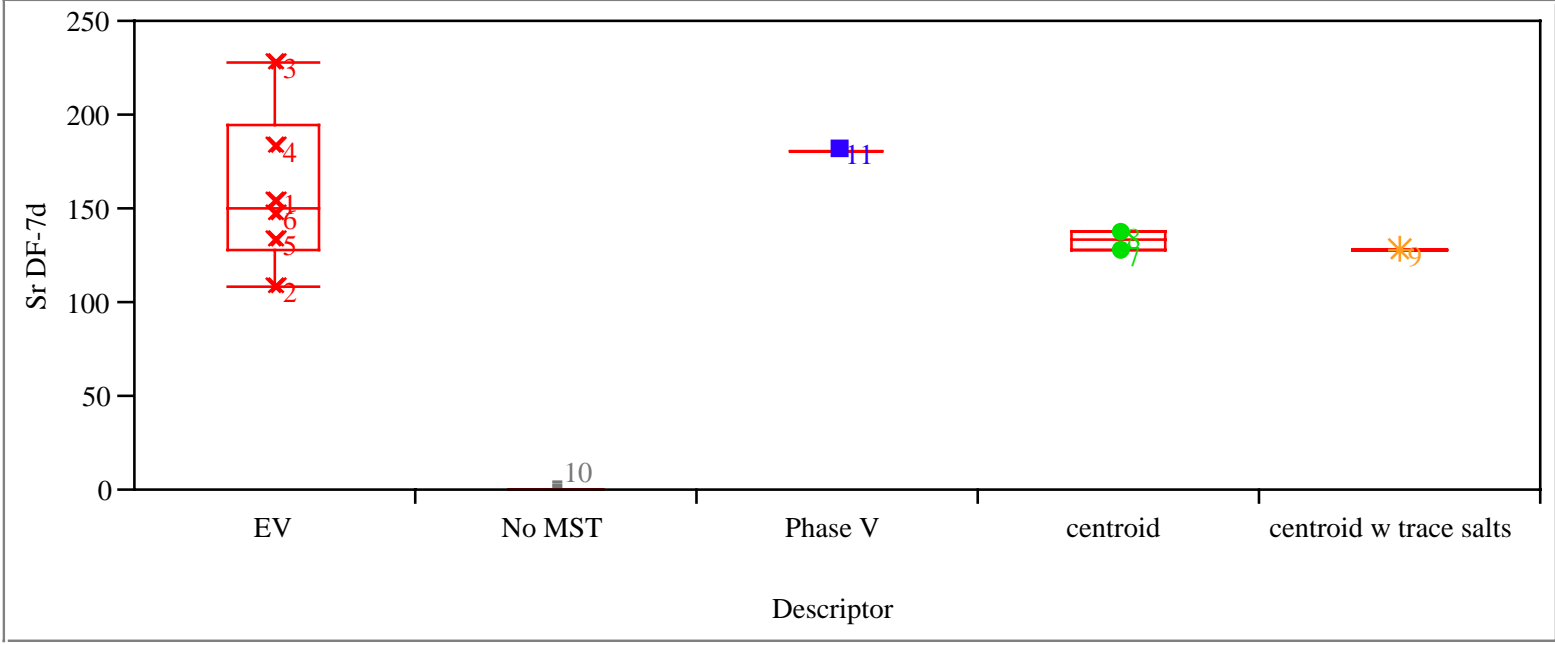

Exhibit 5: Pu DF-24h by Trial Descriptor

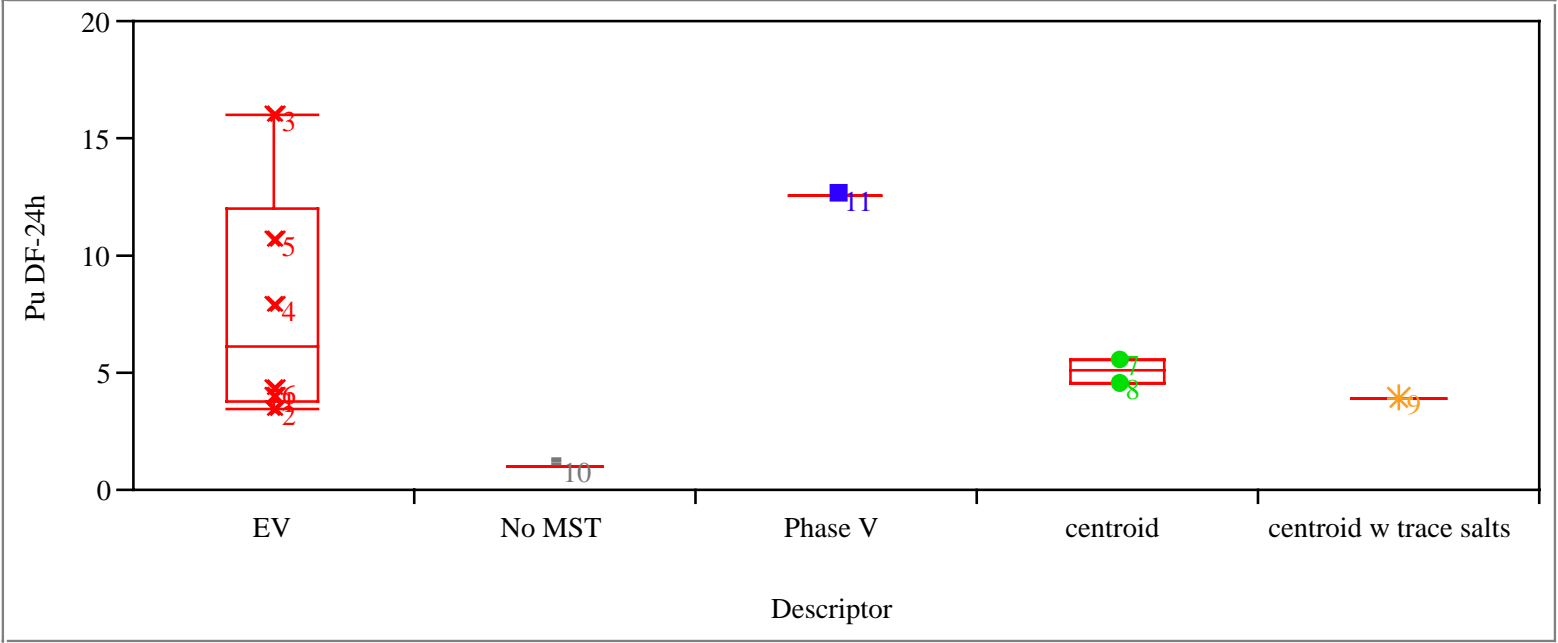


Exhibit 6: Pu DF-7d by Trial Descriptor

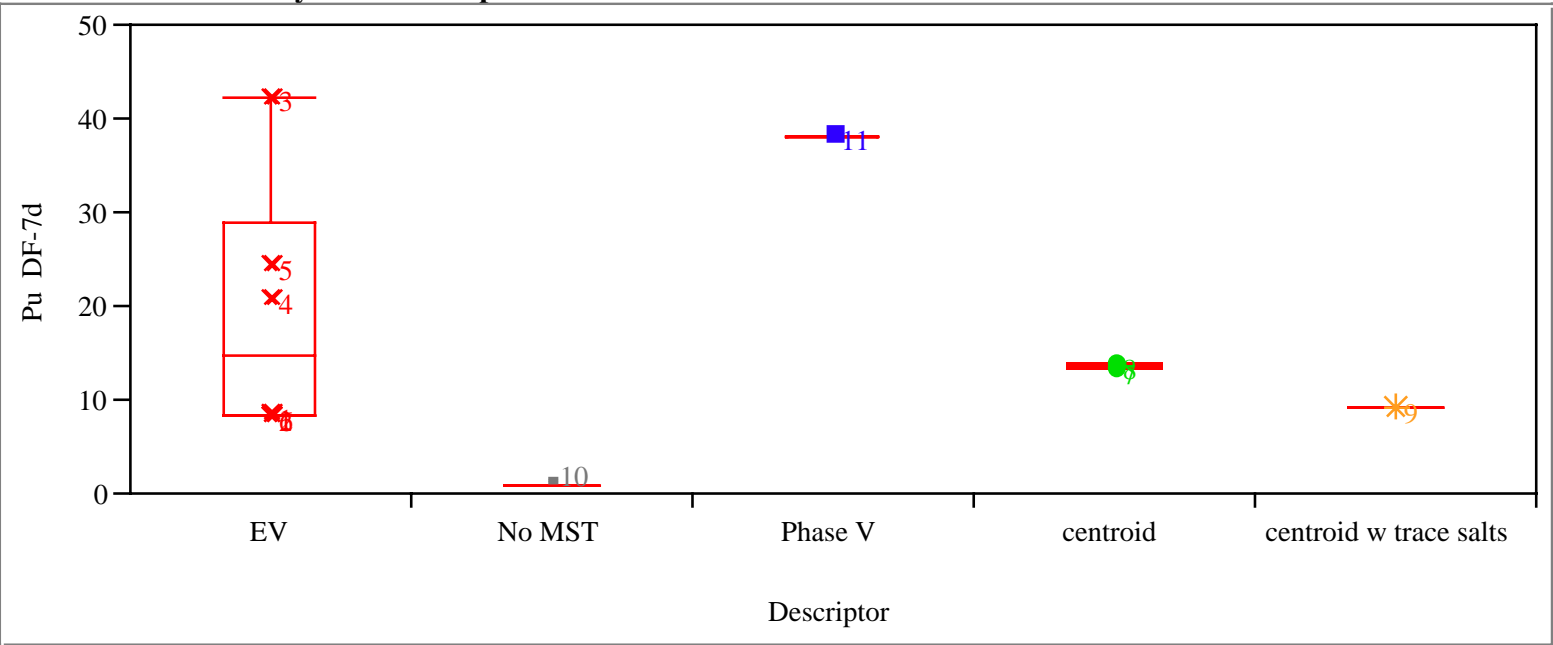

Exhibit 7: U DF-24h by Trial Descriptor

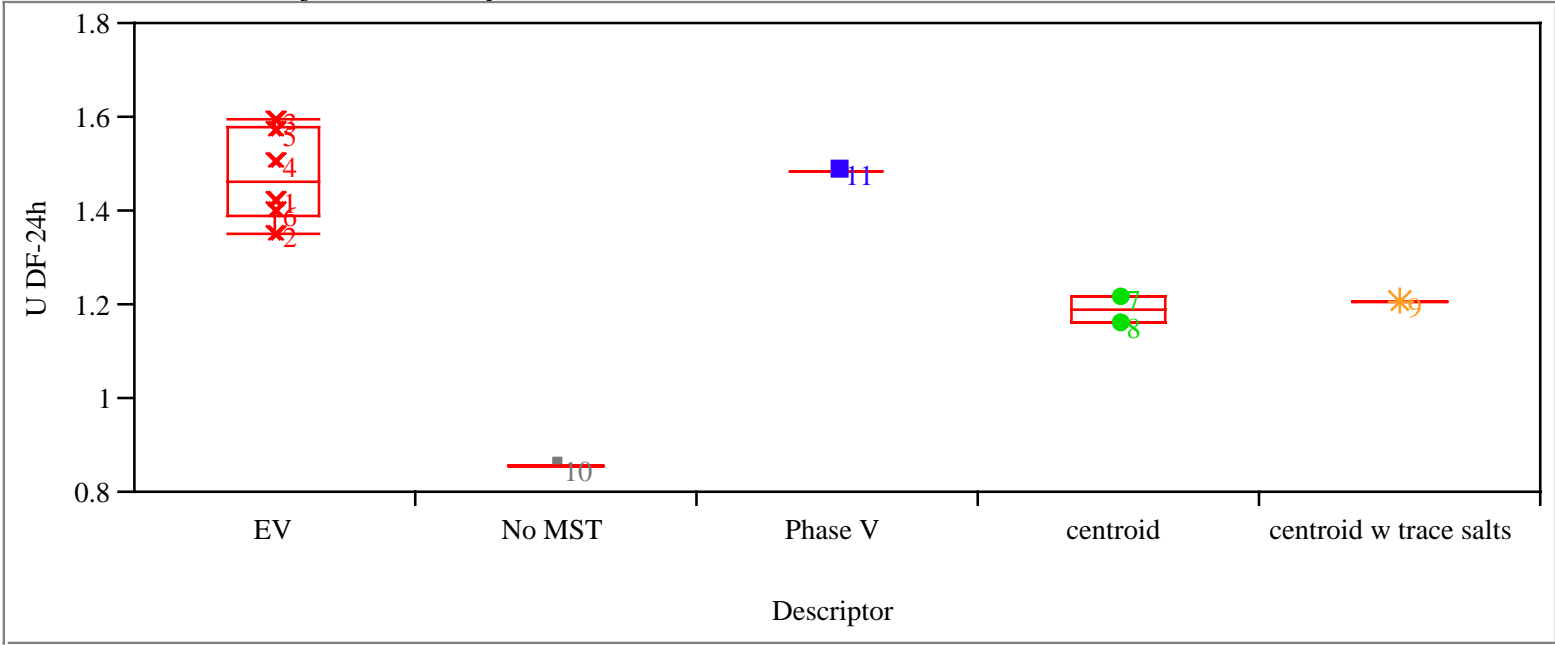

Exhibit 8: U DF-7d by Trial Descriptor

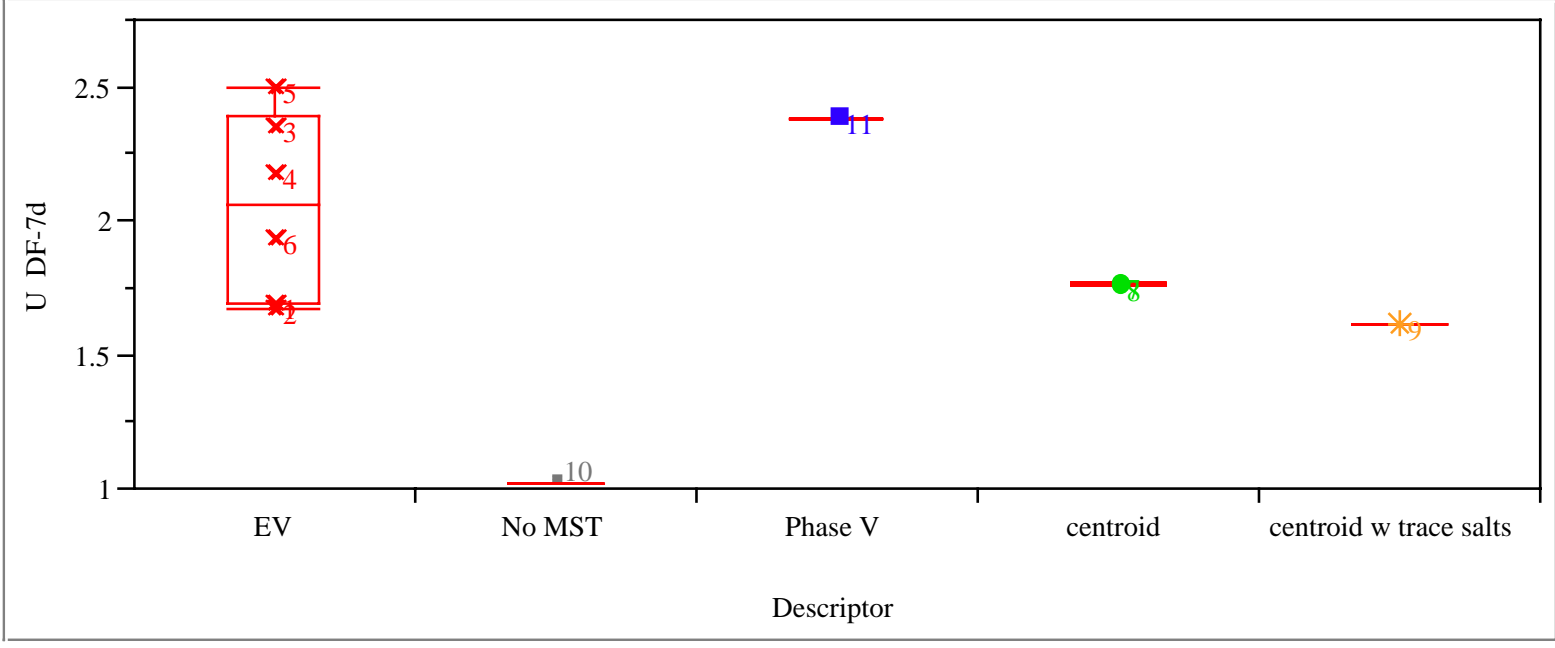


Exhibit 9: Np DF-24h by Trial Descriptor

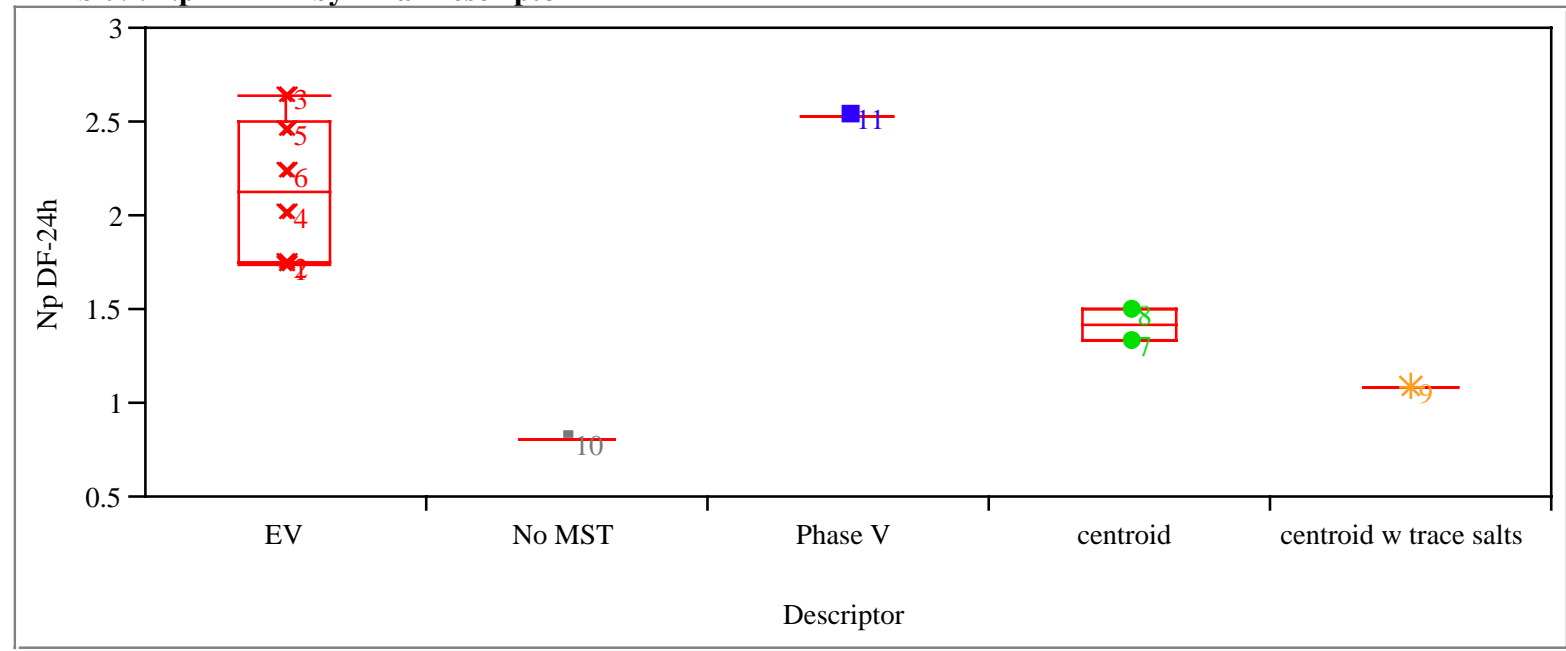

Exhibit 10: Np DF-7d by Trial Descriptor

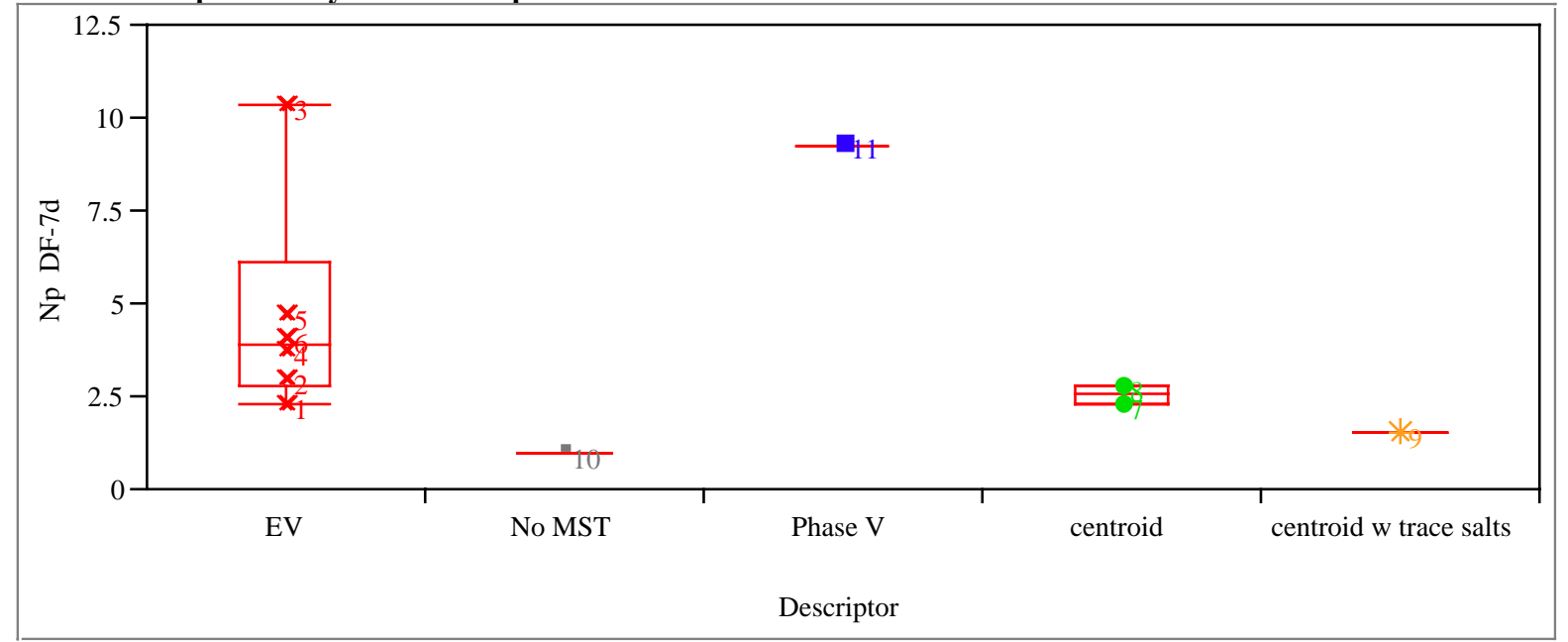


Exhibit 11: Correlations Between and Scatter Plots for Decontamination Factor Values Over the Eleven Trials

\section{Correlations}

$\begin{array}{lrrrrrrrr} & \text { Sr DF-24h } & \text { Sr DF-7d } & \text { Pu DF-24h } & \text { Pu DF-7d } & \text { U DF-24h } & \text { U DF-7d } & \text { Np DF-24h } & \text { Np DF-7d } \\ \text { Sr DF-24h } & 1.0000 & 0.6078 & 0.4584 & 0.4589 & 0.6014 & 0.5879 & 0.4063 & 0.2970 \\ \text { Sr DF-7d } & 0.6078 & 1.0000 & 0.7652 & 0.7662 & 0.8580 & 0.8177 & 0.7689 & 0.7221 \\ \text { Pu DF-24h } & 0.4584 & 0.7652 & 1.0000 & 0.9853 & 0.7642 & 0.8767 & 0.8325 & 0.9326 \\ \text { Pu DF-7d } & 0.4589 & 0.7662 & 0.9853 & 1.0000 & 0.7153 & 0.8474 & 0.7984 & 0.9466 \\ \text { U DF-24h } & 0.6014 & 0.8580 & 0.7642 & 0.7153 & 1.0000 & 0.9127 & 0.9142 & 0.6932 \\ \text { U DF-7d } & 0.5879 & 0.8177 & 0.8767 & 0.8474 & 0.9127 & 1.0000 & 0.9156 & 0.7762 \\ \text { Np DF-24h } & 0.4063 & 0.7689 & 0.8325 & 0.7984 & 0.9142 & 0.9156 & 1.0000 & 0.8498 \\ \text { Np DF-7d } & 0.2970 & 0.7221 & 0.9326 & 0.9466 & 0.6932 & 0.7762 & 0.8498 & 1.0000\end{array}$

\section{Scatterplot Matrix}

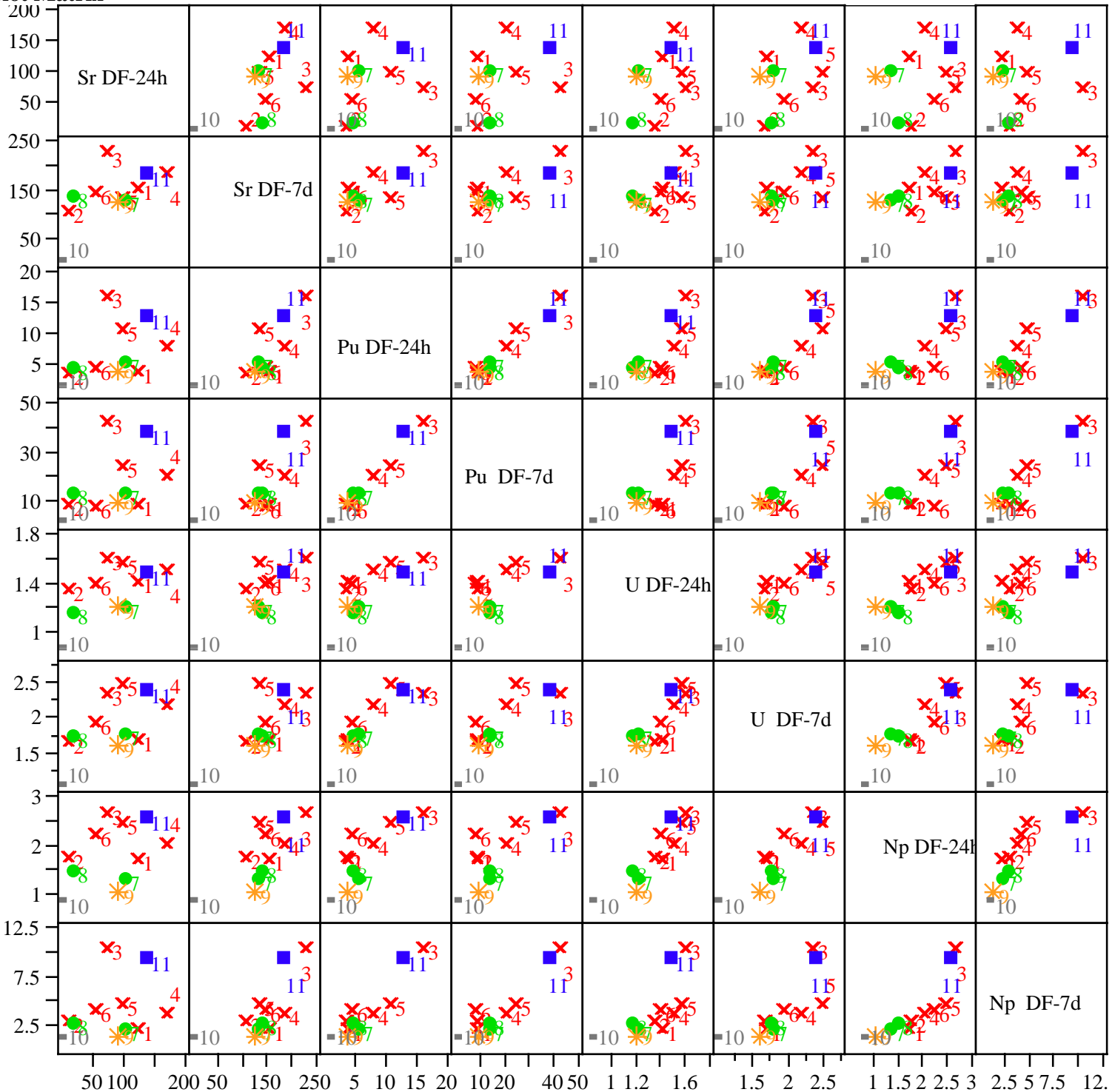


WSRC-TR-2001-00436

45 of 69

Exhibit 12: Plots of Decontamination Factors (DFs) versus Normalized Ionic Strength Fractions

Sr DF-24h By NaNO3 (Nis)

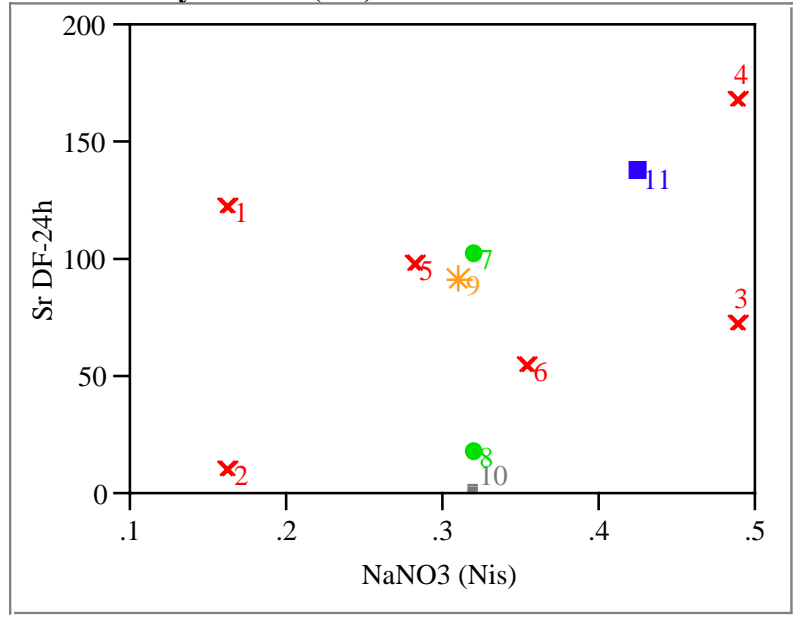

Sr DF-7d By NaNO3 (Nis)

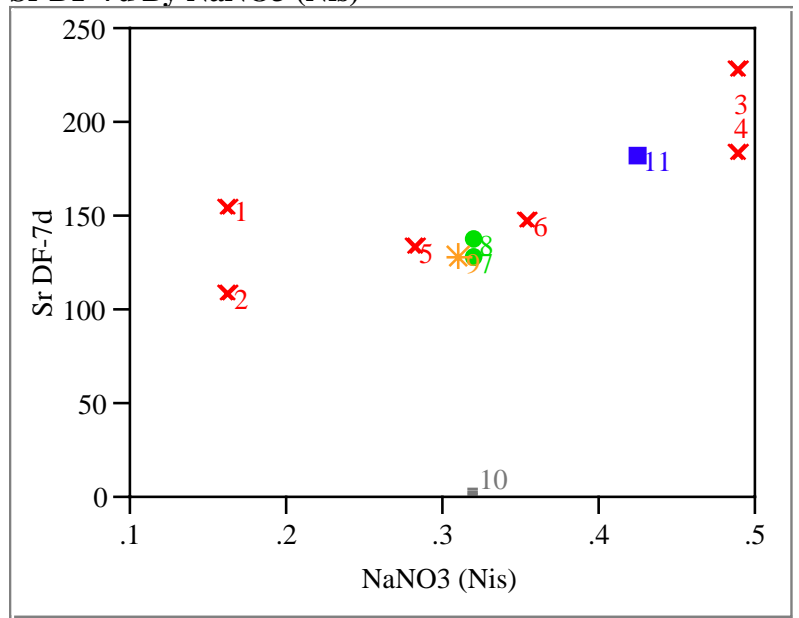

Pu DF-24h By NaNO3 (Nis)

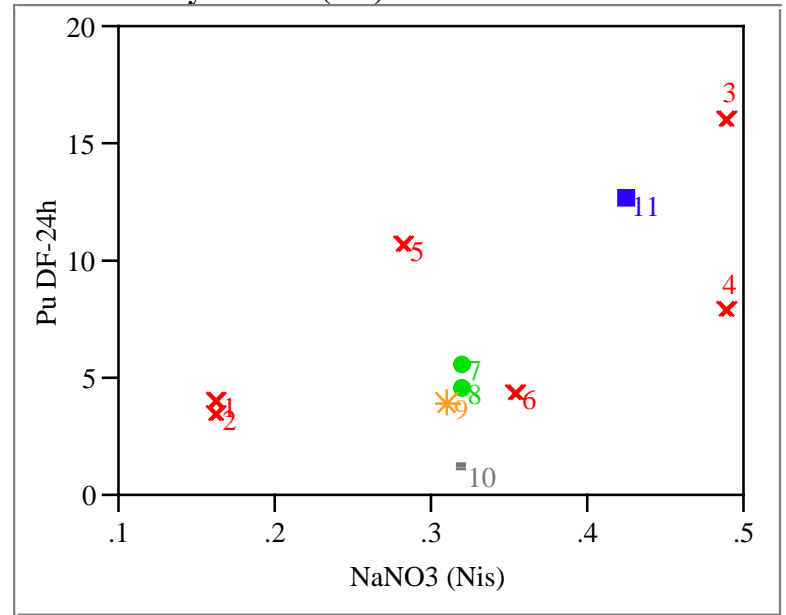

Pu DF-7d By NaNO3 (Nis)

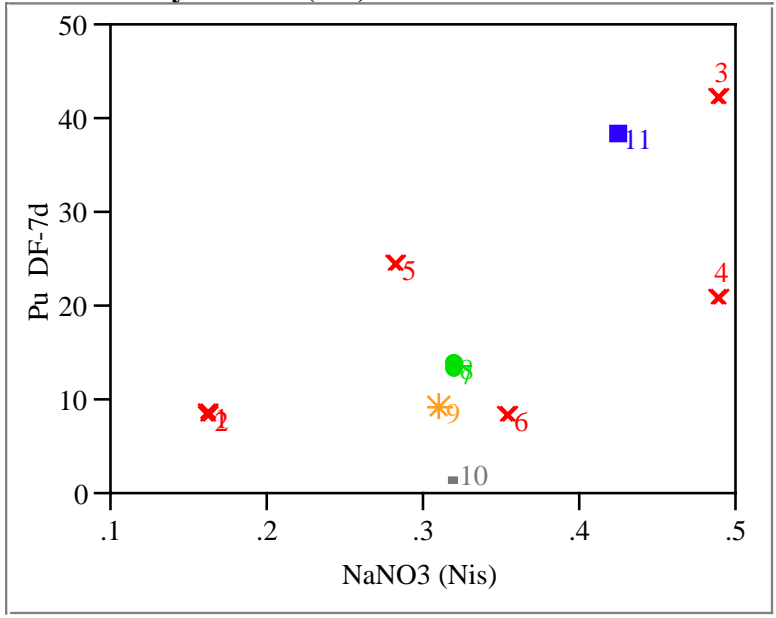

U DF-24h By NaNO3 (Nis)

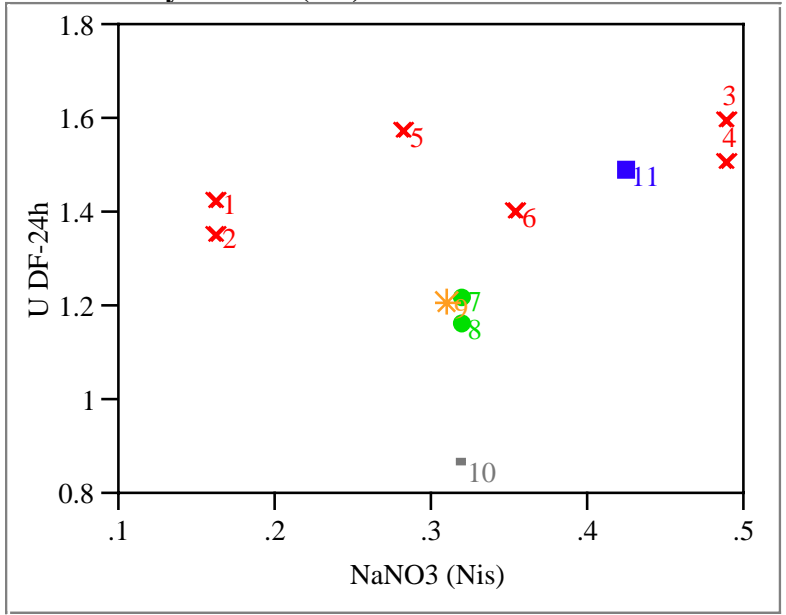

U DF-7d By NaNO3 (Nis)

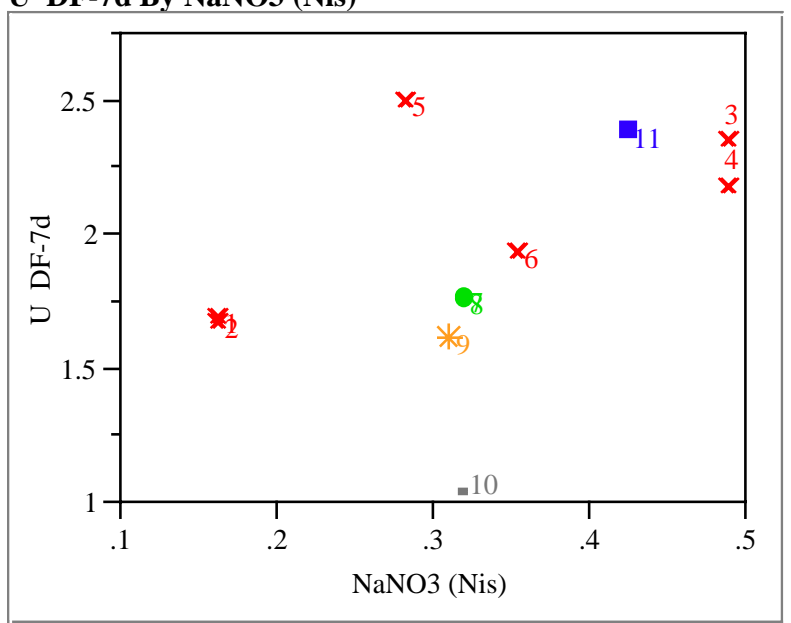


Exhibit 12: Plots of Decontamination Factors (DFs) versus Normalized Ionic Strength Fractions

Np DF-24h By NaNO3 (Nis)

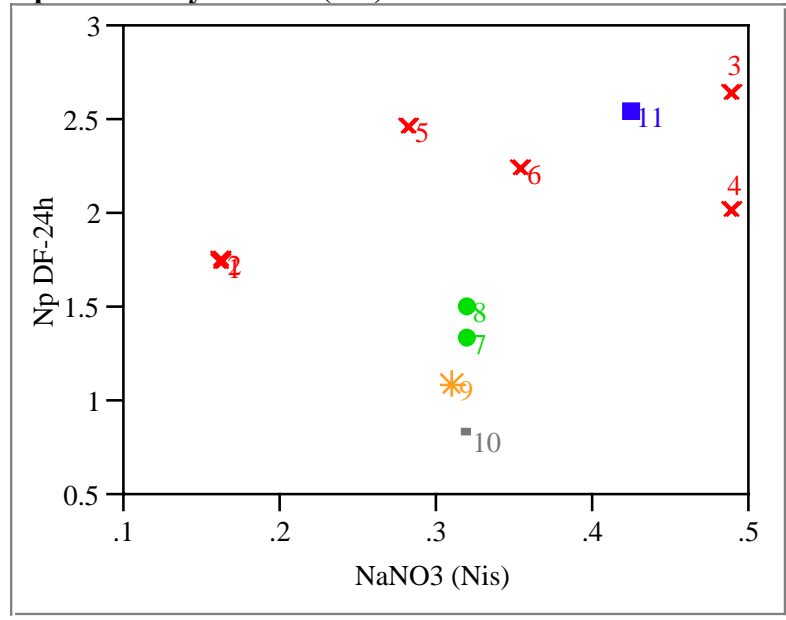

Np DF-7d By NaNO3 (Nis)

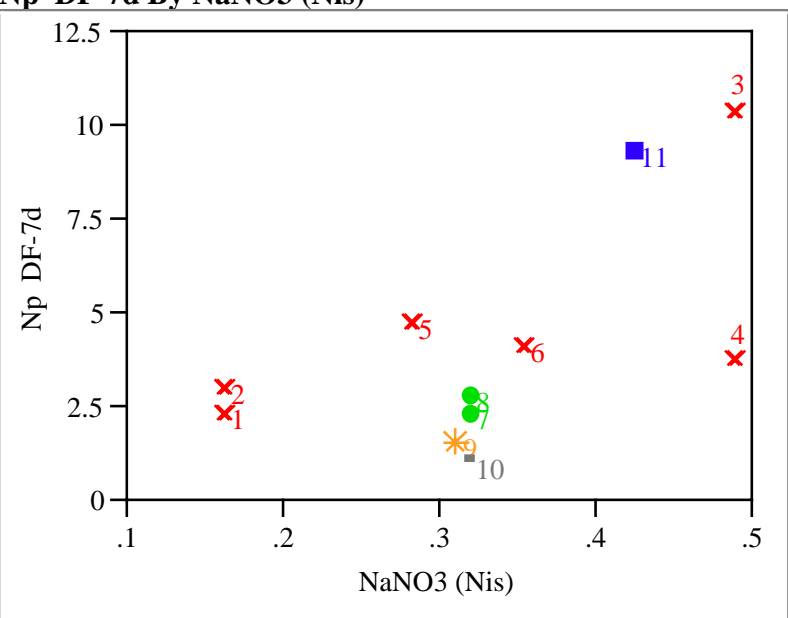

Sr DF-24h By Free NaOH (Nis)

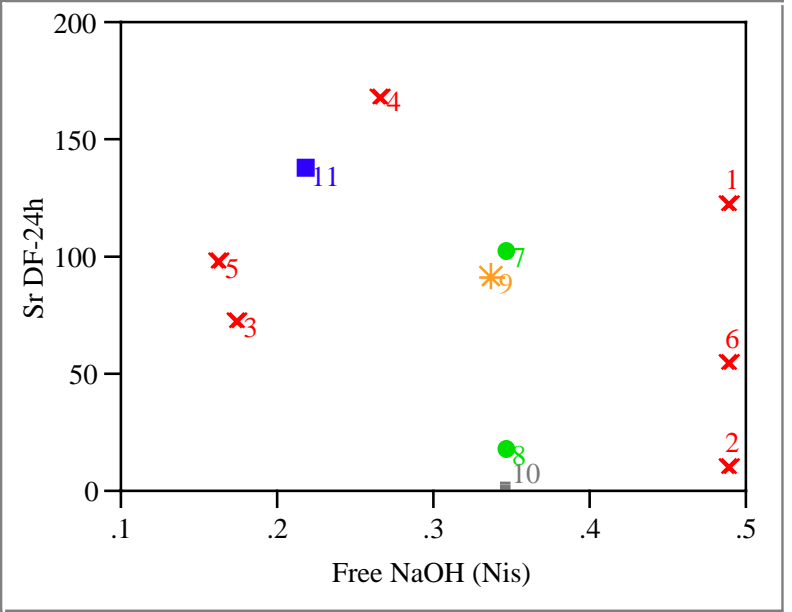

Sr DF-7d By Free NaOH (Nis)

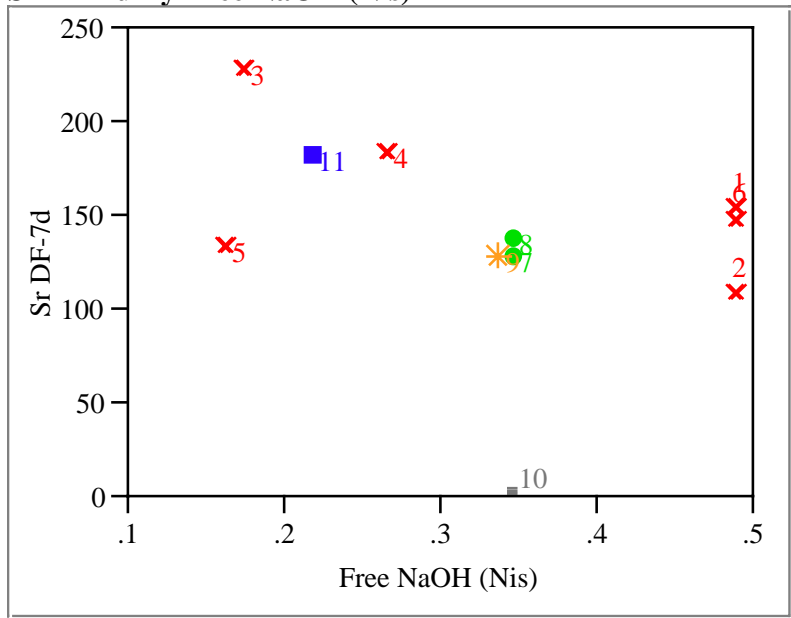

Pu DF-24h By Free NaOH (Nis)

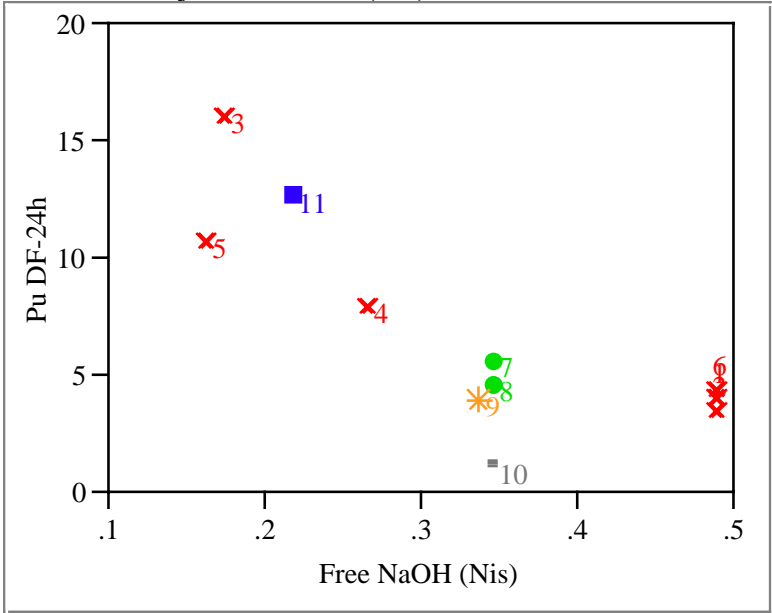

Pu DF-7d By Free NaOH (Nis)

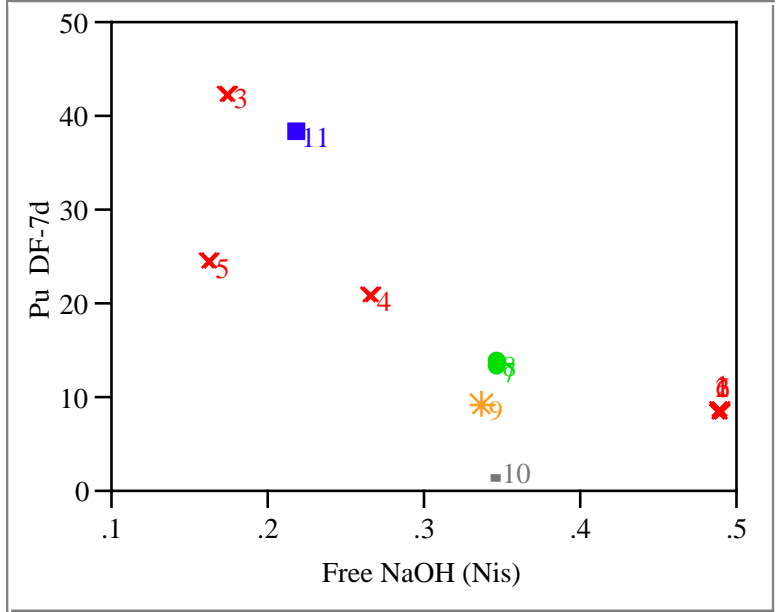


Exhibit 12: Plots of Decontamination Factors (DFs) versus Normalized Ionic Strength Fractions

U DF-24h By Free NaOH (Nis)

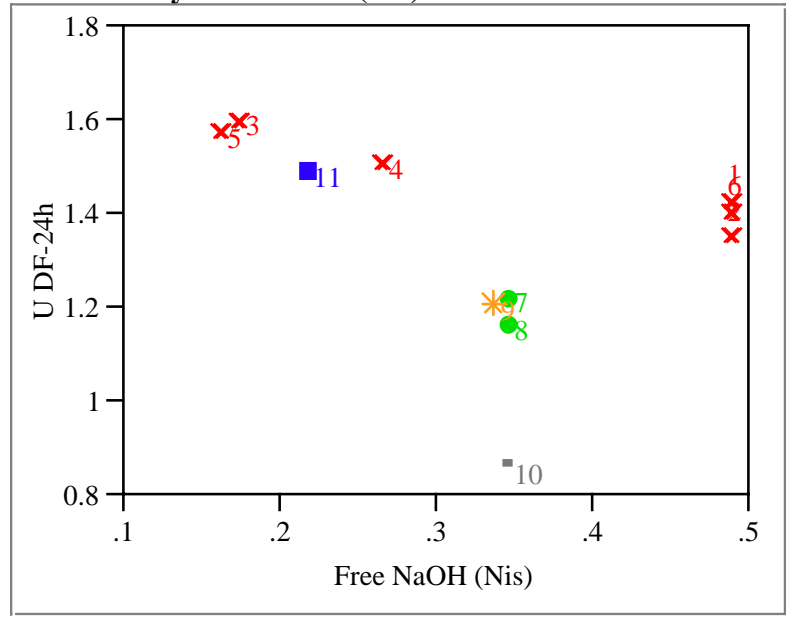

U DF-7d By Free NaOH (Nis)

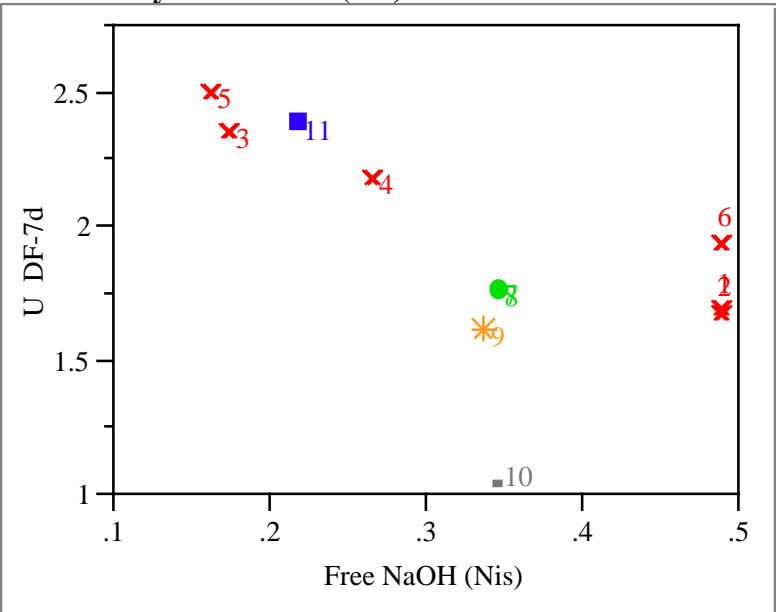

Np DF-24h By Free NaOH (Nis)

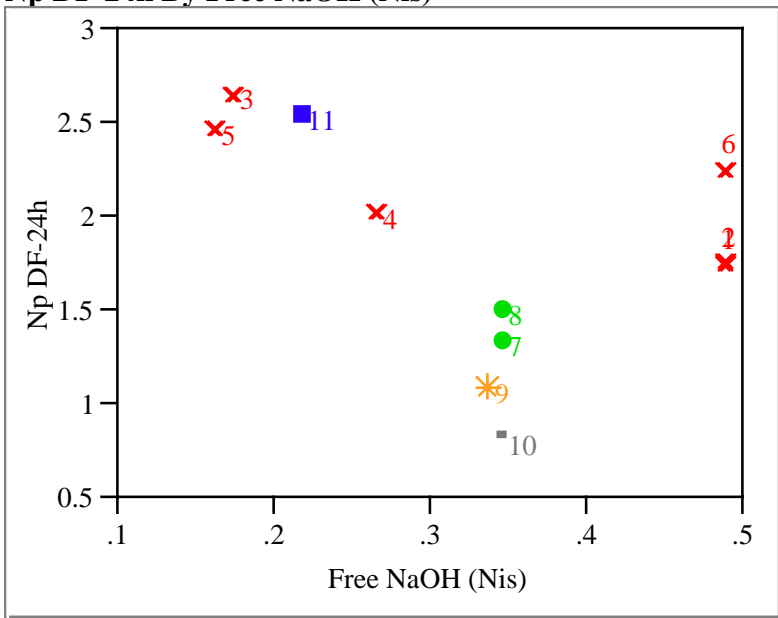

Np DF-7d By Free NaOH (Nis)

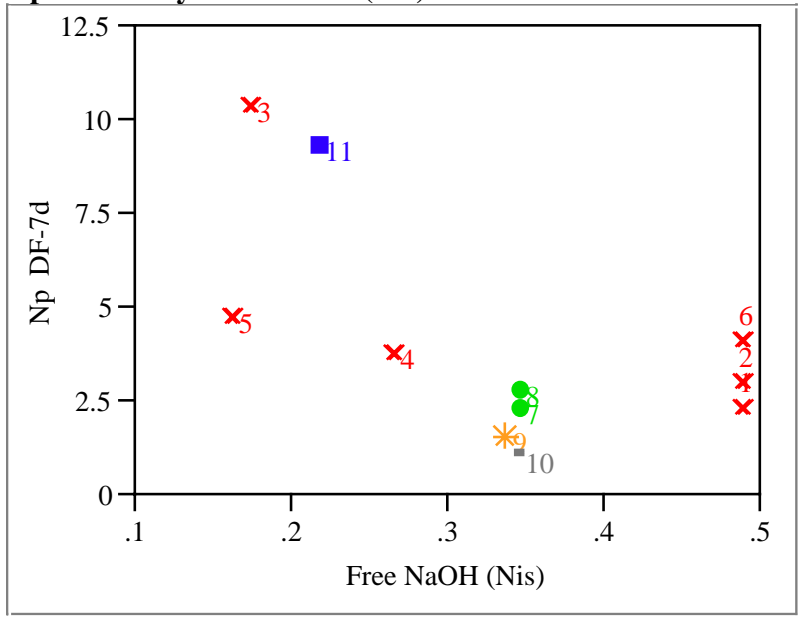

Sr DF-24h By NaNO2 (Nis)

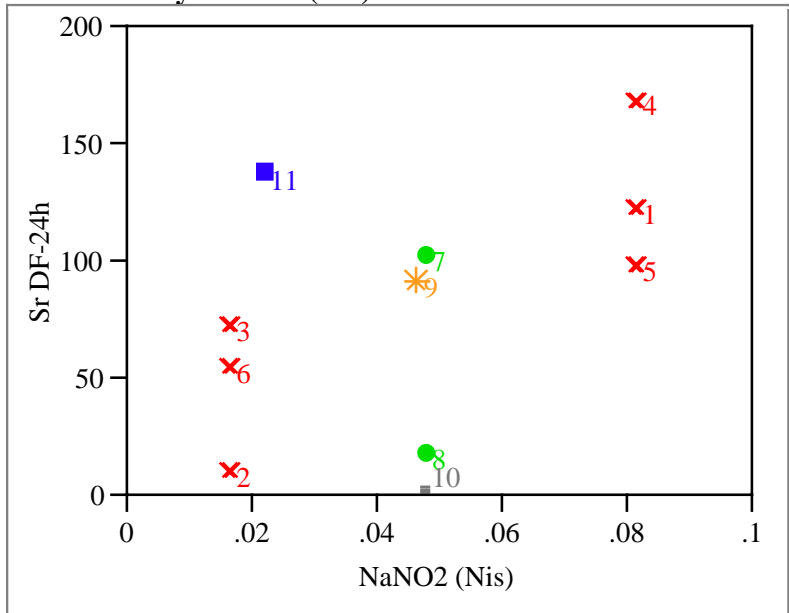

Sr DF-7d By NaNO2 (Nis)

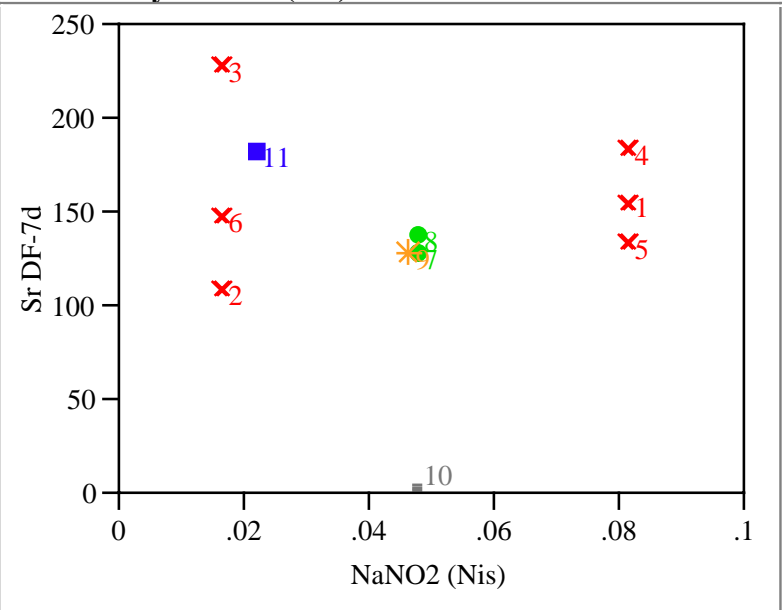


WSRC-TR-2001-00436

48 of 69

Exhibit 12: Plots of Decontamination Factors (DFs) versus Normalized Ionic Strength Fractions

Pu DF-24h By NaNO2 (Nis)

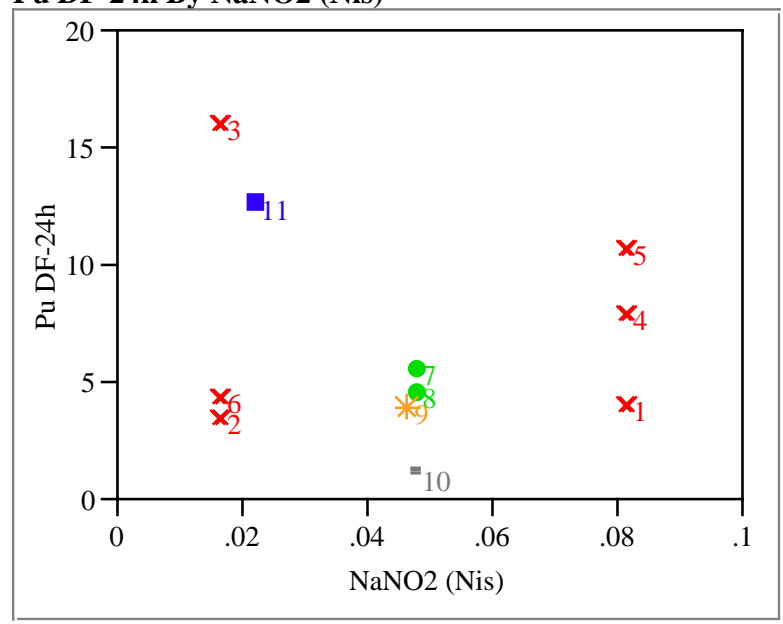

Pu DF-7d By NaNO2 (Nis)

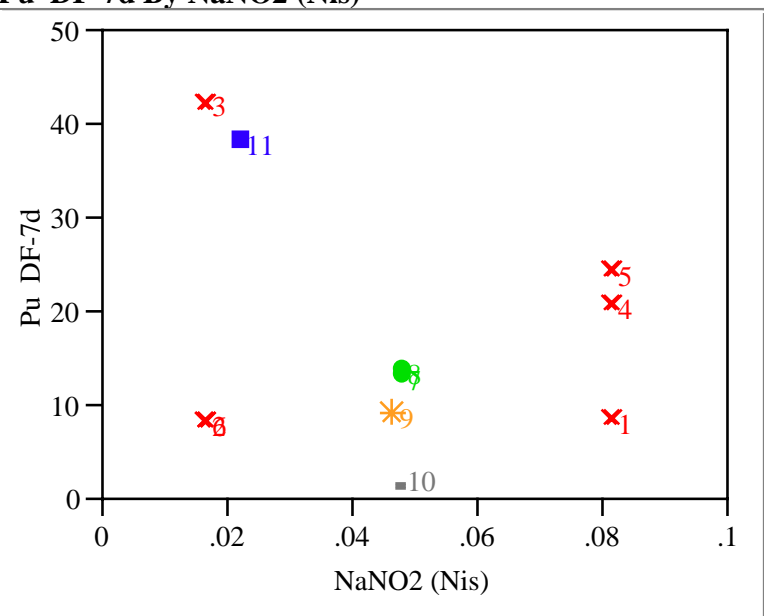

U DF-24h By NaNO2 (Nis)

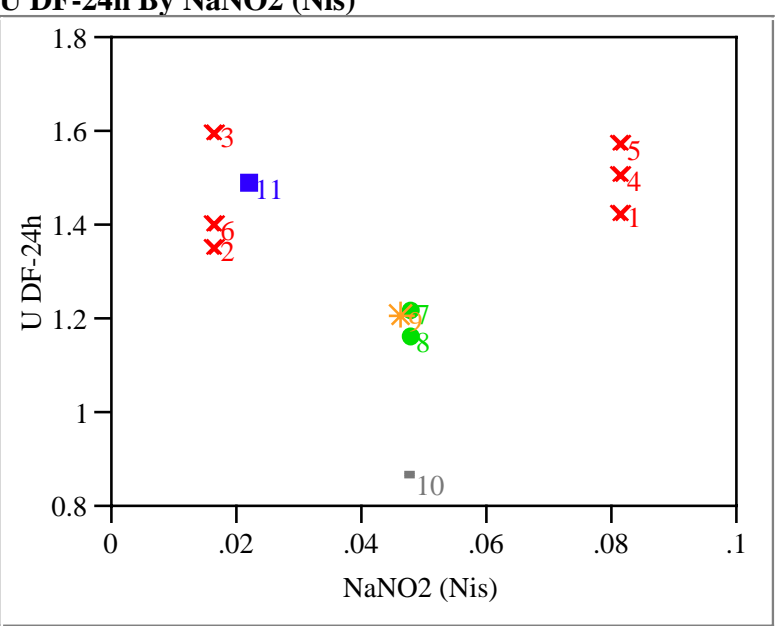

U DF-7d By NaNO2 (Nis)

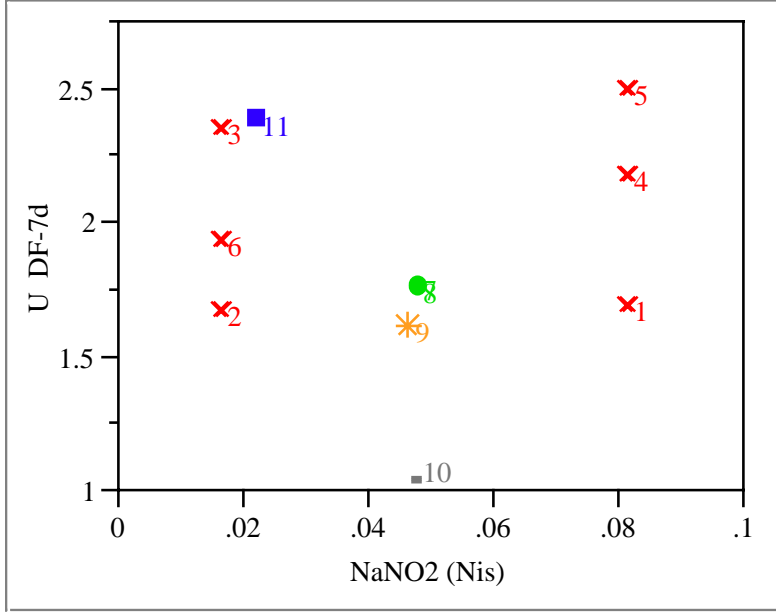

Np DF-24h By NaNO2 (Nis)
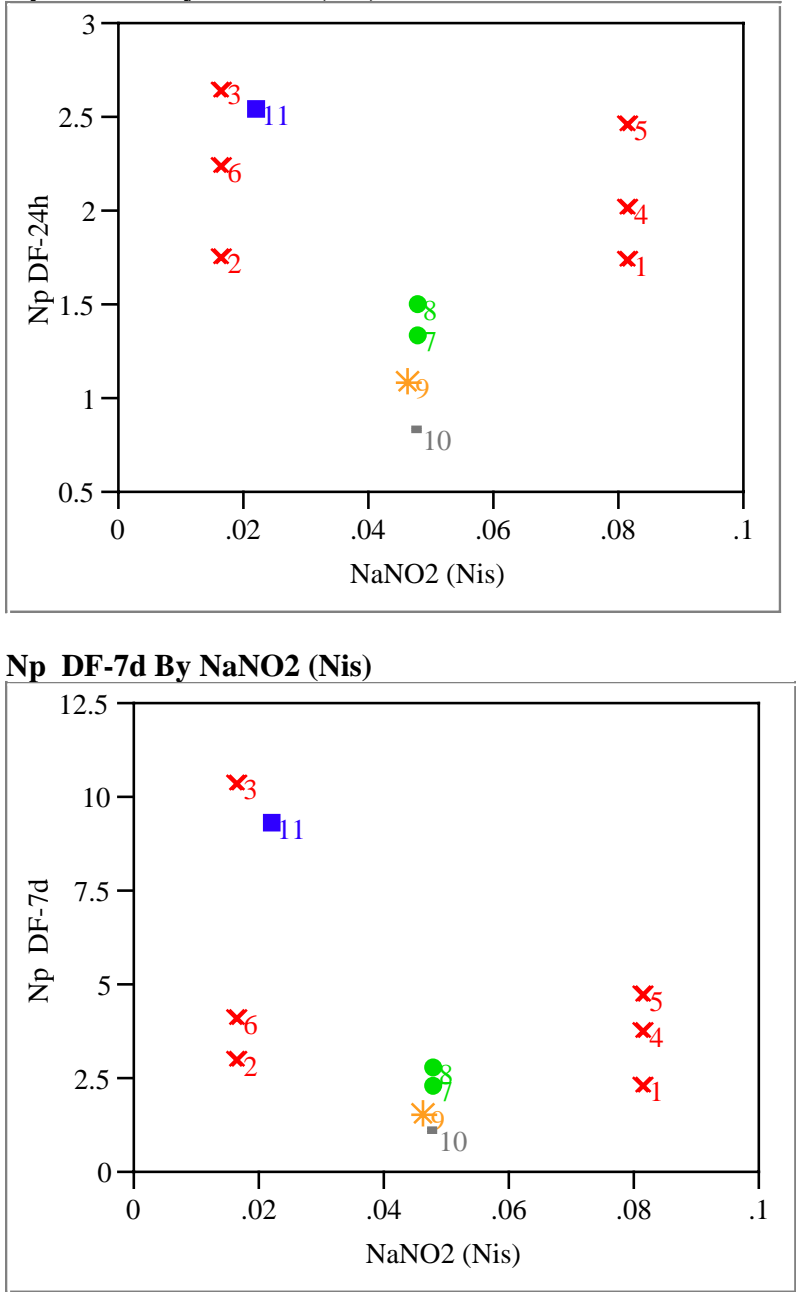
WSRC-TR-2001-00436

49 of 69

Exhibit 12: Plots of Decontamination Factors (DFs) versus Normalized Ionic Strength Fractions

Sr DF-24h By NaAl(OH)4 (Nis)

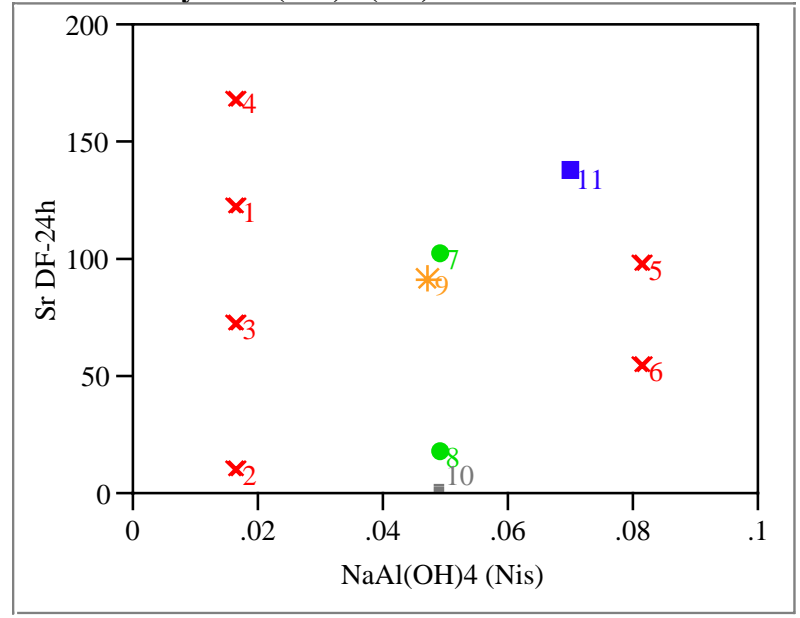

Sr DF-7d By NaAl(OH)4 (Nis)

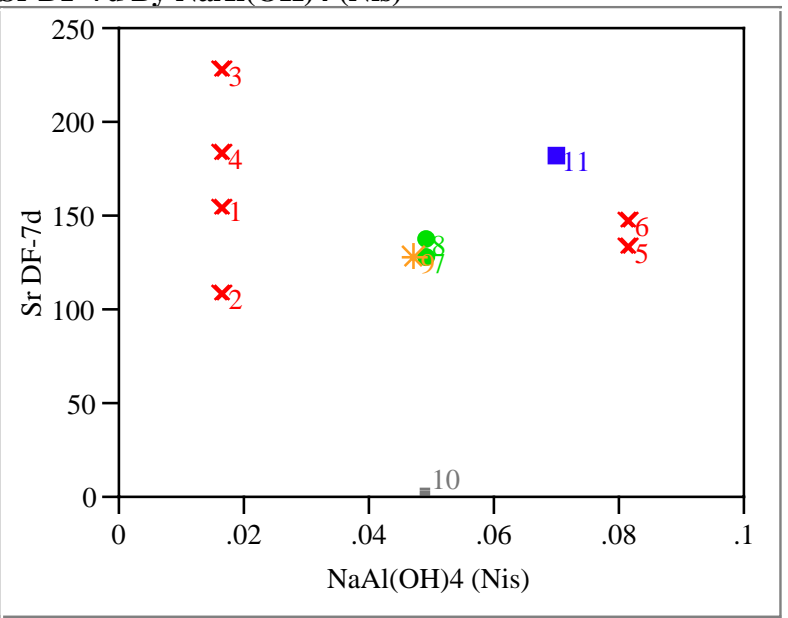

Pu DF-24h By NaAl(OH)4 (Nis)

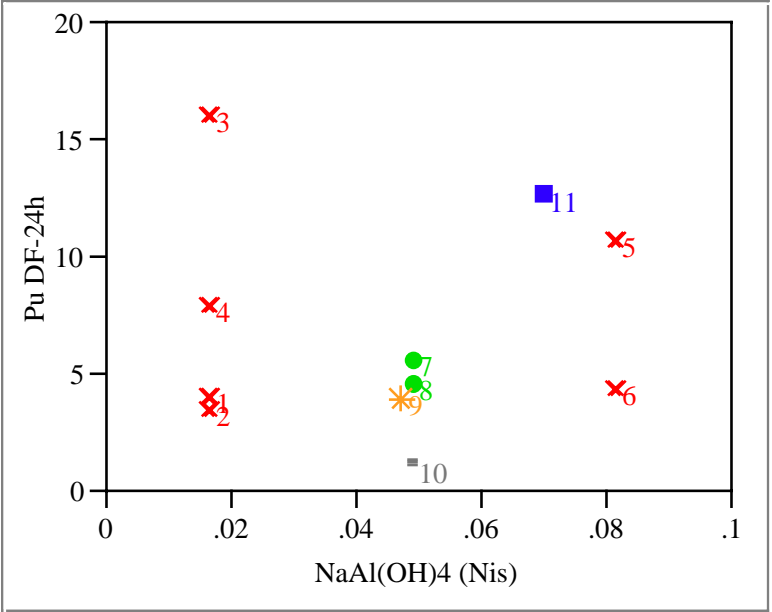

Pu DF-7d By $\mathrm{NaAl}(\mathrm{OH}) 4$ (Nis)

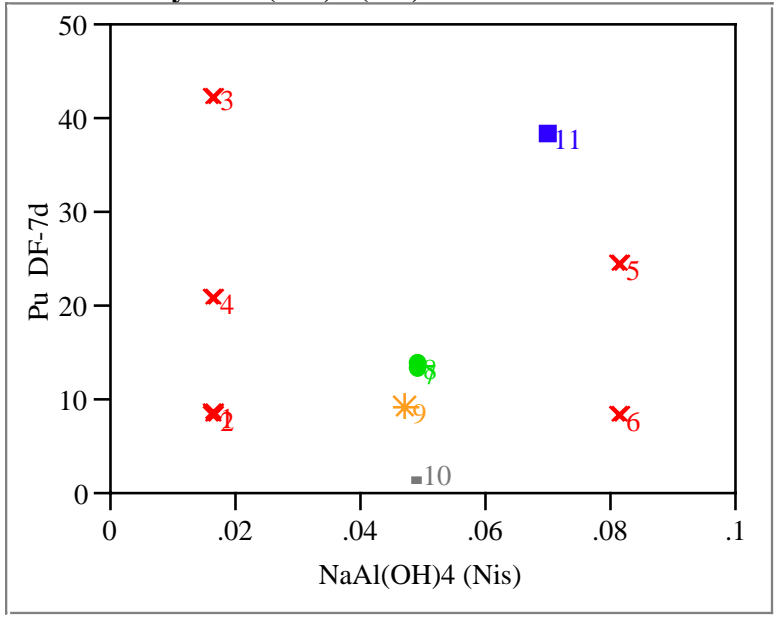

U DF-24h By NaAl(OH)4 (Nis)

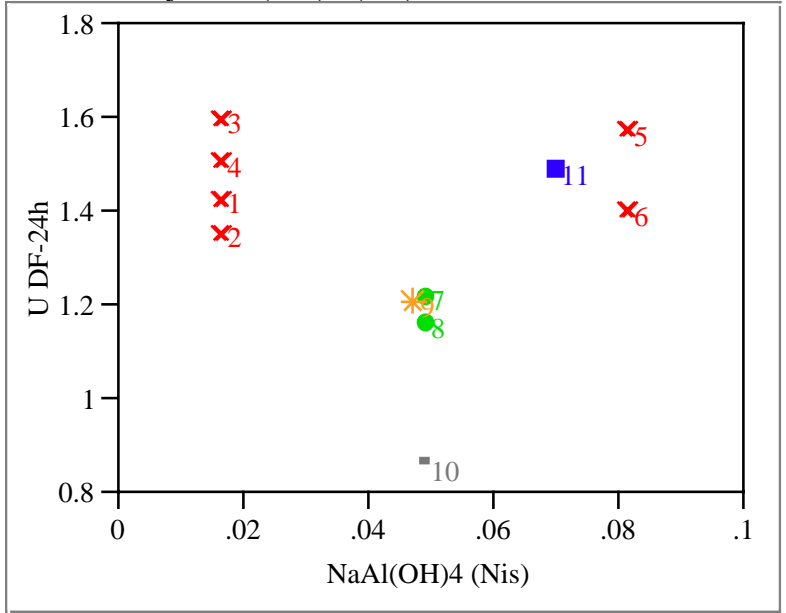

U DF-7d By $\mathrm{NaAl}(\mathrm{OH}) 4$ (Nis)

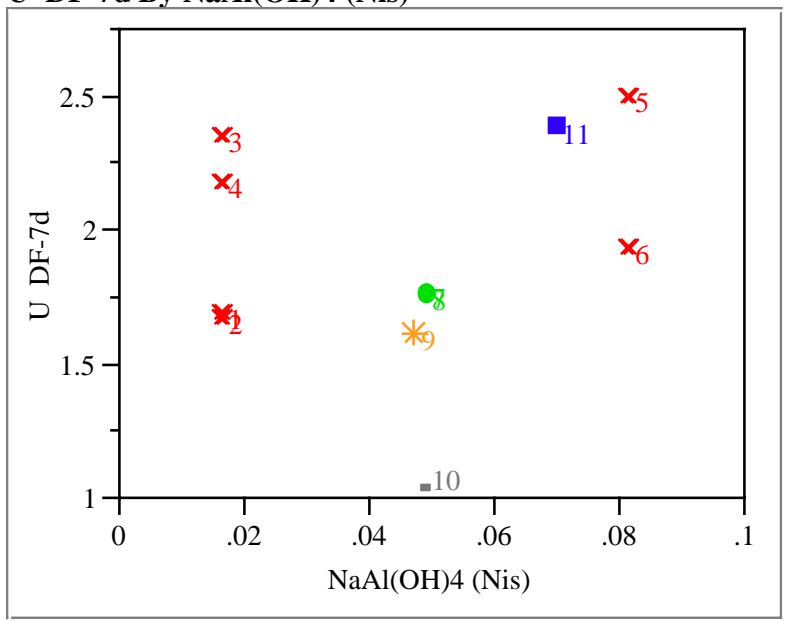


WSRC-TR-2001-00436

Exhibit 12: Plots of Decontamination Factors (DFs) versus Normalized Ionic Strength Fractions

Np DF-24h By $\mathrm{NaAl}(\mathrm{OH}) 4$ (Nis)

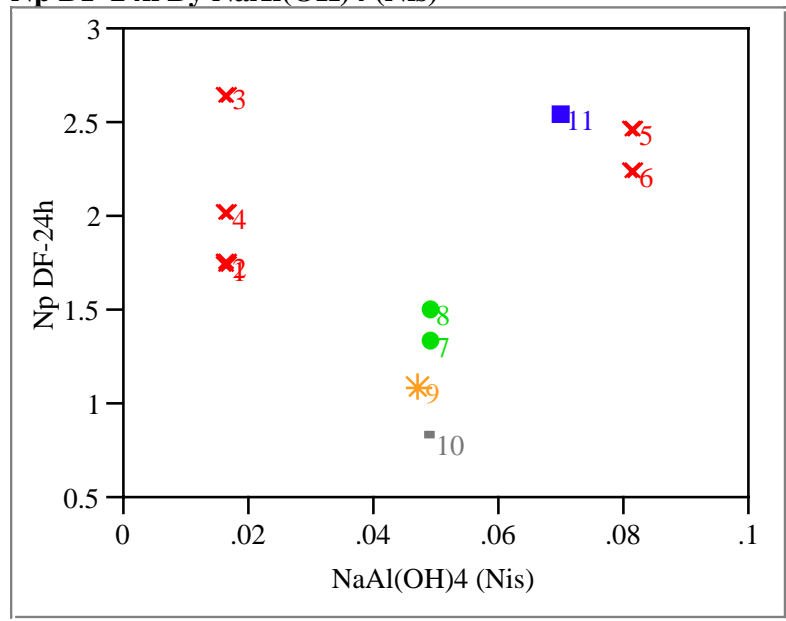

Np DF-7d By NaAl(OH)4 (Nis)

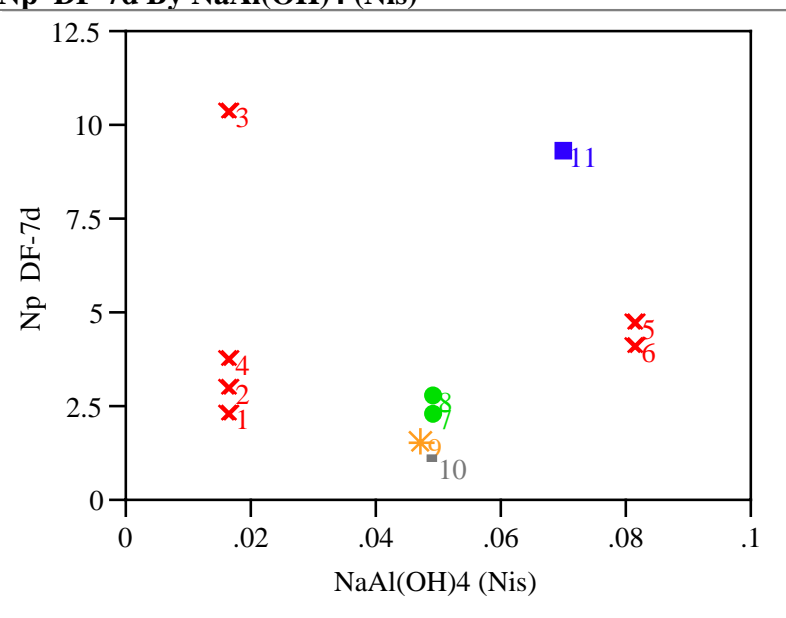

Sr DF-24h By Na2CO3 (Nis)

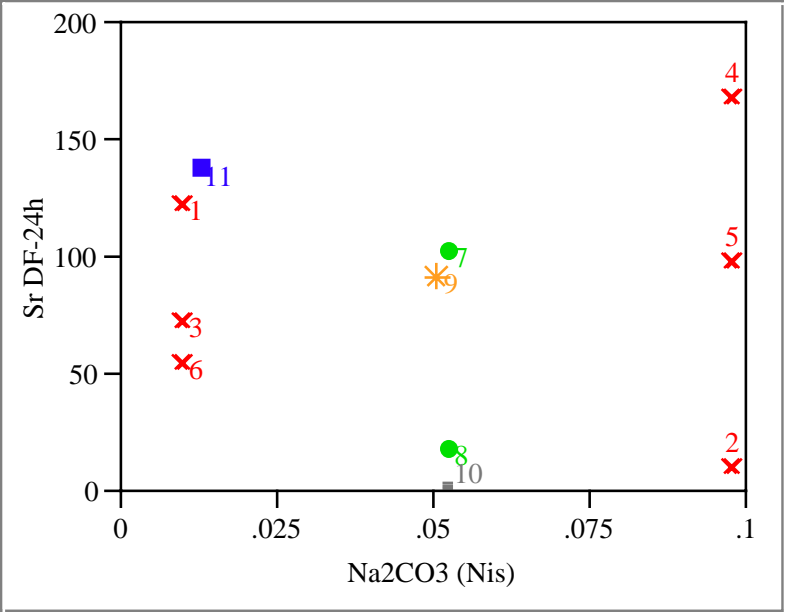

Sr DF-7d By Na2CO3 (Nis)

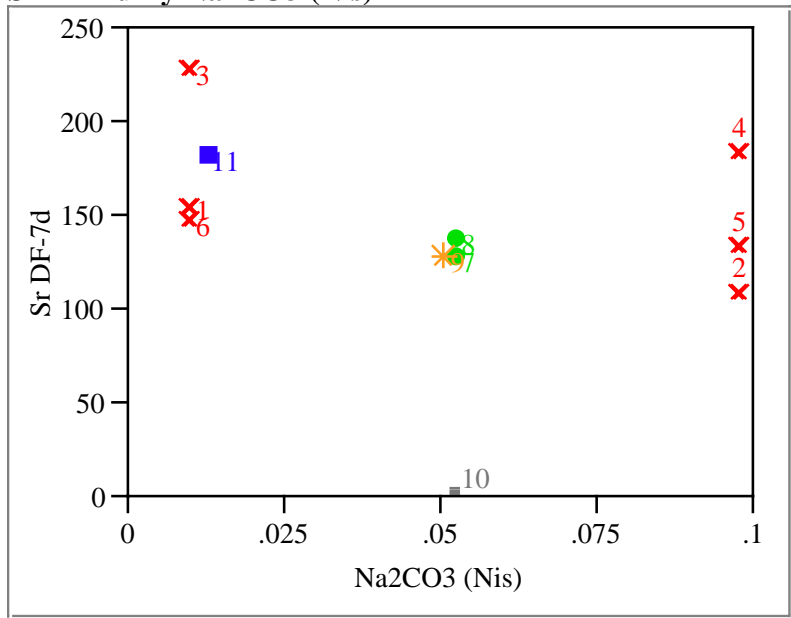

Pu DF-24h By Na2CO3 (Nis)

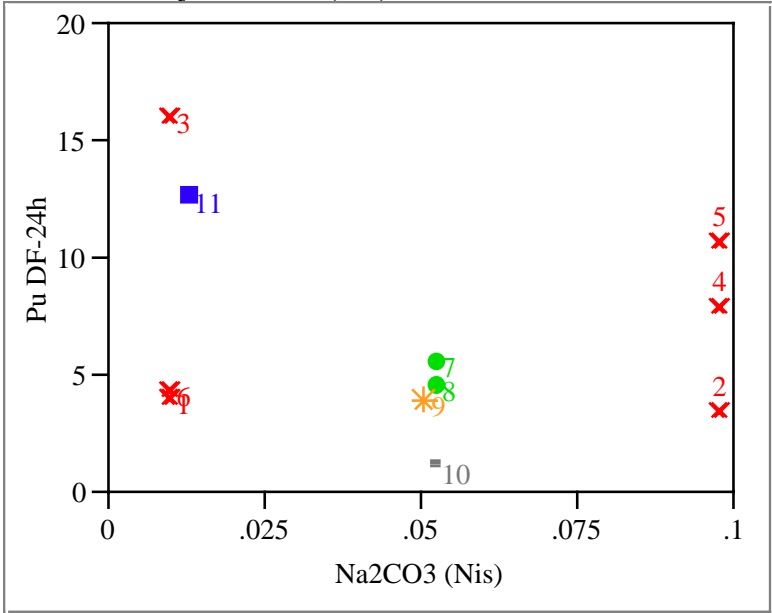

Pu DF-7d By Na2CO3 (Nis)

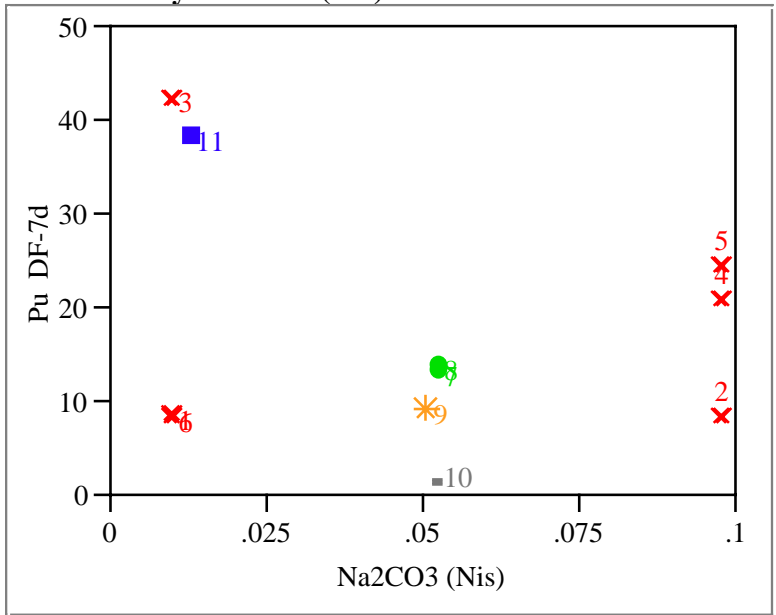


WSRC-TR-2001-00436

51 of 69

Exhibit 12: Plots of Decontamination Factors (DFs) versus Normalized Ionic Strength Fractions

U DF-24h By Na2CO3 (Nis)

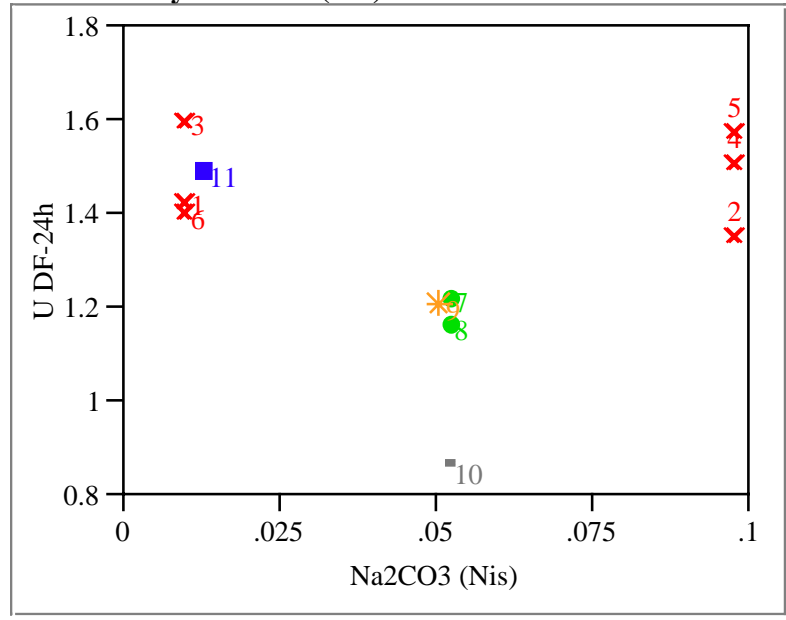

U DF-7d By Na2CO3 (Nis)

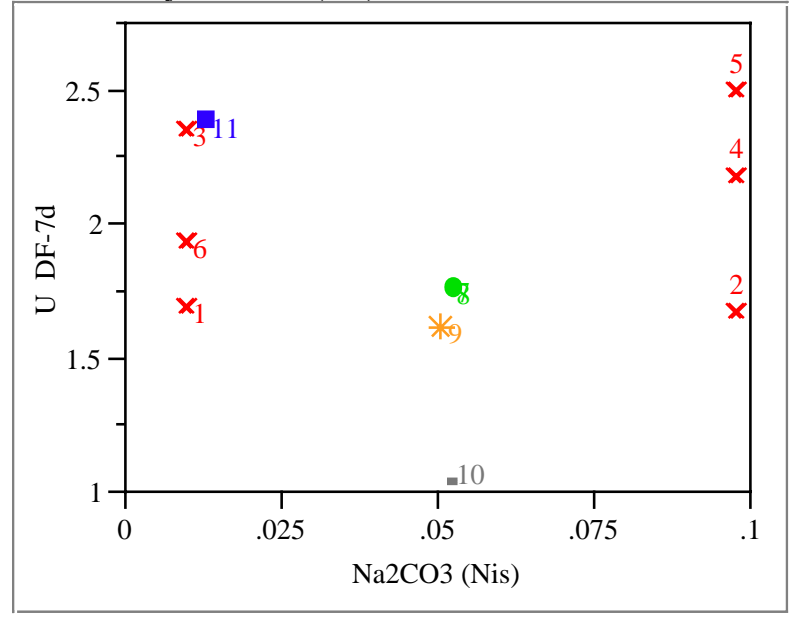

Np DF-24h By Na2CO3 (Nis)

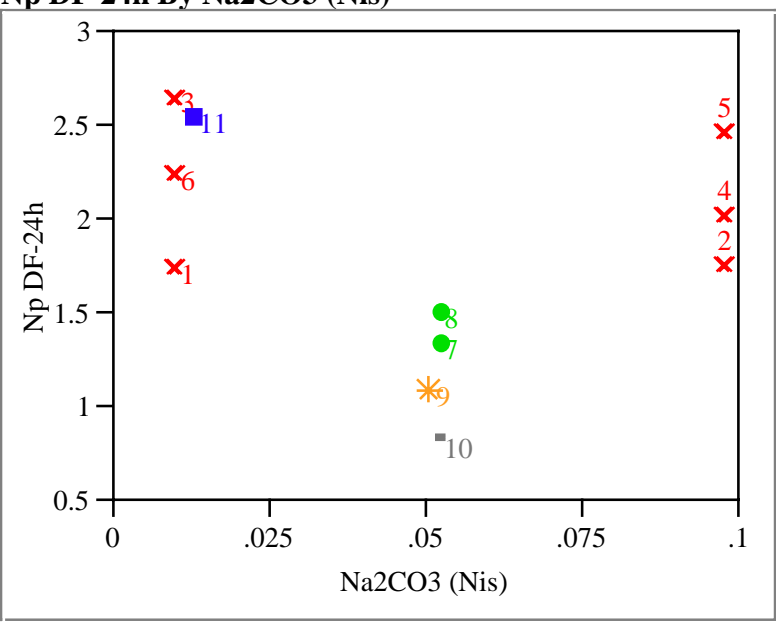

Np DF-7d By Na2CO3 (Nis)

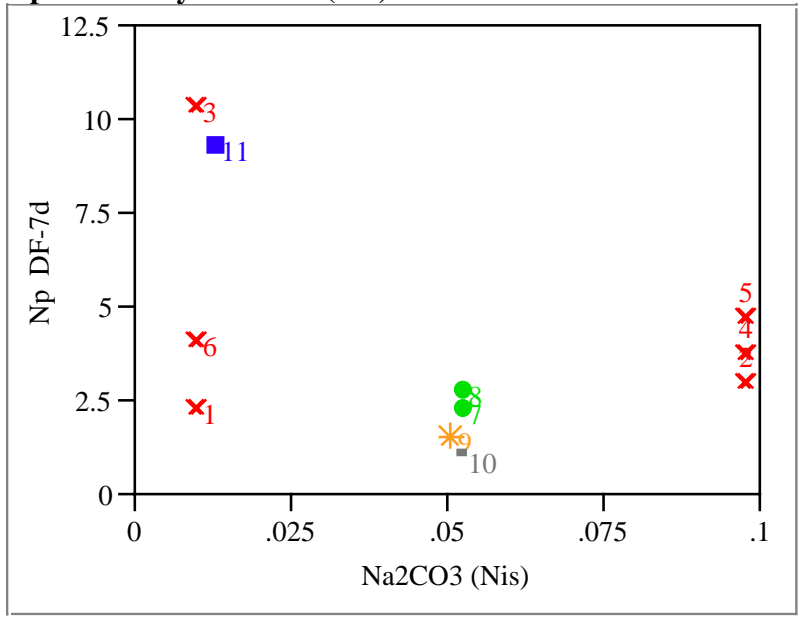

Sr DF-24h By Na2SO4 (Nis)

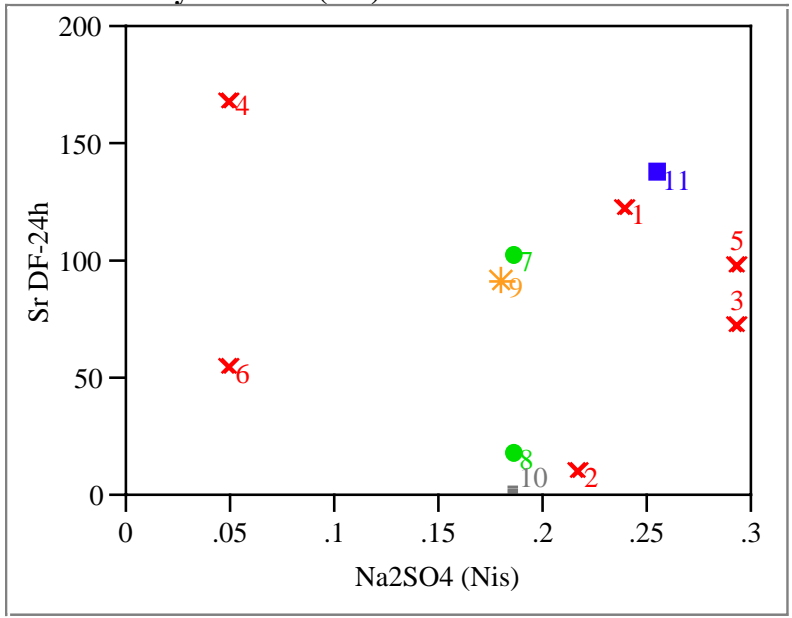

Sr DF-7d By Na2SO4 (Nis)

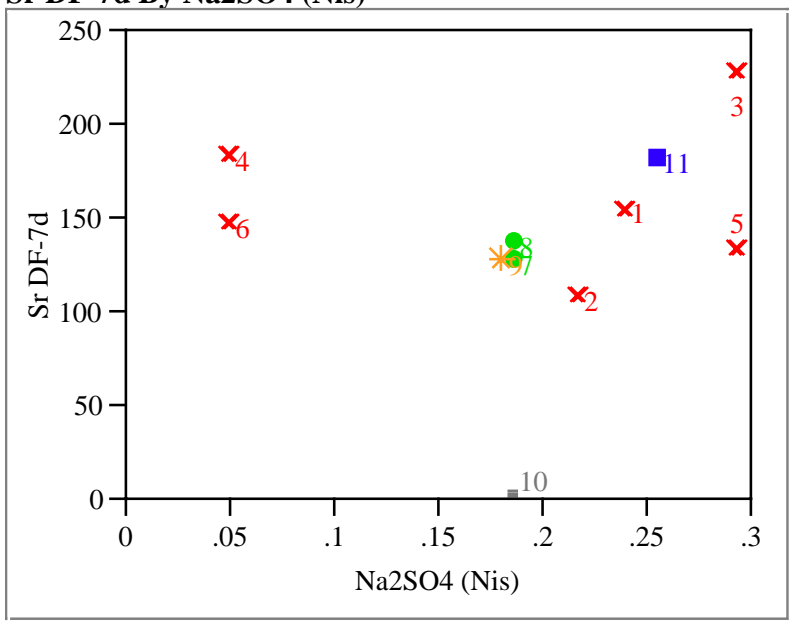


Exhibit 12: Plots of Decontamination Factors (DFs) versus Normalized Ionic Strength Fractions

Pu DF-24h By Na2SO4 (Nis)

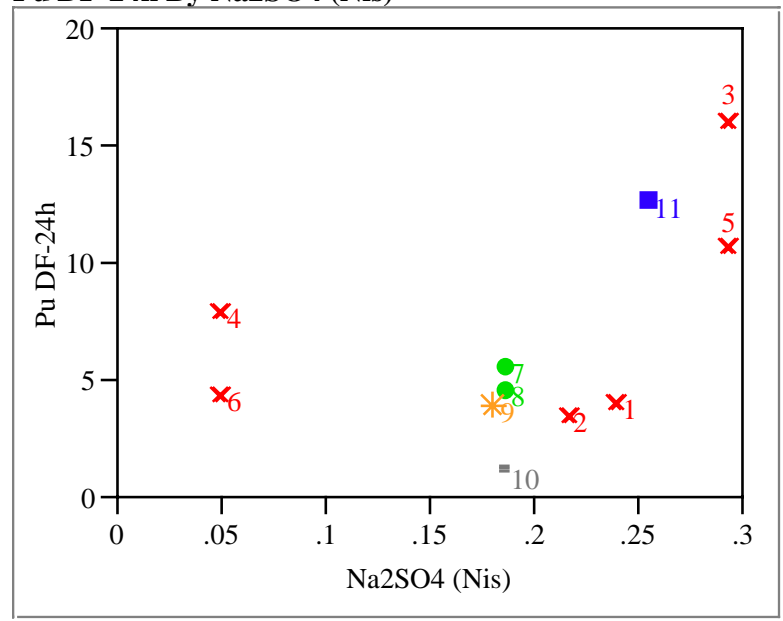

Pu DF-7d By Na2SO4 (Nis)

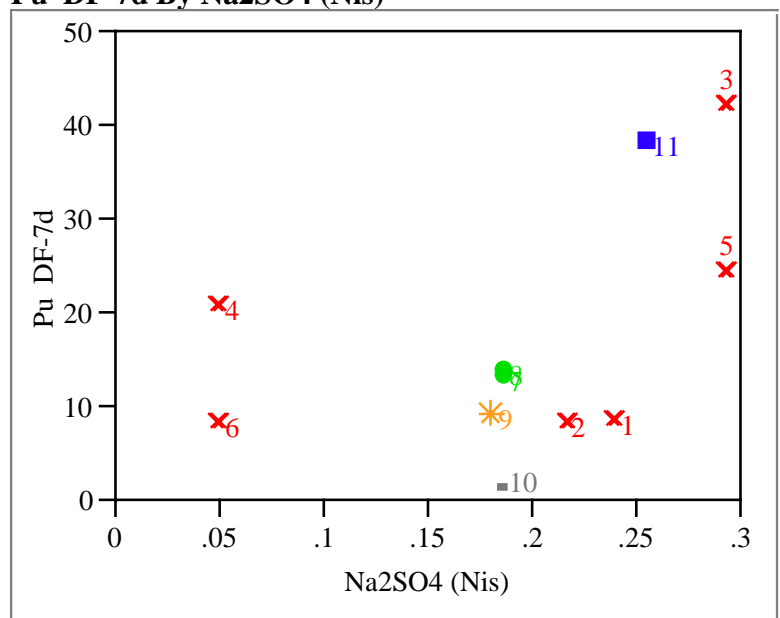

\section{U DF-24h By Na2SO4 (Nis)}

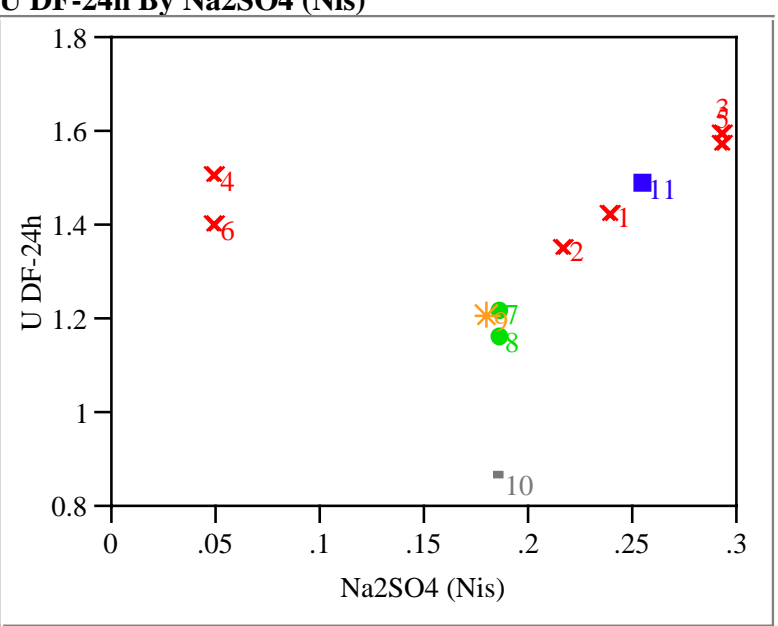

U DF-7d By Na2SO4 (Nis)

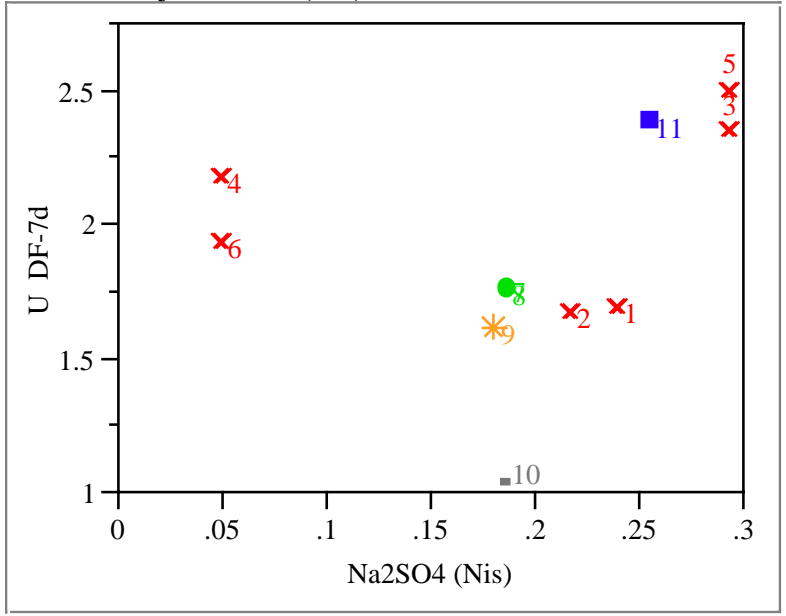

Np DF-24h By Na2SO4 (Nis)
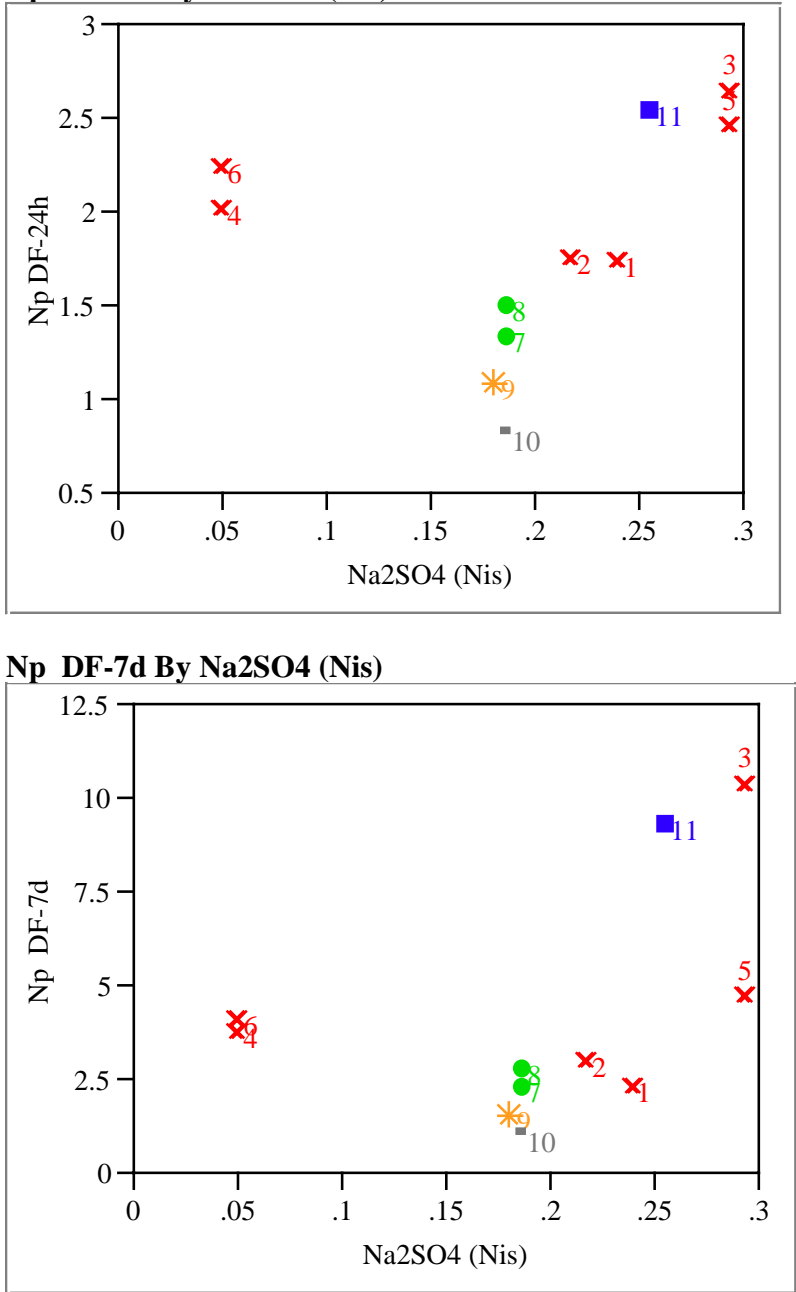
Exhibit 13: Linear Model Relating Strontium (Sr) DF-24h to the Six Primary Salt Solutions Components

Response Sr DF-24h

Actual by Predicted Plot

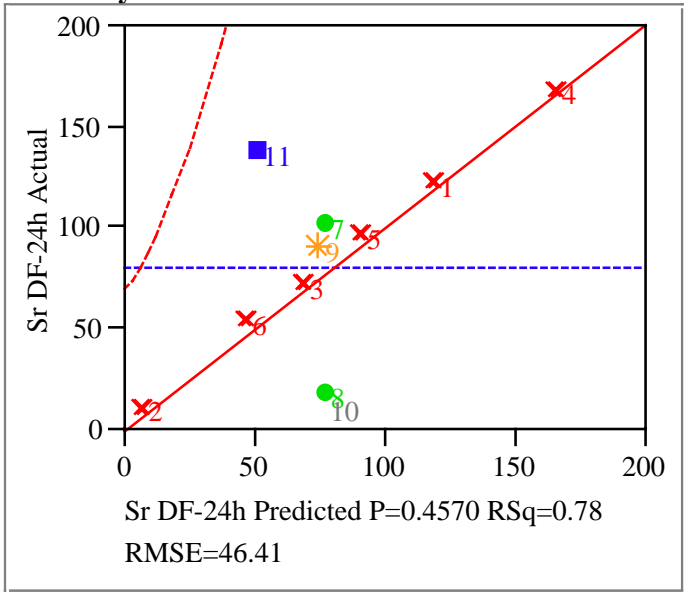

Residual by Predicted Plot

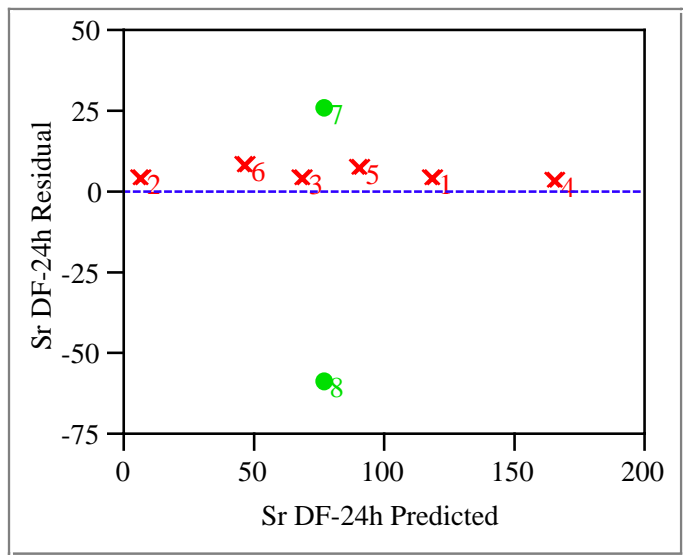

\section{Summary of Fit}

R-square is the portion of variation attributed to the model, between 0 and 1. Root Mean Squared Error "RMSE" estimates the standard deviation of the residual.

RSquare

RSquare Adj

0.783292

Root Mean Square Error

Mean of Response

Observations (or Sum Wgts)

0.241524

46.41023

81.15029

Analysis of Variance

The test that the whole model fits better than a simple mean, i.e. testing that all the parameters are zero except the intercept

$\begin{array}{lrrrr}\text { Source } & \text { DF } & \text { Sum of Squares } & \text { Mean Square } & \text { F Ratio } \\ \text { Model } & 5 & 15570.673 & 3114.13 & 1.4458 \\ \text { Error } & 2 & 4307.819 & 2153.91 & \text { Prob > F } \\ \text { C. Total } & 7 & 19878.492 & & 0.4570\end{array}$

Tested against reduced model: $\mathrm{Y}=$ mean

\section{Lack Of Fit}

Using replicated points as the part of residual error that does not depend on the form of the model so that you can test for the adequacy of the form of the model.

Source

Lack Of Fit

Pure Error

Total Error

DF

1
1

2

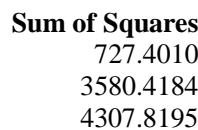

4307.8195

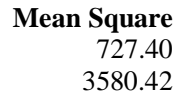

727.40

\section{F Ratio \\ 0.2032 \\ Prob > F \\ 0.7304 \\ Max RSq \\ 0.8199}

\section{Parameter Estimates}

\section{Term}

Intercept

NaNO3 (Nis)

Free $\mathrm{NaOH}$ (Nis)

$\mathrm{NaNO} 2$ (Nis)

$\mathrm{NaAl}(\mathrm{OH}) 4$ (Nis)

$\mathrm{Na} 2 \mathrm{CO} 3$ (Nis)

$\mathrm{Na} 2 \mathrm{SO} 4$ (Nis)
Zeroed

Estimate

155.78347

3.1459008

1457.2522

$-345.7717$

$-216.0979$

$-81.29$

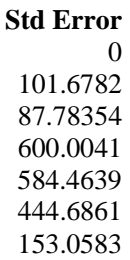

153.0583

t Ratio
1.53
0.04
2.43
-0.59
-0.49
-0.53

Prob $>|\mathbf{t}|$

0.2652

0.9747

0.1358

0.6141

0.6750 
Exhibit 14: Linear Model Relating Strontium (Sr) DF-7d to the Six Primary Salt Solutions Components

\section{Response Sr DF-7d}

Actual by Predicted Plot

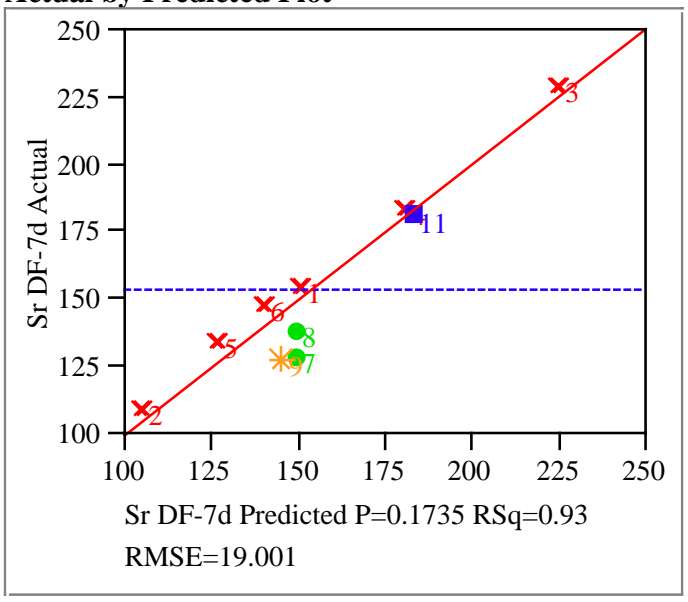

Residual by Predicted Plot

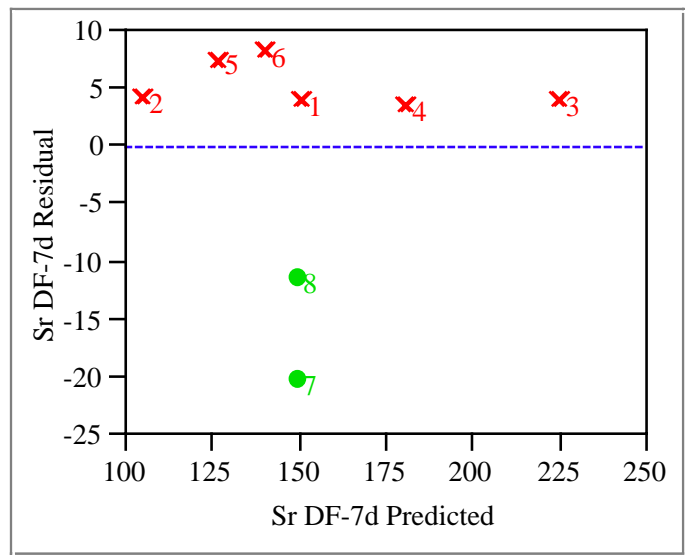

\section{Summary of Fit}

R-square is the portion of variation attributed to the model, between 0 and 1. Root Mean Squared Error "RMSE" estimates the standard deviation of the residual.

RSquare

RSquare Adj

0.926624

0.743182

Root Mean Square Error

Mean of Response

Observations (or Sum Wgts)

19.00081

153.2807

Analysis of Variance

The test that the whole model fits better than a simple mean, i.e. testing that all the parameters are zero except the intercept

$\begin{array}{lrrrr}\text { Source } & \text { DF } & \text { Sum of Squares } & \text { Mean Square } & \text { F Ratio } \\ \text { Model } & 5 & 9118.4457 & 1823.69 & 5.0513 \\ \text { Error } & 2 & 722.0618 & 361.03 & \text { Prob > F } \\ \text { C. Total } & 7 & 9840.5075 & & 0.1735\end{array}$

$\begin{array}{llrr}\text { C. Total } & 7 & 9840.5075 & 0.1735\end{array}$

Tested against reduced model: $\mathrm{Y}=$ mean

\section{Lack Of Fit}

Using replicated points as the part of residual error that does not depend on the form of the model so that you can test for the adequacy of the form of the model.

Source

Lack Of Fit

Pure Error

Total Error

DF

1
1

2

Sum of Squares
683.84450
38.21730
722.06180

722.06180

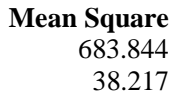

38.217

\section{F Ratio \\ 17.8936 \\ Prob > F \\ 0.1478 \\ Max RSq \\ 0.9961}

\section{Parameter Estimates}

\section{Term}

Intercept

NaNO3 (Nis)

Free $\mathrm{NaOH}$ (Nis)

$\mathrm{NaNO} 2$ (Nis)

$\mathrm{NaAl}(\mathrm{OH}) 4$ (Nis)

$\mathrm{Na} 2 \mathrm{CO} 3$ (Nis)

$\mathrm{Na} 2 \mathrm{SO} 4$ (Nis)
Zeroed

Estimate

328.91168

81.797327

259.1237

$-331.4975$

$-276.1282$

182.85458
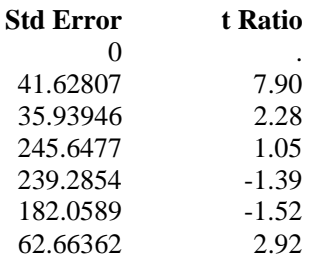

Prob $>|\mathbf{t}|$

0.0156

0.1506

0.4021

0.3002

0.2686

0.1001 
Exhibit 15: Linear Model Relating Plutonium (Pu) DF-24h to the Six Primary Salt Solutions Components

Response Pu DF-24h

Actual by Predicted Plot

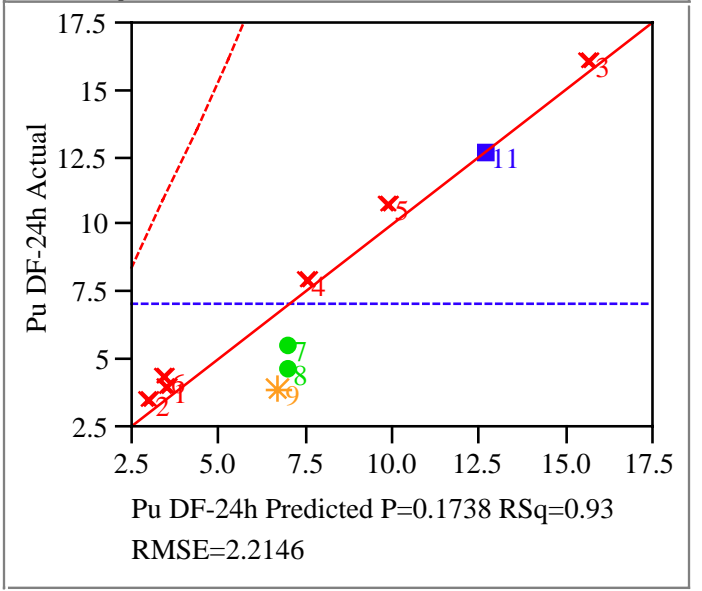

Residual by Predicted Plot

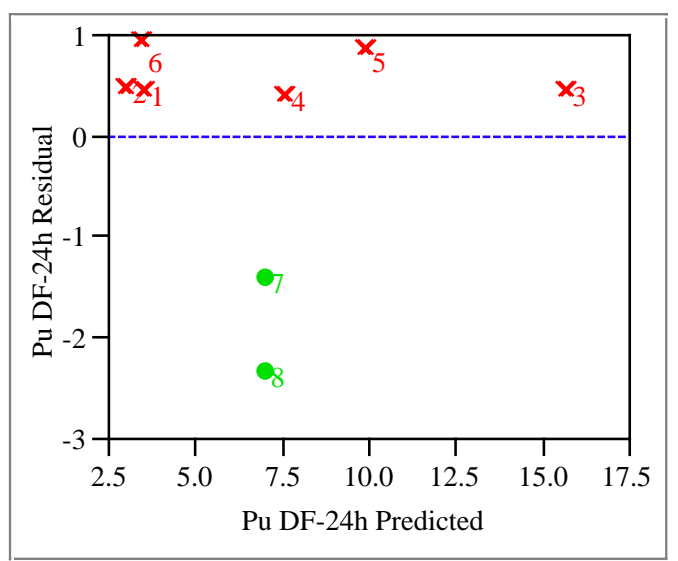

\section{Summary of Fit}

R-square is the portion of variation attributed to the model, between 0 and 1. Root Mean Squared Error "RMSE" estimates the standard deviation of the residual.

RSquare

RSquare Adj

0.926495

0.742732

$\begin{array}{ll}\text { Root Mean Square Error } & 2.214636 \\ \text { Mean of Response } & 7.117602\end{array}$

Mean of Response

Observations (or Sum Wgts)

$$
8
$$

\section{Analysis of Variance}

The test that the whole model fits better than a simple mean, i.e. testing that all the parameters are zero except the intercept

$\begin{array}{lrrrr}\text { Source } & \text { DF } & \text { Sum of Squares } & \text { Mean Square } & \text { F Ratio } \\ \text { Model } & 5 & 123.64012 & 24.7280 & 5.0418 \\ \text { Error } & 2 & 9.80922 & 4.9046 & \text { Prob }>\text { F } \\ \text { C. Total } & 7 & 133.44934 & & 0.1738\end{array}$

Using replicated points as the part of residual error that does not depend on the form of the model so that you can test for the adequacy of the form of the

Tested against reduced model: $Y=$ mean

\section{Lack Of Fit} model.

Source

Lack Of Fit

Pure Error

Total Error

DF
1
1
2

Sum of Squares
9.3797627
0.4294581
9.8092208
Mean Square
9.37976
0.42946

0.1738

$\begin{array}{lrrrr}\begin{array}{l}\text { Parameter Estimates } \\ \text { Term }\end{array} & \text { Estimate } & \text { Std Error } & \text { t Ratio } & \text { Prob>|t| } \\ \text { Intercept } & \text { Zeroed } & 0 & . & \\ \text { NaNO3 (Nis) } & 21.483399 & 4.851951 & 4.43 & 0.0474 \\ \text { Free NaOH (Nis) } & -10.01745 & 4.188916 & -2.39 & 0.1392 \\ \text { NaNO2 (Nis) } & -9.504671 & 28.63141 & -0.33 & 0.7715 \\ \text { NaAl(OH)4 (Nis) } & -2.801132 & 27.88985 & -0.10 & 0.9292 \\ \text { Na2CO3 (Nis) } & -6.919366 & 21.21984 & -0.33 & 0.7753 \\ \text { Na2SO4 (Nis) } & 24.292712 & 7.303744 & 3.33 & 0.0797\end{array}$


Exhibit 16: Linear Model Relating Plutonium (Pu) DF-7d to the Six Primary Salt Solutions Components

\section{Response Pu DF-7d}

Actual by Predicted Plot

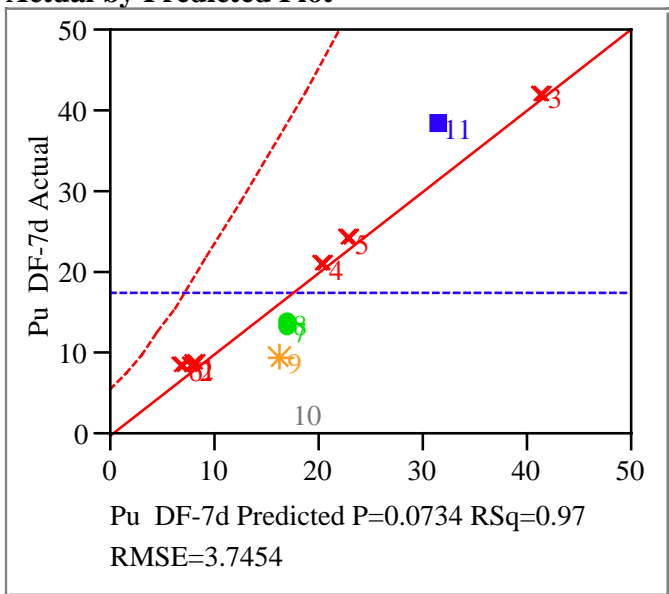

Residual by Predicted Plot

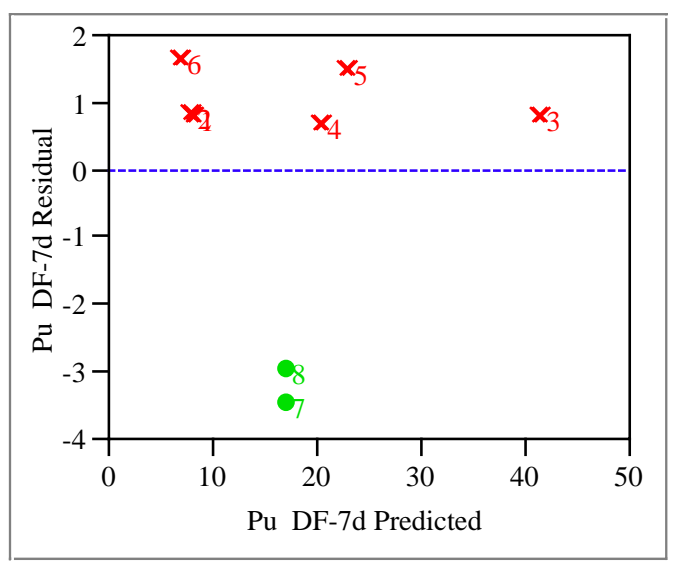

\section{Summary of Fit}

R-square is the portion of variation attributed to the model, between 0 and 1. Root Mean Squared Error "RMSE" estimates the standard deviation of the residual.

RSquare

RSquare Adj

0.969987

Root Mean Square Error

0.894954

Mean of Response

Observations (or Sum Wgts)

3.745429

17.6535

Analysis of Variance

The test that the whole model fits better than a simple mean, i.e. testing that all the parameters are zero except the intercept

$\begin{array}{lrrrr}\text { Source } & \text { DF } & \text { Sum of Squares } & \text { Mean Square } & \text { F Ratio } \\ \text { Model } & 5 & 906.75302 & 181.351 & 12.9275 \\ \text { Error } & 2 & 28.05647 & 14.028 & \text { Prob }>\text { F } \\ \text { C. Total } & 7 & 934.80949 & & 0.0734\end{array}$

Using replicated points as the part of residual error that does not depend on the form of the model so that you can test for the adequacy of the form of the

Tested against reduced model: $Y=$ mean

Lack Of Fit model.

Source

Lack Of Fit

Pure Error

Total Error

DF
1
1
2
Sum of Squares
27.944001
0.112470
28.056471
Mean Square
27.9440
0.1125

0.0734

\section{Parameter Estimates}

Term

Intercept

NaNO3 (Nis)

Free $\mathrm{NaOH}$ (Nis)

$\mathrm{NaNO} 2$ (Nis)

$\mathrm{NaAl}(\mathrm{OH}) 4$ (Nis)

$\mathrm{Na} 2 \mathrm{CO} 3$ (Nis)

$\mathrm{Na} 2 \mathrm{SO} 4$ (Nis)
Zeroed

Estimate
0
59.56008
-26.2868
-35.86907
-44.60449
-13.21168
62.338539

Std Error
0
8.2057
7.084364
48.42192
47.16778
35.88734
12.35221

F Ratio

248.4568

Prob > F

0.0403

Max RSq

0.9999

$\begin{array}{rr}\text { t Ratio } & \text { Prob }>|\mathbf{t}| \\ . & \cdot \\ 7.26 & 0.0185 \\ -3.71 & 0.0656 \\ -0.74 & 0.5360 \\ -0.95 & 0.4441 \\ -0.37 & 0.7481 \\ 5.05 & 0.0371\end{array}$


Exhibit 17: Linear Model Relating Uranium (U) DF-24h to the Six Primary Salt Solutions Components

Response U DF-24h

Actual by Predicted Plot

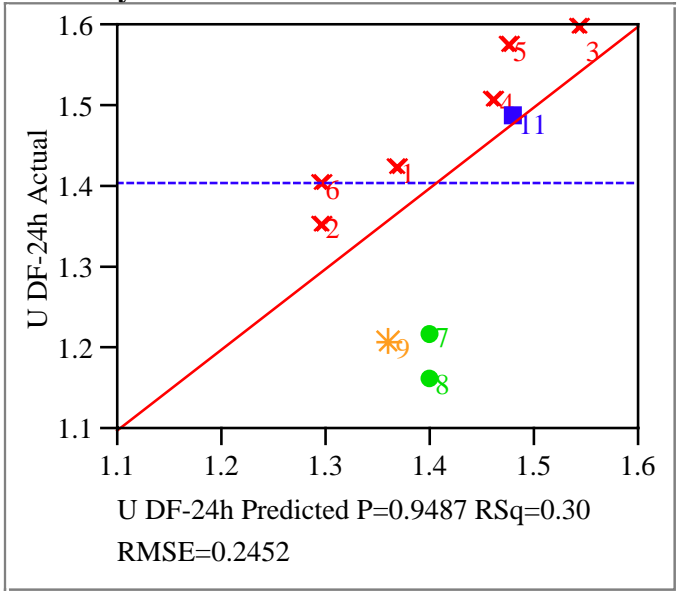

Residual by Predicted Plot

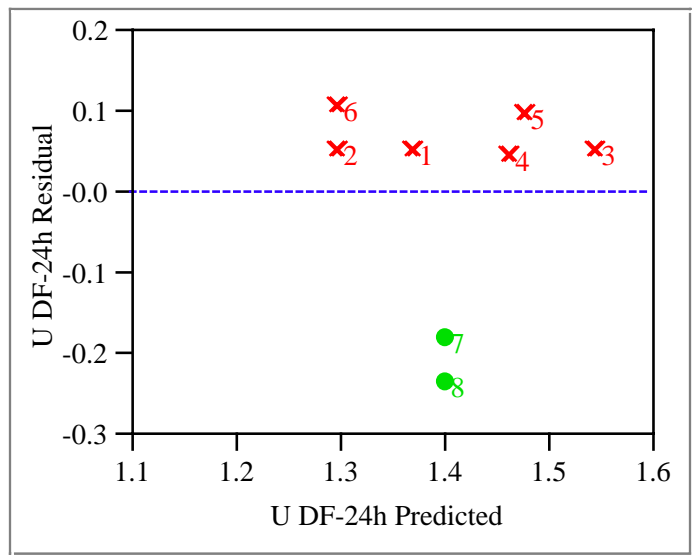

Summary of Fit

$\mathrm{R}$-square is the portion of variation attributed to the model, between 0 and 1. Root Mean Squared Error "RMSE" estimates the standard deviation of the residual.

RSquare

RSquare Adj

0.304711

Root Mean S

$-1.43351$

0.245179

Mean of Response

1.405462

Observations (or Sum Wgts)

8

Analysis of Variance

The test that the whole model fits better than a simple mean, i.e. testing that all the parameters are zero except the intercept

$\begin{array}{lrrrr}\text { Source } & \text { DF } & \text { Sum of Squares } & \text { Mean Square } & \text { F Ratio } \\ \text { Model } & 5 & 0.05268898 & 0.010538 & 0.1753 \\ \text { Error } & 2 & 0.12022587 & 0.060113 & \text { Prob }>\text { F } \\ \text { C. Total } & 7 & 0.17291485 & & 0.9487\end{array}$

$\begin{array}{lrrr}\text { C. Total } & 7 & 0.17291485 & 0.9487\end{array}$

Tested against reduced model: $\mathrm{Y}=$ mean

\section{Lack Of Fit}

Using replicated points as the part of residual error that does not depend on the form of the model so that you can test for the adequacy of the form of the model.

Source

Lack Of Fit

Pure Error

Total Error
DF

1
1

2
Sum of Squares
0.11868997
0.00153590
0.12022587

Mean Square
0.118690
0.001536
F Ratio
77.2772
Prob > F
0.0721
Max RSq
0.9911

\section{Parameter Estimates}

\section{Term}

Intercept

NaNO3 (Nis)

Free $\mathrm{NaOH}$ (Nis)

$\mathrm{NaNO} 2$ (Nis)

$\mathrm{NaAl}(\mathrm{OH}) 4$ (Nis)

$\mathrm{Na} 2 \mathrm{CO} 3$ (Nis)

$\mathrm{Na} 2 \mathrm{SO} 4$ (Nis)
Zeroed

Estimate

1.6654684

1.0349979

2.0225676

0.9114191

1.1121986

1.6695054

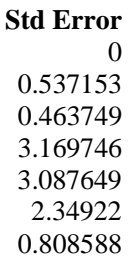

t Ratio

Prob $>|t|$

0.0902

0.1553

0.5887

0.7957

0.6825 
Exhibit 18: Linear Model Relating Uranium (U) DF-7d to the Six Primary Salt Solutions Components

Response U DF-7d

Actual by Predicted Plot

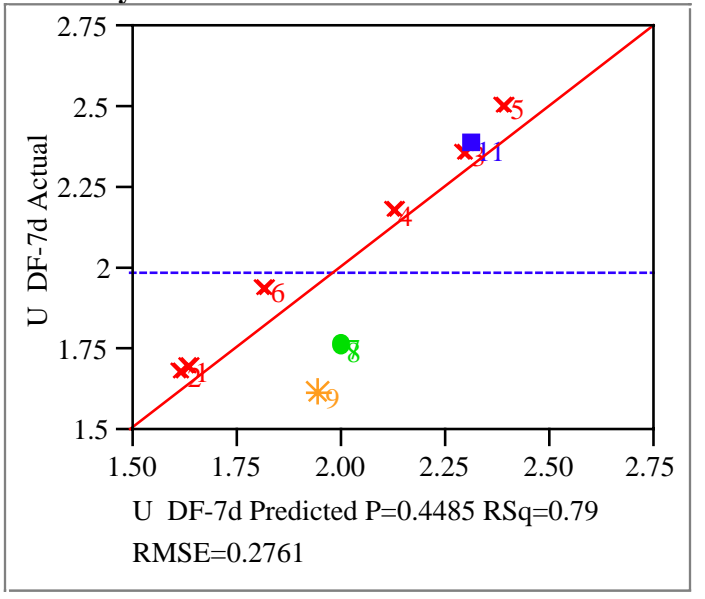

Residual by Predicted Plot

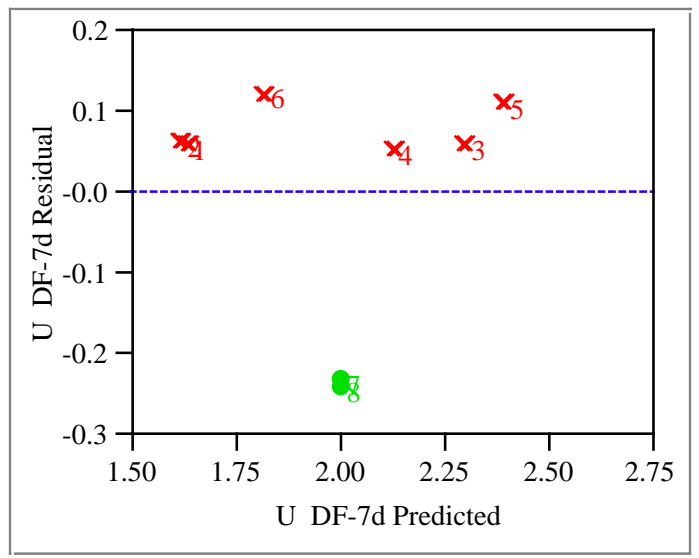

Summary of Fit

$\mathrm{R}$-square is the portion of variation attributed to the model, between 0 and 1. Root Mean Squared Error "RMSE" estimates the standard deviation of the residual.

RSquare

RSquare Adj

0.788156

0.258546

0.27614

Root Mean Square Error

Mean of Response

Observations (or Sum Wgts)

1.985293

Analysis of Variance

The test that the whole model fits better than a simple mean, i.e. testing that all the parameters are zero except the intercept

$\begin{array}{lrrrr}\text { Source } & \text { DF } & \text { Sum of Squares } & \text { Mean Square } & \text { F Ratio } \\ \text { Model } & 5 & 0.56739411 & 0.113479 & 1.4882 \\ \text { Error } & 2 & 0.15250662 & 0.076253 & \text { Prob > F } \\ \text { C. Total } & 7 & 0.71990073 & & 0.4485\end{array}$

$\begin{array}{lrrr}\text { C. Total } & 7 & 0.71990073 & 0.4485\end{array}$

Tested against reduced model: $\mathrm{Y}=$ mean

\section{Lack Of Fit}

Using replicated points as the part of residual error that does not depend on the form of the model so that you can test for the adequacy of the form of the model.

Source

Lack Of Fit

Pure Error

Total Error
DF

1
1

2

Sum of Squares
0.15245141
0.00005520
0.15250662

F Ratio

2761.621

Prob > F

0.0121

Max RSq

0.9999

\section{Parameter Estimates}

\section{Term}

Intercept

NaNO3 (Nis)

Free $\mathrm{NaOH}$ (Nis)

$\mathrm{NaNO} 2$ (Nis)

$\mathrm{NaAl}(\mathrm{OH}) 4$ (Nis)

$\mathrm{Na} 2 \mathrm{CO} 3$ (Nis)

$\mathrm{Na} 2 \mathrm{SO} 4$ (Nis)
Zeroed

Estimate

2.7321177

0.6142553

2.5755196

4.4898721

2.3230774

2.4297437

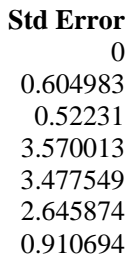

Prob $>|t|$

0.0457

0.3606

0.5456

0.3258

0.4725 
Exhibit 19: Linear Model Relating Neptunium (Np) DF-24h to the Six Primary Salt Solutions Components

Response Np DF-24h

Actual by Predicted Plot

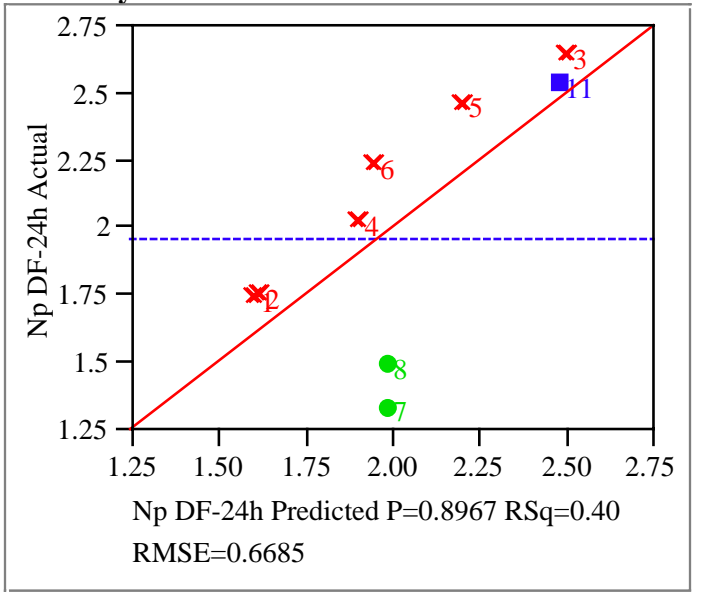

Residual by Predicted Plot

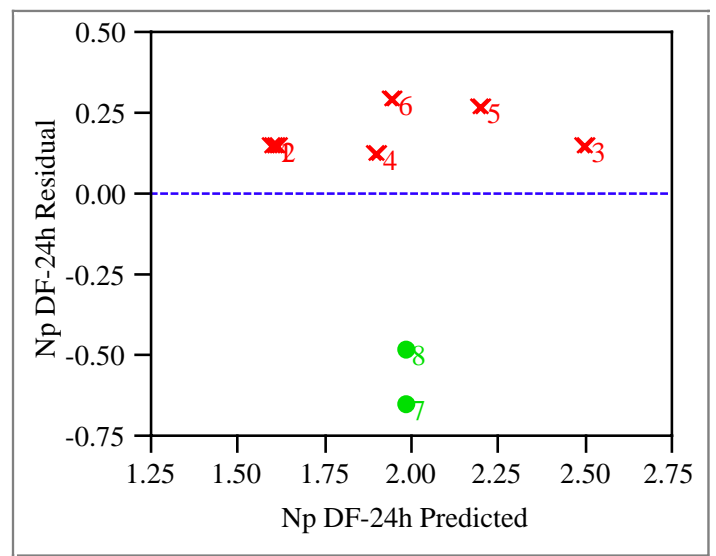

Summary of Fit

$\mathrm{R}$-square is the portion of variation attributed to the model, between 0 and 1. Root Mean Squared Error "RMSE" estimates the standard deviation of the residual.

RSquare

RSquare Adj

0.40333

Root Mean Squar

$-1.08834$

0.668546

Mean of Response

1.965631

Observations (or Sum Wgts) 8

Analysis of Variance

The test that the whole model fits better than a simple mean, i.e. testing that all the parameters are zero except the intercept

$\begin{array}{lrrrr}\text { Source } & \text { DF } & \text { Sum of Squares } & \text { Mean Square } & \text { F Ratio } \\ \text { Model } & 5 & 0.6042551 & 0.120851 & 0.2704 \\ \text { Error } & 2 & 0.8939088 & 0.446954 & \text { Prob }>\text { F } \\ \text { C. Total } & 7 & 1.4981639 & & 0.8967\end{array}$

$\begin{array}{lrrr}\text { C. Total } & 7 & 1.4981639 & 0.8967\end{array}$

Tested against reduced model: $\mathrm{Y}=$ mean

\section{Lack Of Fit}

Using replicated points as the part of residual error that does not depend on the form of the model so that you can test for the adequacy of the form of the model.

Source

Lack Of Fit

Pure Error

Total Error

DF

1
1

2
Sum of Squares
0.88001807
0.01389068
0.89390875

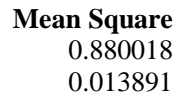

0.880018

0.013891

\section{F Ratio \\ 63.3531 \\ Prob > F \\ 0.0796 \\ Max RSq \\ 0.9907}

\section{Parameter Estimates}

\section{Term}

Intercept

NaNO3 (Nis)

Free $\mathrm{NaOH}$ (Nis)

$\mathrm{NaNO} 2$ (Nis)

$\mathrm{NaAl}(\mathrm{OH}) 4$ (Nis)

$\mathrm{Na} 2 \mathrm{CO} 3$ (Nis)

$\mathrm{Na} 2 \mathrm{SO} 4$ (Nis)
Zeroed

Estimate

2.9699234

0.7864903

$-0.3855$

4.5172419

0.5726724

2.85479
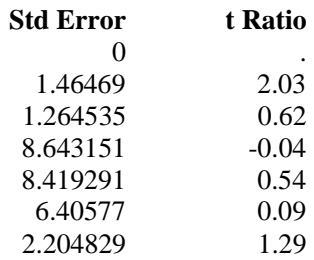

Prob $>|\mathbf{t}|$

0.1798

0.5974

0.9685

0.6453

0.9369

0.3247 
Exhibit 20: Linear Model Relating Neptunium (Np) DF-7d to the Six Primary Salt Solutions Components

Response Np DF-7d Actual by Predicted Plot

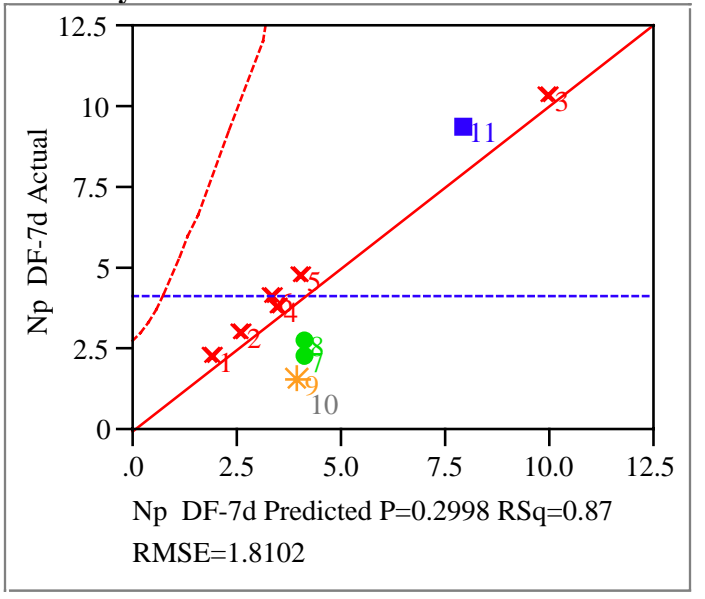

Residual by Predicted Plot

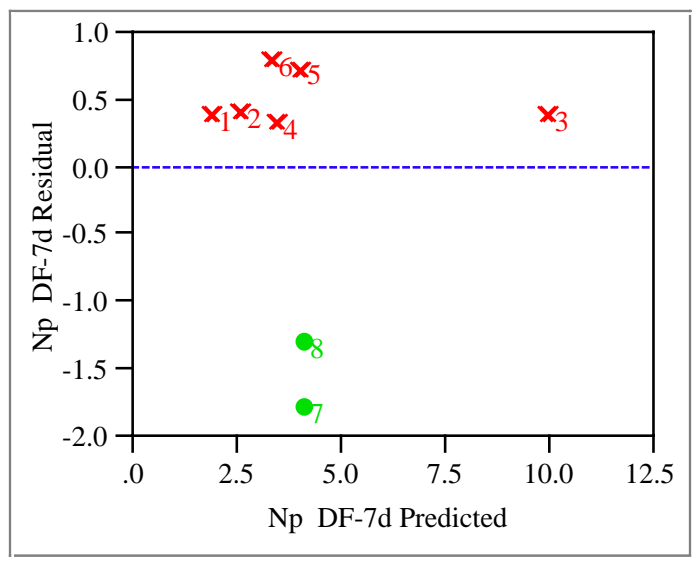

\section{Summary of Fit}

R-square is the portion of variation attributed to the model, between 0 and 1. Root Mean Squared Error "RMSE" estimates the standard deviation of the residual.

RSquare

RSquare Adj

0.86712

0.53492

Root Mean Square Error

Mean of Response

1.810206

Observations (or Sum Wgts)

4.193309

Analysis of Variance

The test that the whole model fits better than a simple mean, i.e. testing that all the parameters are zero except the intercept

$\begin{array}{lrrrr}\text { Source } & \text { DF } & \text { Sum of Squares } & \text { Mean Square } & \text { F Ratio } \\ \text { Model } & 5 & 42.766664 & 8.55333 & 2.6102 \\ \text { Error } & 2 & 6.553692 & 3.27685 & \text { Prob > F } \\ \text { C. Total } & 7 & 49.320356 & & 0.2998\end{array}$

Tested against reduced model: $\mathrm{Y}=$ mean

\section{Lack Of Fit}

Using replicated points as the part of residual error that does not depend on the form of the model so that you can test for the adequacy of the form of the model.

Source

Lack Of Fit

Pure Error

Total Error
DF

1

1
Mean Square
6.43352
0.12018

0.1201766

6.5536918

\section{F Ratio \\ 53.5339 \\ Prob > F \\ 0.0865 \\ Max RSq \\ 0.9976}

Parameter Estimates

\section{Term}

Intercept

Zeroed

NaNO3 (Nis)

Free $\mathrm{NaOH}$ (Nis)

$\mathrm{NaNO} 2$ (Nis)

$\mathrm{NaAl}(\mathrm{OH}) 4$ (Nis)

$\mathrm{Na} 2 \mathrm{CO} 3$ (Nis)

$\mathrm{Na} 2 \mathrm{SO} 4$ (Nis)

$\begin{array}{rr}\text { Estimate } & \text { Std Error } \\ 0 & 0 \\ 13.989464 & 3.965903 \\ -2.723434 & 3.42395 \\ -28.89155 & 23.40284 \\ -5.423186 & 22.7967 \\ -9.571154 & 17.34474 \\ 14.582325 & 5.969958\end{array}$

Prob $>|\mathbf{t}|$

0.0718

0.5098

0.3424

0.8341

0.6365

0.1346 
Exhibit 21: Predicted versus Actual Sr DF-24h with Predicted Line, Confidence Intervals, and Prediction Intervals for Individual DFs

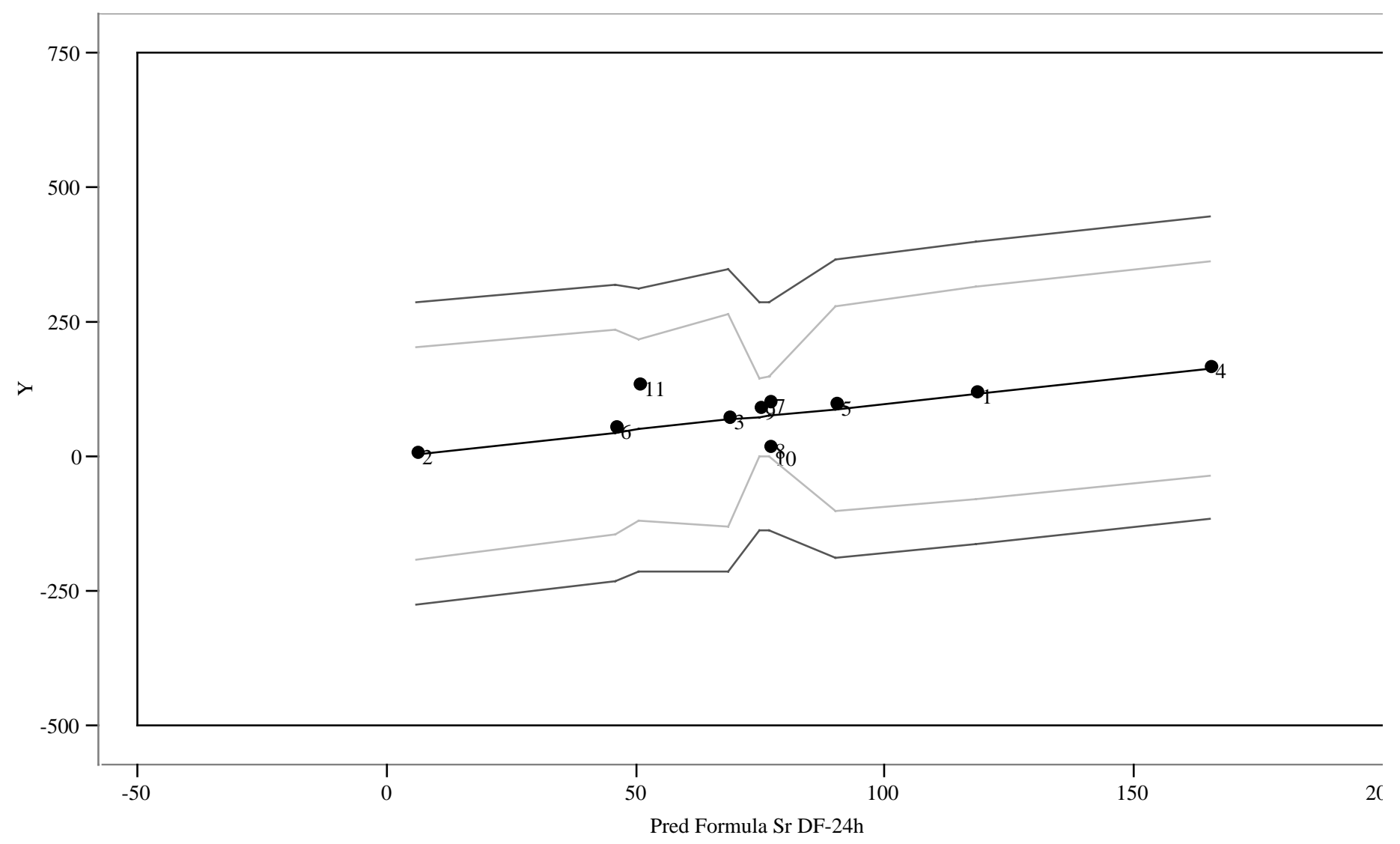

Y SrDF-24h

- Pred Formula Sr DF-24h

Lower 95\% Mean Sr DF-24h

- Upper 95\% Mean Sr DF-24h

- Lower 95\% Indiv Sr DF-24h

- Upper 95\% Indiv Sr DF-24h 
Exhibit 22: Predicted versus Actual Sr DF-7d with Predicted Line, Confidence Intervals, and Prediction Intervals for Individual DFs

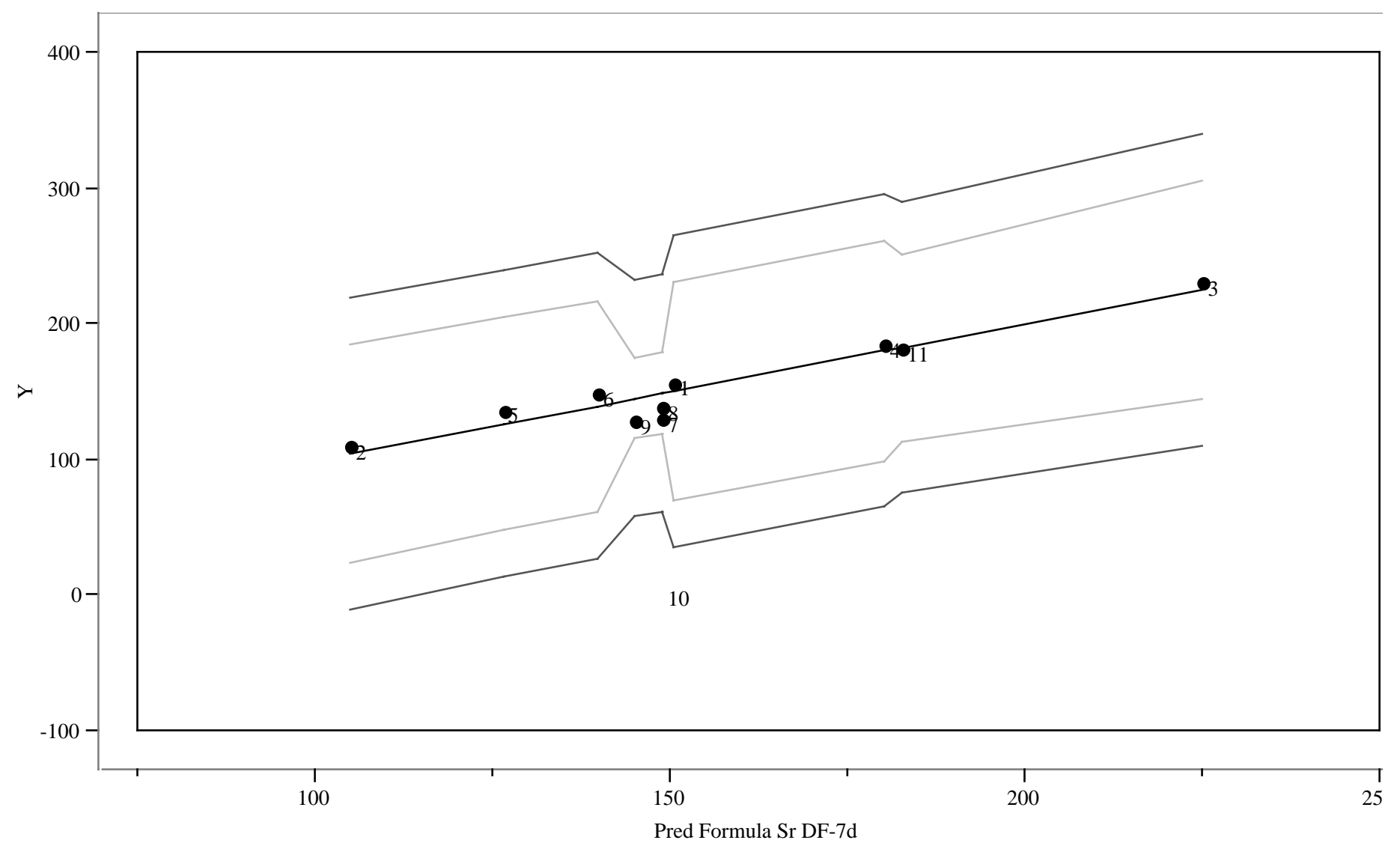

$\mathrm{Y}-S r D F-7 d$

Pred Formula Sr DF-7d

— Lower 95\% Mean Sr DF-7d

- Upper 95\% Mean Sr DF-7d

Lower 95\% Indiv Sr DF-7d

- Upper 95\% Indiv Sr DF-7d 
Exhibit 23: Predicted versus Actual Pu DF-24h with Predicted Line, Confidence Intervals, and Prediction Intervals for Individual DFs

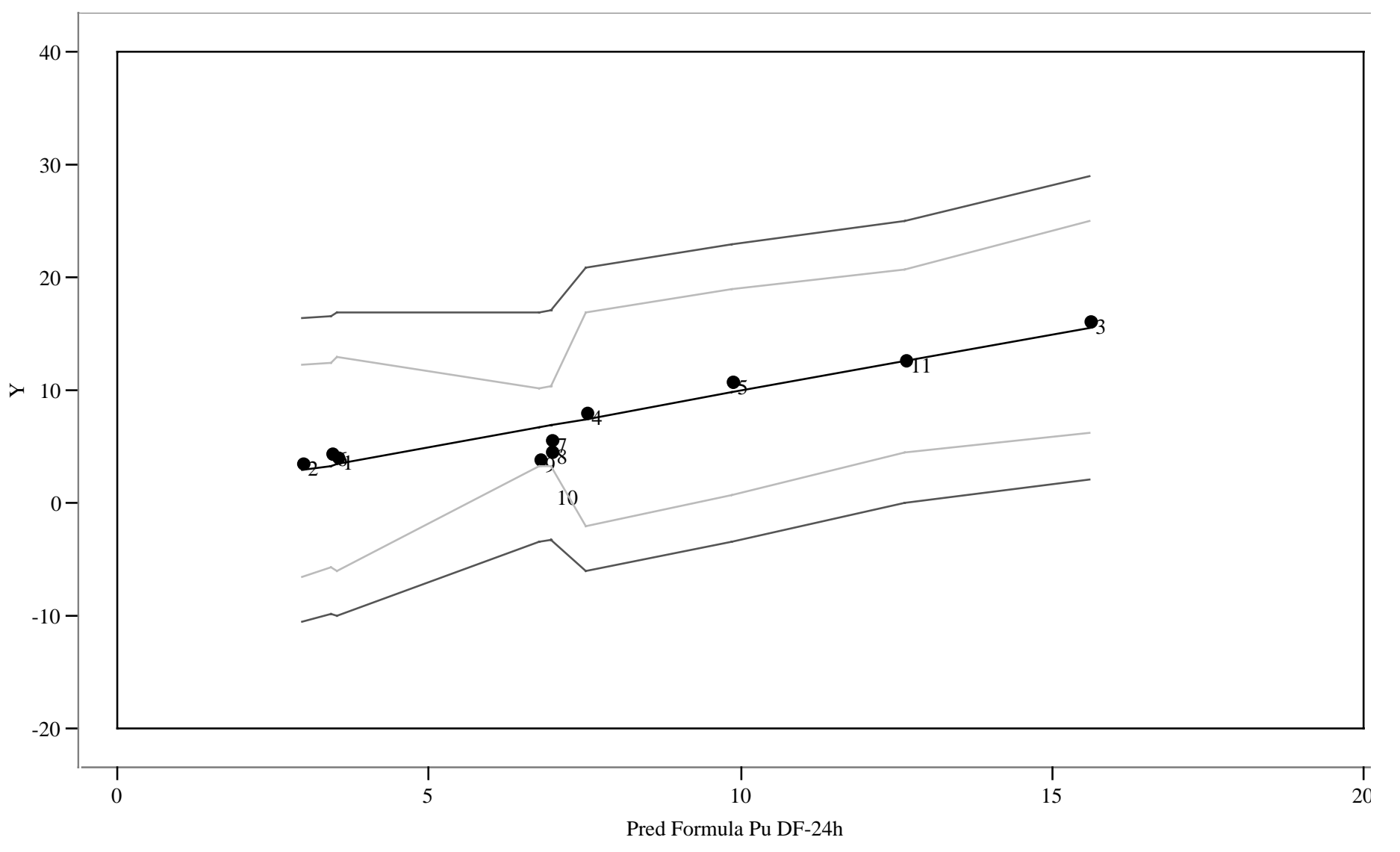

$\mathrm{Y}-\mathrm{Pu} \mathrm{DF}-24 \mathrm{~h}$

- Pred Formula Pu DF-24h

— Lower 95\% Mean Pu DF-24h

- Upper 95\% Mean Pu DF-24h

- Lower 95\% Indiv Pu DF-24h

— Upper 95\% Indiv Pu DF-24h 
Exhibit 24: Predicted versus Actual Pu DF-7d with Predicted Line, Confidence Intervals, and Prediction Intervals for Individual DFs

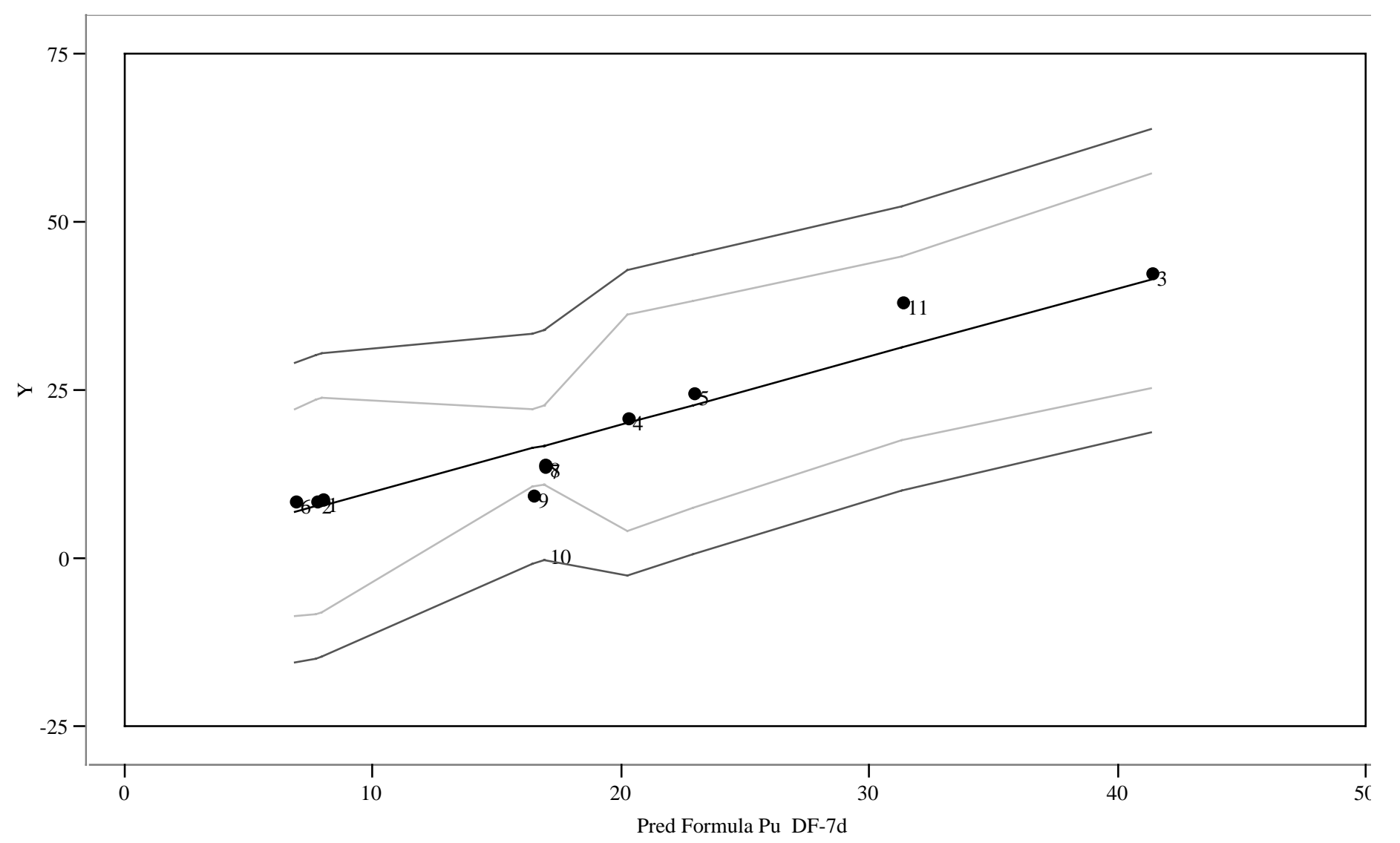

$\mathrm{Y}-\mathrm{Pu} \mathrm{DF}-7 \mathrm{~d}$

- Pred Formula Pu DF-7d

Lower 95\% Mean Pu DF-7d

- Upper 95\% Mean Pu DF-7d

- Lower 95\% Indiv Pu DF-7d

- Upper 95\% Indiv Pu DF-7d 
Exhibit 25: Predicted versus Actual U DF-24h with Predicted Line, Confidence Intervals, and Prediction Intervals for Individual DFs

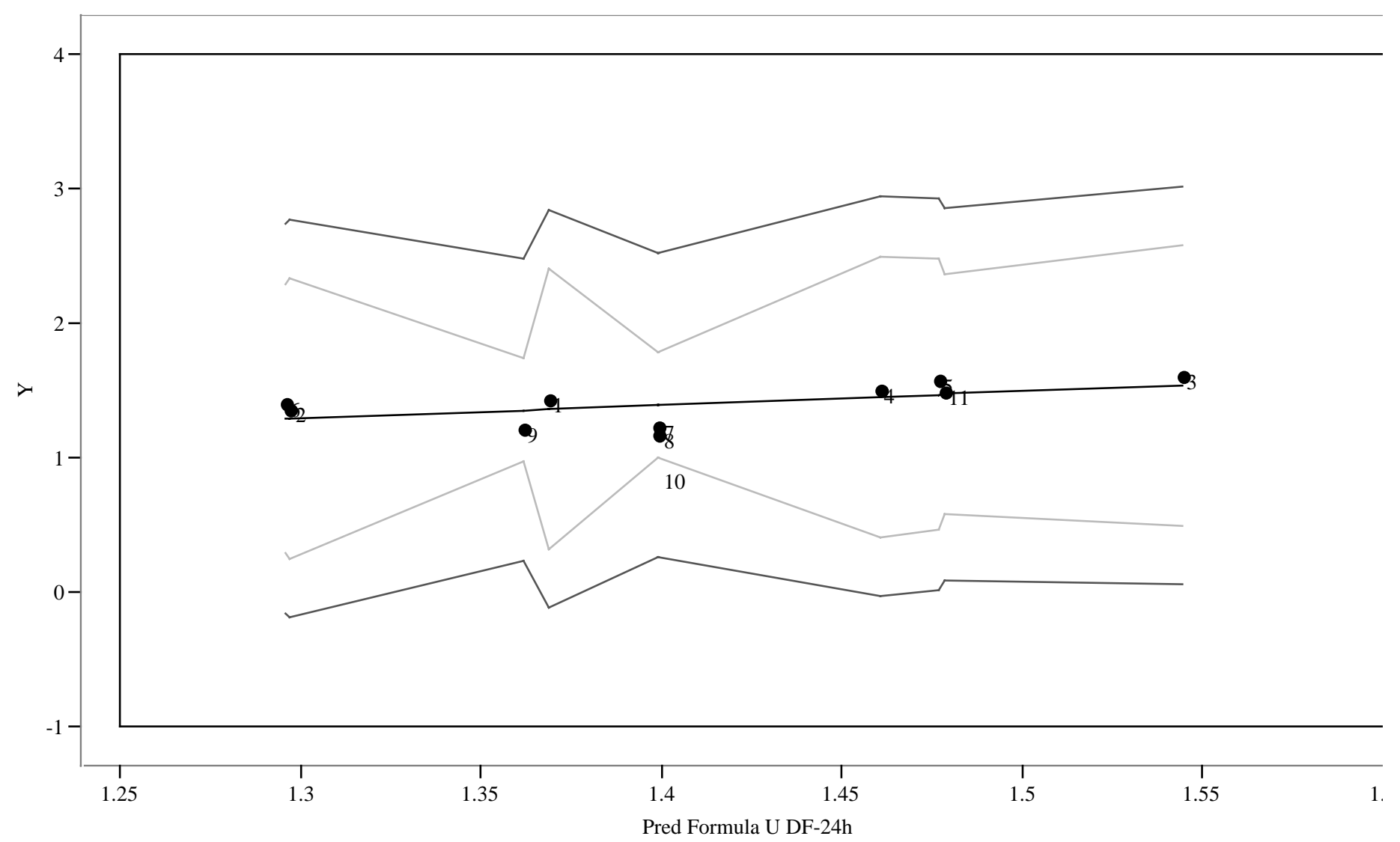

$\mathrm{Y} \cdot \mathrm{UDF}-24 \mathrm{~h}$

- Pred Formula U DF-24h

Lower 95\% Mean U DF-24h

- Upper 95\% Mean U DF-24h

- Lower 95\% Indiv U DF-24h

Upper $95 \%$ Indiv U DF-24h 
Exhibit 26: Predicted versus Actual U DF-7d with Predicted Line, Confidence Intervals, and Prediction Intervals for Individual DFs

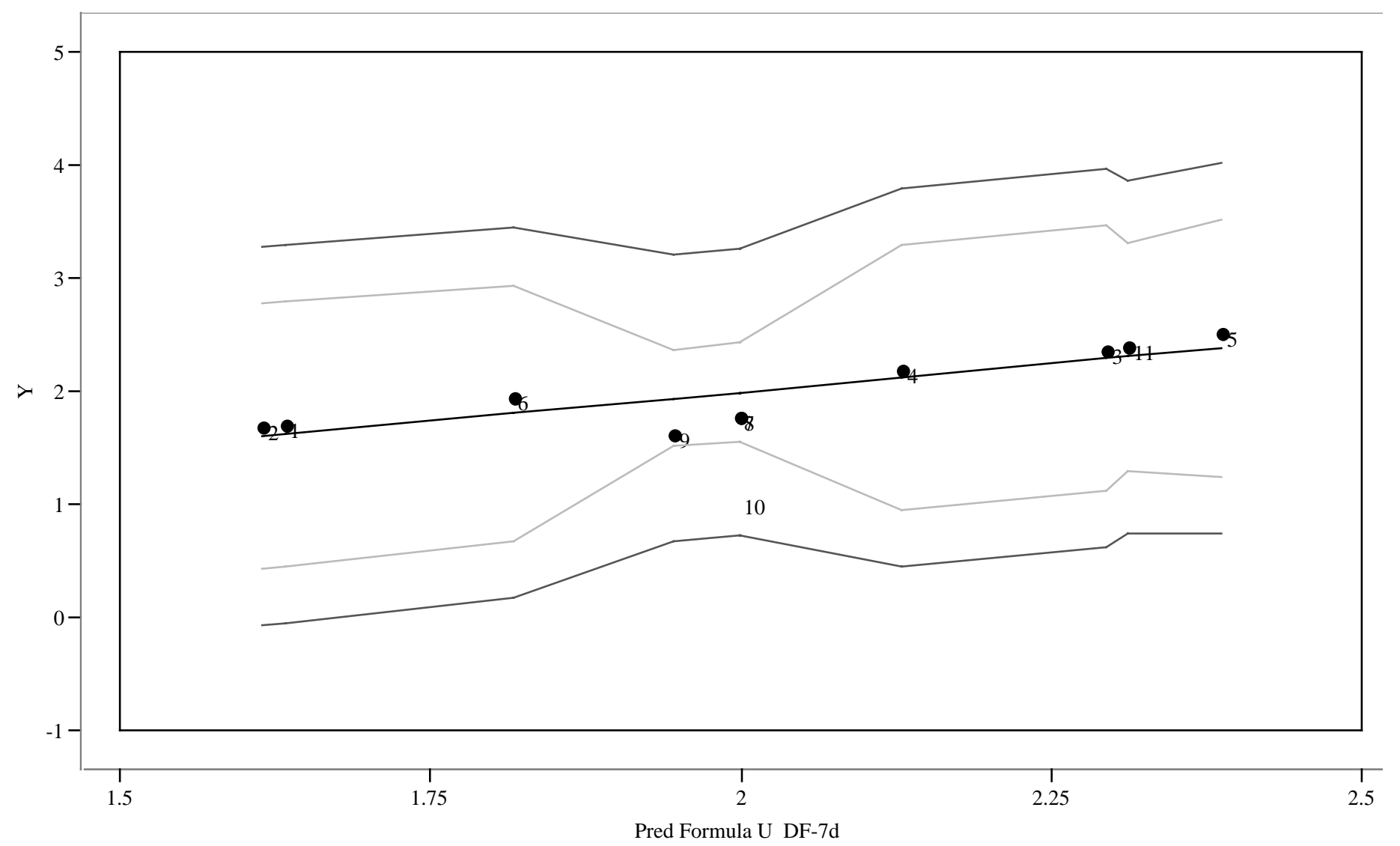

$\mathrm{Y}-\mathrm{U}$ DF-7d

- Pred Formula U DF-7d

- Lower 95\% Mean U DF-7d

- Upper 95\% Mean U DF-7d

Lower 95\% Indiv U DF-7d

— Upper 95\% Indiv U DF-7d 
Exhibit 27: Predicted versus Actual Np DF-24h with Predicted Line, Confidence Intervals, and Prediction Intervals for Individual DFs

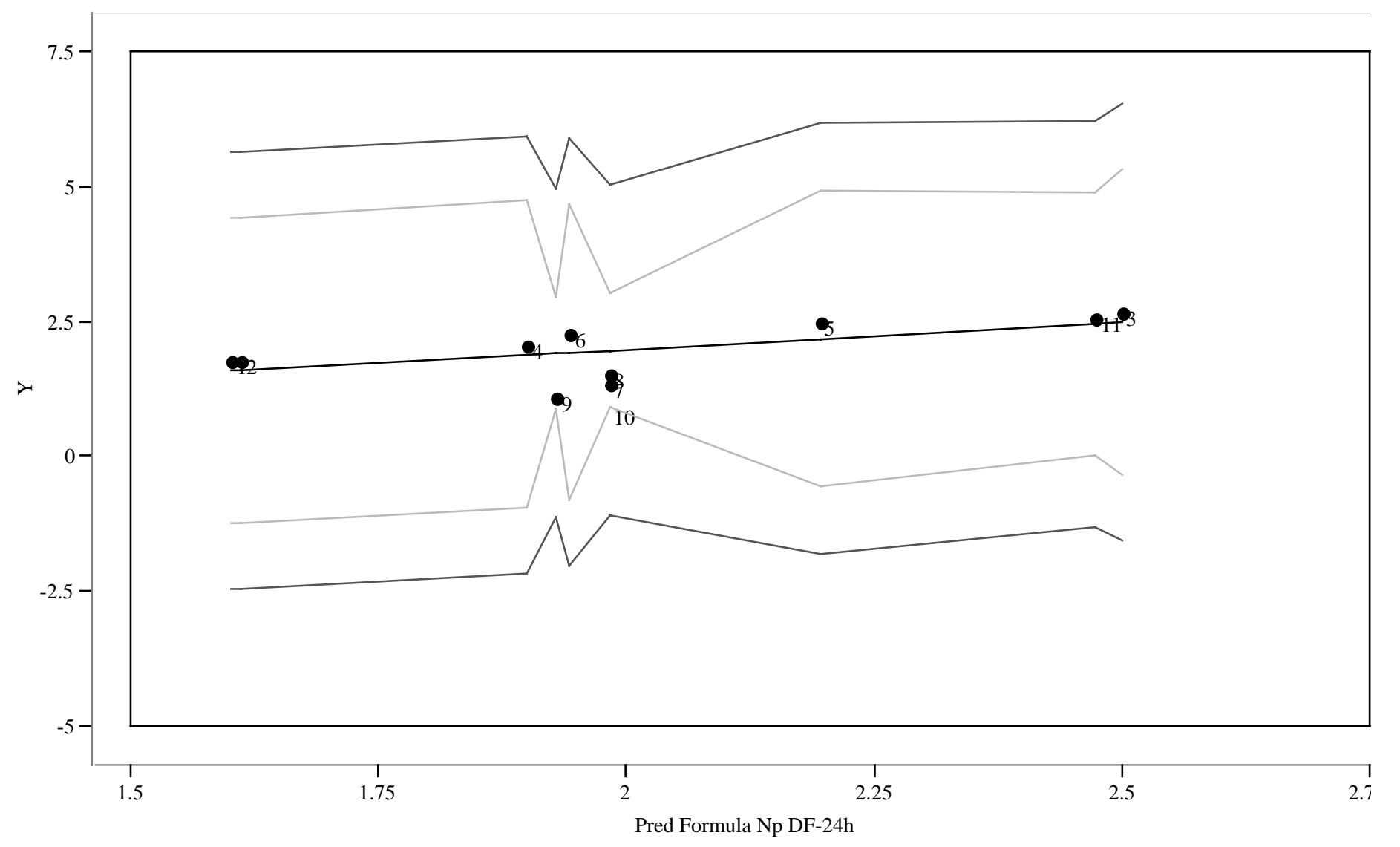

$\mathrm{Y}-\mathrm{NpDF}-24 \mathrm{~h}$

- Pred Formula Np DF-24h

- Lower 95\% Mean Np DF-24h

- Upper 95\% Mean Np DF-24h

— Lower 95\% Indiv Np DF-24h

— Upper 95\% Indiv Np DF-24h 
Exhibit 28: Predicted versus Actual Np DF-7d with Predicted Line, Confidence Intervals, and Prediction Intervals for Individual DFs

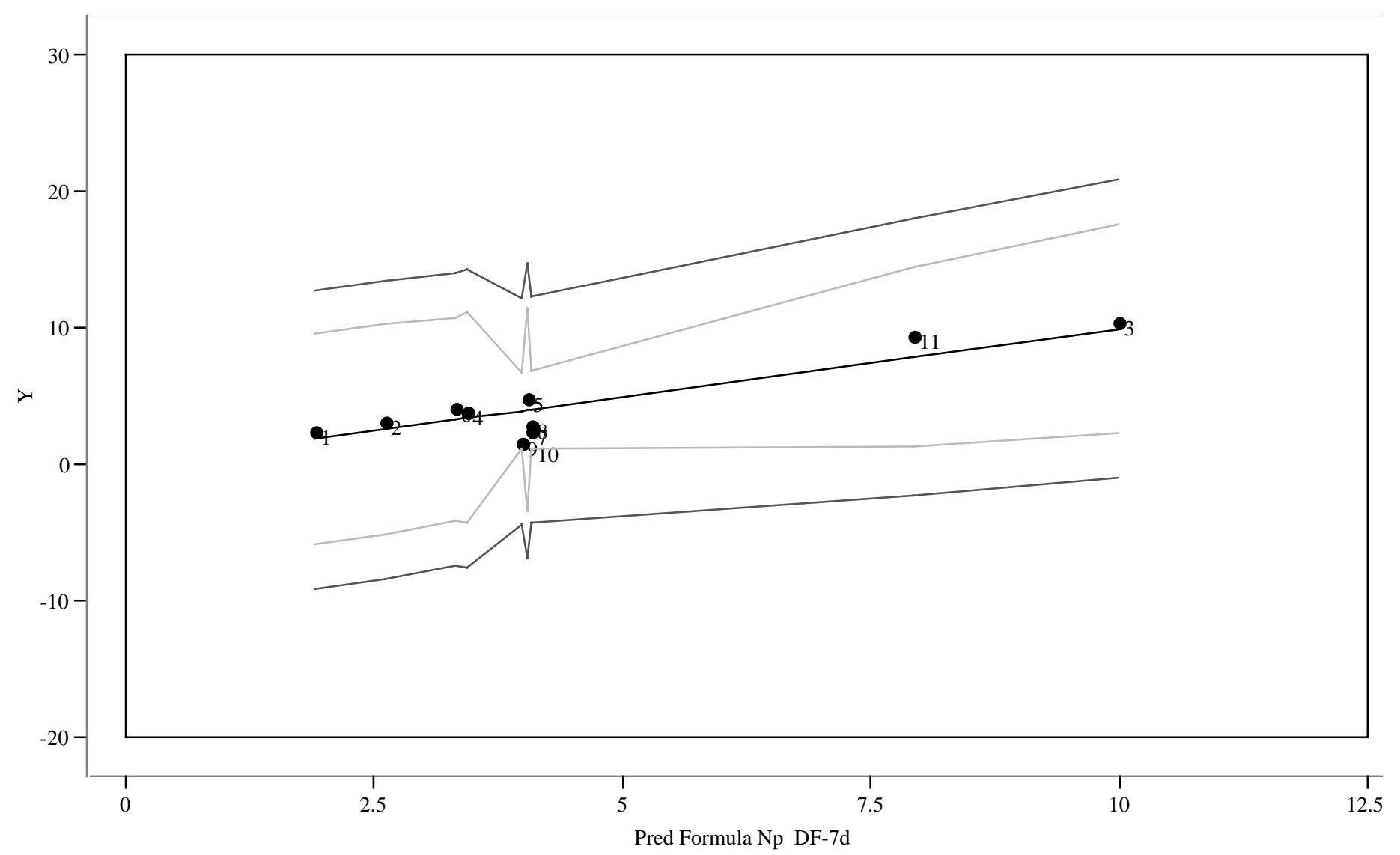

$\mathrm{Y}-\mathrm{Np}$ DF-7d

- Pred Formula Np DF-7d

Lower 95\% Mean Np DF-7d

- Upper 95\% Mean Np DF-7d

- Lower 95\% Indiv Np DF-7d

— Upper 95\% Indiv Np DF-7d 
Distribution: [C. Canada to add) 